Société d'histoire de la révolution de 1848 et des

révolutions du XIXe siècle

29 | 2004

Varia

\title{
Les batailles pour la création du Métro : un choix de mode de vie, un succès pour la démocratie locale
}

The struggles for the creation of the Parisian underground railway: the choice of a way of life and a success for local democracy

\section{Alain Cottereau}

\section{OpenEdition}

Journals

Édition électronique

URL : http://journals.openedition.org/rh19/702

DOI : $10.4000 /$ rh19.702

ISSN : $1777-5329$

Éditeur

La Société de 1848

Édition imprimée

Date de publication : 1 décembre 2004

Pagination : 89-151

ISSN : 1265-1354

Référence électronique

Alain Cottereau, "Les batailles pour la création du Métro : un choix de mode de vie, un succès pour la démocratie locale », Revue d'histoire du XIXe siècle [En ligne], 29 | 2004, mis en ligne le 20 juin 2005, consulté le 19 avril 2019. URL : http://journals.openedition.org/rh19/702 ; DOI : 10.4000/rh19.702

Ce document a été généré automatiquement le 19 avril 2019

Tous droits réservés 


\section{Les batailles pour la création du Métro: un choix de mode de vie, un succès pour la démocratie locale}

The struggles for the creation of the Parisian underground railway: the choice of a way of life and a success for local democracy

\section{Alain Cottereau}

\section{Un métro à tutoyer}

1 Les Parisiens auront un métro à tutoyer. C'est l'expression ironique que laissa tomber le préfet Poubelle, dit-on, en novembre 1895, lorsqu'il apprit que le gouvernement se résignait à céder aux exigences municipales, à l'approche de l'Exposition universelle de 1900. Au lieu des projets prestigieux des grandes compagnies, de la construction de gares nouvelles dans le centre, à l'Opéra, aux Invalides, au lieu de la promotion de majestueux hôtels terminus pour accueillir les visiteurs de marque du monde entier, la capitale se résignerait à laisser construire le petit train des petites gens de Paris, le métro des radicaux socialistes, le joujou électoral des intérêts à courte vue, pour ouvriers de la petite industrie, épiciers, marchands de vin du petit commerce et goguettes des dimanches de midinettes, aux barrières de Paris.

2 Le succès du métro, dès ses premières années, après l'Expo, retourna le sens de l'appréciation. Loin d'exprimer un mépris, un métro à tutoyer connota désormais le style particulier d'une réussite : à la différence des métros de Londres, New York, Bruxelles, Berlin, le métro parisien s'est imposé comme l'outil familier de tous les habitants et visiteurs de Paris. Une familiarité sans vouvoiement, en quelque sorte, presque sans distance, presque de plain-pied, car son mode d'emploi connotait une proximité sans dépaysement des usagers, un faible cloisonnement entre les lieux publics urbains, qu'on ne trouve pas dans les autres métropoles. Le métro parisien fait contraste aussi, sur le 
plan technique, par la conjonction unique du petit gabarit et du grand débit. Les métros dits à grand gabarit, comme celui de Londres, beaucoup plus coûteux, enterrés loin de la surface, aux stations et aux trains plus espacés, ne pouvaient, à la différence de leur homologue parisien, quadriller à moins de cinq minutes chaque quartier, faire passer des trains à cadences rapprochées aux heures de pointe, ni être accessibles par des escaliers à peine plus profonds que des accès de caves à vin.

Cet aspect du succès est bien connu. Des générations d'usagers et de visiteurs en ont fait l'expérience. Mais ce que l'on ne sait plus si bien apprécier, aujourd'hui, est la longue bataille politique qui a lié étroitement une progression de la démocratie locale, un succès de débat public et une manière spécifiquement parisienne de concevoir l'urbanisation. La capitale a connu un développement de vie publique sans précédent après le traumatisme de la Commune, suivant un parcours progressif à partir de 1872 jusqu'à une apogée entre 1896 et 1900. Par la suite est venue une certaine régression, liée à l'affaire Dreyfus ainsi qu'à l'élection d'une majorité nationaliste au conseil municipal en 1900.

L'expérience démocratique parisienne des années 1872 à 1899 a, par la suite, été occultée par un filtre politique redoutablement efficace. Deux courants symétriquement opposés se sont couplés pour la mépriser jusqu'à l'insignifiance et l'invisibilité : d'une part, une hostilité à l'extension de la démocratie au sein du libéralisme économique français; d'autre part, une hostilité à la légitimité démocratique hors contrôle, dans les traditions marxistes $\mathrm{du} 20^{\mathrm{e}}$ siècle. Le cas est particulièrement frappant lorsqu'il s'agit du radicalsocialisme et du municipalisme réformiste de cette époque: le dédain de l'élite conservatrice se combinait avec l'anti-réformisme idéologique du communisme pour redéfinir, avec une convergence irrésistible, ce qui méritait l'attention, et ce qui pouvait tomber dans l'oubli. Il s'agit là, semble-t-il, d'un schéma très général qui touche l'ensemble de l'historiographie du XIX siècle: les expériences démocratiques et les aventures de la sphère publique demandent à être redécouvertes ou réévaluées, pour peu que l'ancien discrédit fasse place à un souci de compréhension. Le présent article espère y apporter une contribution ${ }^{1}$.

\section{Une occasion historique manquée : la création d'un réseau ferré régional d'île de France (1872-1879)}

5 La première décision juridique de créer le métro remonte à une délibération du Conseil général de la Seine, le 10 novembre 1871. Le rapporteur d'une commission d'étude, Léveillée, fait adopter un texte, dont voici des extraits :

«La Commission est arrivée à cette conviction que la création d'un réseau de chemins de fer dans Paris et dans le département de la Seine était nécessaire, qu'elle était possible et qu'il fallait l'entreprendre. [...] une commission spéciale pour l'étude des chemins de fer et tramways à établir dans Paris et dans le département de la Seine [...] sera chargée d'étudier l'ensemble [...] réalisant, autant que possible, les conditions suivantes:

1. Mettre les différentes parties du département de la Seine en communication avec un chemin de fer de ceinture qui serait placé à l'intérieur de Paris, en dedans du chemin de fer de ceinture actuel.

2. Mettre ce nouveau chemin de fer de ceinture en communication avec le centre de la Ville de Paris.

3. Desservir la ligne des quais en prolongeant le tracé à l'amont et l'aval du fleuve. 
4. Desservir la ligne des boulevards intérieurs.

5. Relier les différentes gares des chemins de fer soit entre elles, soit avec le nouveau chemin de fer de ceinture, soit avec le centre de Paris. " ${ }^{2}$

\section{Le paysage en 1872}

6 Le programme tentait de remédier aux insuffisances manifestes de la politique urbaine de l'Empereur et de l'haussmannisation. Ainsi regrettait-on maintenant d'avoir laissé les gares à la périphérie d'alors. Regret d'autant mieux étayé qu'à la même époque, la capitale britannique avait fait un choix différent : le premier chemin de fer métropolitain de Londres (metropolitan railway, déjà traduit couramment en métropolitain à la fin du Second Empire) avait commencé de fonctionner en 1863. Une boucle centrale permettait d'interconnecter les principales compagnies, sur laquelle des trains de banlieue venaient faire leur manège et distribuer les passagers, occasionnels ou quotidiens. Grâce aux solutions souterraines, les locomotives n'avaient pas défiguré la ville et, tant bien que mal, les inconvénients de la vapeur dans les longs tunnels étaient atténués par des dispositifs techniques de rétention et d'évacuation. À Paris, le chemin de fer dit de petite ceinture, en bordure intérieure des nouvelles fortifications, construit au temps d'Haussmann, seul moyen d'interconnexion des réseaux, ne pouvait tenir la place d'un métropolitain. Il était beaucoup trop excentré, et conçu pour le transit des marchandises. Les tentatives d'y ajouter des services pour voyageurs n'attirèrent jamais qu'un nombre minime d'usagers.

7 L'expression de la délibération, créer un réseau, peut sembler anodine aujourd'hui ; elle soulevait à l'époque une nuée de problèmes. C'était en effet remettre frontalement en cause la politique des chemins de fer mise en place sous le Second Empire. À l'échelle de la France, dès les dernières années de l'Empire, la concentration des réseaux en six grandes compagnies avait fait l'objet d'attaques venues de tous les côtés. Les conseils d'administration étaient assimilés à l'Empire lui-même. L'offensive politique avait repris de plus belle après 1870 . Aux républicains se joignaient les conservateurs et beaucoup de milieux royalistes. Aux petits industriels et commerçants, qui s'estimaient sacrifiés par les tarifs, se joignaient aussi de puissants lobbys patronaux, ceux des houillères et des forges. La fin de l'Empire et de la guerre amenait une nouvelle manie des chemins de fer : des projets de lignes nouvelles étaient promus par des petites et moyennes compagnies, avec l'espoir de rompre le monopole des six grands réseaux. Une loi sur les chemins de fer locaux et la nouvelle liberté de créer des sociétés anonymes en 1867 en fournissaient les points d'appui juridiques. Dans la Seine même, en avril 1872, 48 projets de nouvelles voies de chemins de fer d'intérêt local ou de métropolitain sont recensés ${ }^{3}$. C'était donc le moment favorable, aux yeux des conseillers généraux et municipaux.

8 Mais en quelques mois, ils durent déchanter. Le préfet de la Seine Léon Say, un républicain, célèbre pour l'efficacité de ses critiques à l'égard d'Haussmann, refuse de corriger les défauts de la politique urbaine de l'Empire. En accord avec le ministre des Travaux publics et sa toute puissante administration des Ponts et Chaussées, il se soucie davantage de faire des économies et de protéger les intérêts des grandes compagnies. Dans ce but, il crée une commission spéciale de quatorze ingénieurs où prédominent les représentants des grandes compagnies et leurs correspondants dans les services de l'État ${ }^{4}$ 
9 Le rassemblement des plus hautes compétences techniques en matière de voies ferrées pouvait faire espérer une innovation aussi hardie qu'à Londres, adaptée à la situation parisienne. Mais le résultat, présenté avec un projet de métropolitain et de tramways, suscita une forte déception. Pas question de créer un réseau régional, disaient en substance les conclusions tirées par Léon Say de la commission: le réseau actuel des compagnies y pourvoira, pour peu que l'on complète la petite ceinture par deux lignes diamétrales, et que l'on en confie le soin au même Syndicat des grandes compagnies - Syndicat qui a déjà en charge la petite ceinture et exploitera bientôt aussi la grande ceinture, réservée au transit des marchandises: on vient d'en décider le tracé et la réalisation, en rase campagne, loin des agglomérations, pour l'établir rapidement à bon marché (voir le tracé commenté du projet de métropolitain, proposé par Léon Say, figure 1 ). Pour les voyageurs du département de la Seine, est proposé et voté un nouveau réseau de tramways (à chevaux ou à vapeur), à concéder par adjudication.

Fig. 1 - Tracé de métropolitain proposé par le Préfet Léon Say, accepté en partie par le Conseil Général le 11 mai 1872

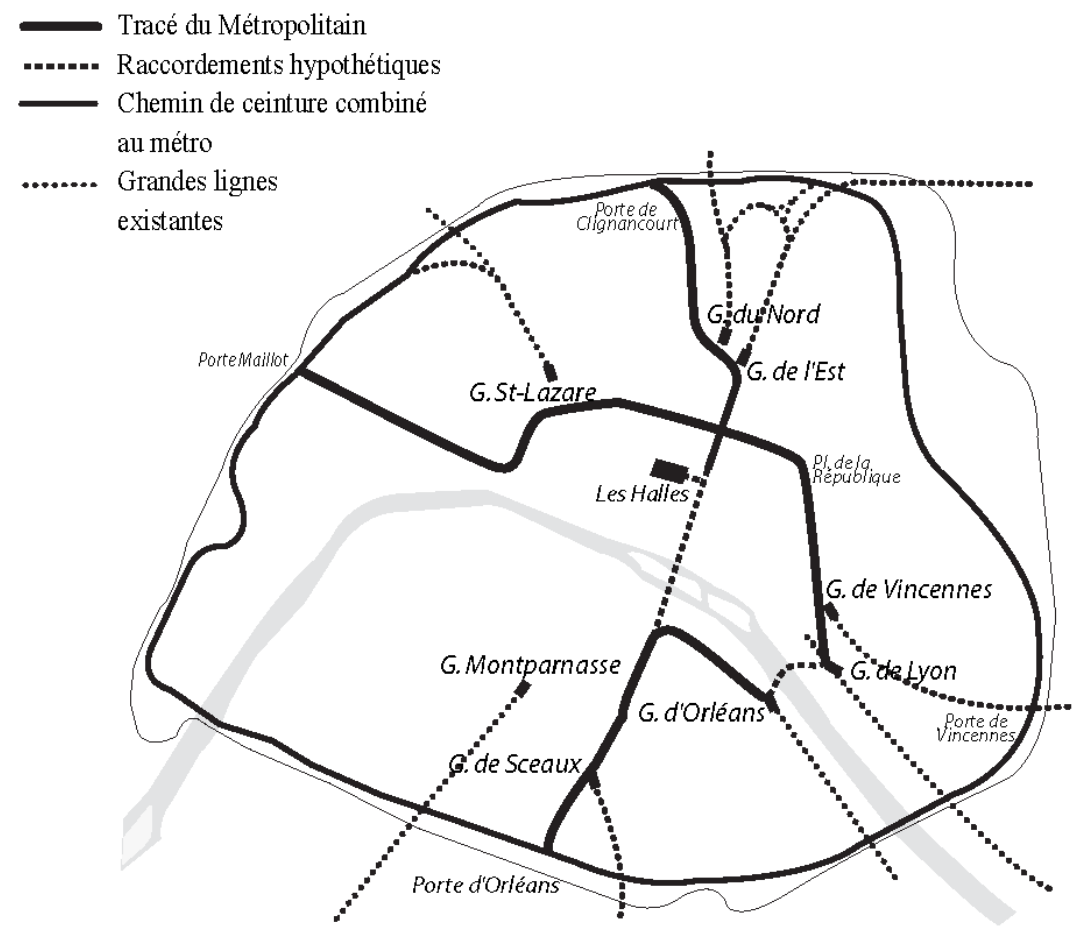

Invité à proposer un chemin de fer régional, le Préfet Léon Say limite les ambitions à deux diamètres reliés à la Ceinture, Est-Ouest et Nord-Sud. Le Conseil général, déçu de l'absence de réseau autonome, et soucieux de réserver l'avenir hors emprise des grandes compagnies, réduit encore le tracé, préférant s'en tenir prudemment au diamètre Est-Ouest. En revanche, il a demandé que cette ligne EstOuest soit si possible interconnectée à toutes les gares rive droite : Saint-Lazare, Gare du Nord, Gare de l'Est, Gare de Vincennes, Gare de Lyon, permettant de développer un trafic banlieue, amorçant un système un peu analogue au métro de Londres.

10 Déçu et surpris à la fois, le Conseil général, dans un premier temps, préfère voter un équipement encore plus modeste, pour ne pas compromettre l'avenir d'un vrai métro. Il approuve seulement l'éventuelle concession de la transversale Est-Ouest. Durant les mois qui suivent, une contre-offensive de plus en plus critique s'en prend à la réticence conjuguée des grandes compagnies et des ingénieurs de la haute administration. 
11 Au Conseil général, en octobre, le ton a monté : « Pourquoi hésiter à construire un véritable chemin de fer desservant tous les intérêts suburbains? ", s'écrie un rapporteur, M. Sueur. « La vitalité de l'industrie parisienne est ici tout entière en jeu ; c'est la prospérité du pays qu'il s'agit de relever et de secourir ; c'est le travail d'un million de bras qu'il faut assurer ».

De nouveau est demandée l'étude immédiate d'un anneau suburbain, d'agglomération à agglomération, pouvant jouer un rôle structurant pour le futur réseau régional. " L'administration est invitée à faire procéder à des études complètes pour arriver à la réalisation d'un chemin de fer circulaire départemental à créer dans la banlieue de Paris... ». Et cette fois, au lieu de fuir les agglomérations de la banlieue, comme le fait le projet de grande ceinture, la ligne suburbaine devait établir ses gares aux futurs points de rencontre avec l'expansion des villages, avant que l'urbanisation ne prenne de l'ampleur et ne décuple les coûts. En complément, une fonction accessoire de la transversale Est-Ouest était ajoutée, pour ménager l'avenir : celle-ci devait être au contact des autres gares parisiennes des grandes lignes, et si possible interconnectée, en prévision d'un prochain développement des migrations résidentielles - pour l'instant très minimes. Le 9 mai précédent, le rapporteur en justifiait ainsi le besoin prévisible, d'après la comparaison que l'on pouvait faire avec Londres :

«On a dit qu'une fraction importante du trafic du métropolitain de Londres était due aux habitudes d'une grande partie de la population, qui a deux domiciles : l'un, dans la Cité, pour les affaires; l'autre, à la campagne, pour la famille. Or on remarque, depuis plusieurs années, que la même tendance se développe à Paris, même chez les personnes d'une aisance médiocre. Les compagnies de chemins de fer, celles de l'Ouest et de l'Est surtout, ont favorisé autant qu'elles l'ont pu cette tendance. Toute la partie occidentale de Paris ressemble à Londres; le chemin de fer de l'Ouest joue le rôle d'un vrai chemin métropolitain ; il transporte nombre de voyageurs à plus de trois kilomètres. Enfin certaines voies, dans Paris, sont au moins aussi encombrées qu'à Londres.

Tous ces faits motivent le raccordement dont on parle. [...] Les trains de banlieue passant alternativement dans le métropolitain, de cinq minutes en cinq minutes, de provenances et à des destinations diverses, c'est là l'idéal qu'on peut espérer dans l'avenir et qu'on doit préparer dès à présent.... $»^{5}$

L'analyse prospective des transports et de la vie urbaine élargit son cercle. Elle se nourrit du climat politique très particulier des lendemains de la Commune. Si les ouvriers, décimés, et parfois massacrés jusqu'au tiers de leurs effectifs dans certaines professions, ne se manifestent pas tout de suite en collectif, la plus grande partie des notables parisiens est néanmoins aux antipodes des propos tenus à Versailles. Ils déplorent la tragédie, se gardent d'accabler les victimes, et tous en tirent comme conséquence la nécessité de changer la relation entre les dirigeants et les citoyens. Les républicains, majoritaires dès les premières élections municipales, deux mois après la Semaine sanglante, en juillet 1871, cachent plus ou moins leur colère contre les réactionnaires, tant que dure la répression contre les survivants : la prospective est alors un bon exercice pour amorcer une démocratie en attendant que puissent revenir les grandes questions politiques. Les réseaux d'aide sociale, autour des mairies d'arrondissement, sont très denses et resserrés dans le climat de l'après-catastrophe. Une vie associative se renoue rapidement et prépare une vitalité inédite dans les activités publiques de la cité.

14 L'étude d'un réseau régional fait partie de cette effervescence participative. Un promoteur de projet, l'ingénieur belge Jules Brunfaut, après avoir déposé un dossier de réseau à la préfecture de la Seine, repris d'une étude de 1868 et inspiré de la délibération des élus de 1871, se heurte comme les autres au refus d'accepter d'étudier les 
propositions d'ouvrir une enquête d'utilité publique. Mais au lieu de se résigner à l'absence d'autorisation d'enquête, après être revenu à la charge auprès du Conseil général et avoir reçu un accueil favorable, il passe outre le refus ministériel et organise en parallèle une enquête dans tout le département de la Seine (voir le tracé du projet, figure 2).

Fig. 2 - Projet de réseau régional, soutenu par le Conseil Général de la Seine, en 1872

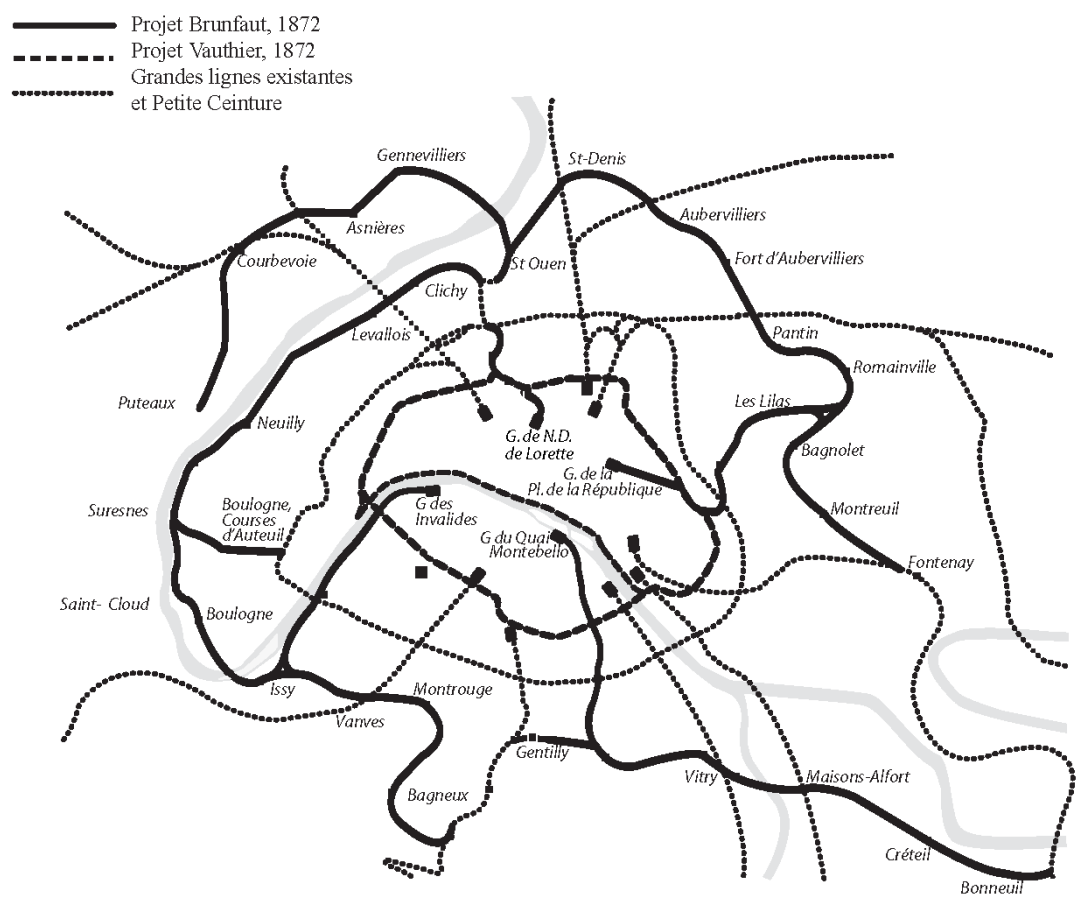

Un projet de réseau régional a été proposé et discuté en 1872, par deux demandeurs de concession, distincts et coordonnés. Le projet ajoutait une circulaire par les grands boulevards, joignant les nouveaux quartiers d'ouvriers refoulés par Haussmann, et une circulaire de banlieue, joignant les principales agglomérations et offrant des raccordements aux nouvelles usines, présentes et futures. Au gabarit de la Petite Ceinture et des grandes lignes, l'ancienne et les deux nouvelles circulaires étaient liées aux anciens rayons de pénétration, auxquels étaient ajoutées quatre nouvelles pénétrantes, avec quatre nouvelles gares: Gare de Notre Dame de Lorette, Gare de la Place de la République (dite alors « Place du Château d'Eau »), Gare du Quai Montebello, Gare des Invalides.

D’octobre 1872 à juin 1873, la compagnie du Chemin de fer métropolitain et de la banlieue de Paris, constituée pour obtenir la concession de ce projet Brunfaut, suscite ainsi la constitution d'une cinquantaine de conseils de notables afin de délibérer sur le projet de réseau départemental. L'élargissement du débat n'est certes pas la démocratie de tous les Parisiens, mais il provoque néanmoins une participation impensable quatre ans auparavant, à l'époque d'Haussmann. Sur listes de notables fournies par les mairies d'arrondissements de Paris et les communes suburbaines de la Seine, des réunions sont convoquées, élisent des commissions spéciales d'étude des projets où les compétences se mêlent aux intéressés les plus directs: côté compétences, on trouve beaucoup d'ingénieurs et d'architectes habitant les circonscriptions; côté intéressés, les plus impliqués sont de grands industriels, des associations de propriétaires, des journalistes chroniqueurs de questions urbaines, des représentants des grandes halles, marchés et entrepôts (halle aux vins, halle aux cuirs, syndicats d'usagers d'abattoirs...). Cinquante deux comptes rendus de débats et de rapports de ces sortes de conseils de quartier sont 
publiés. De leur côté, 170 chefs d'usine répondent favorablement et indiquent les conditions dans lesquelles ils utiliseraient le futur réseau, avec tonnages de trafic et éventuels raccordements de voies ${ }^{6}$.

Les discussions abordent tous les aspects du projet - économie, faisabilité technique, esthétique urbaine, variantes pour concilier les différents intérêts. Leur fonction n'est pas simplement consultative, elle est délibérative, et même, dans plusieurs cas, élaborative, si l'on peut dire.

Plusieurs quartiers et communes étudient des alternatives, à l'aide des données fournies sur demande par la compagnie et en mobilisant les compétences de leurs propres ingénieurs et architectes résidents. Par exemple, les commissions des $5^{\mathrm{e}}$ et $13^{\mathrm{e}}$ arrondissements mettent à l'étude et font adopter une variante de parcours, ainsi qu'un changement d'emplacement de gare, afin de ne pas défigurer les avenues des Gobelins et d'Italie par un tracé en tranchée ouverte (voir figure 3, sur le paysage proposé par Brunfaut). Au lieu d'un terminus sur le quai Montebello (rive gauche, à hauteur du chevet de Notre-Dame indiqué sur le plan de la figure 2), ils font reculer le terminus au contact entre le Paris historique et le Paris des entrepôts industriels : la gare terminus aurait une façade voyageurs à l'angle du futur boulevard Saint Germain et du quai rive gauche (le boulevard et le futur pont Henri IV sont alors inachevés, stoppés par la chute d'Haussmann). En contrebas, face à la Halle aux Vins (l'actuelle faculté de Jussieu), se trouverait la gare de marchandises, constituée en entrepôt, sur les quais, jusqu'aux grandes meuneries du $13^{\mathrm{e}}$ arrondissement. Dans le $15^{\mathrm{e}}$ arrondissement, la desserte des grandes usines est elle aussi assurée par une ligne de quais. Un contre-projet des usines Cail est adopté, qui arrange tout le monde. Le plus gros établissement industriel parisien de l'époque, fabriquant de locomotives, de wagons et autres grosses machines, employant jusqu'à 3000 ouvriers, encombrait les rues par ses convois exceptionnels de plus en plus fréquents, transbordant des véhicules de chemins de fer avant d'atteindre les rails. Le projet établit un raccordement ferré sur le tout nouveau port de Javel. 
Fig.3 - Projet Brunfaut, 1872 - Sortie de Paris en tranchée ouverte, dans une large avenue

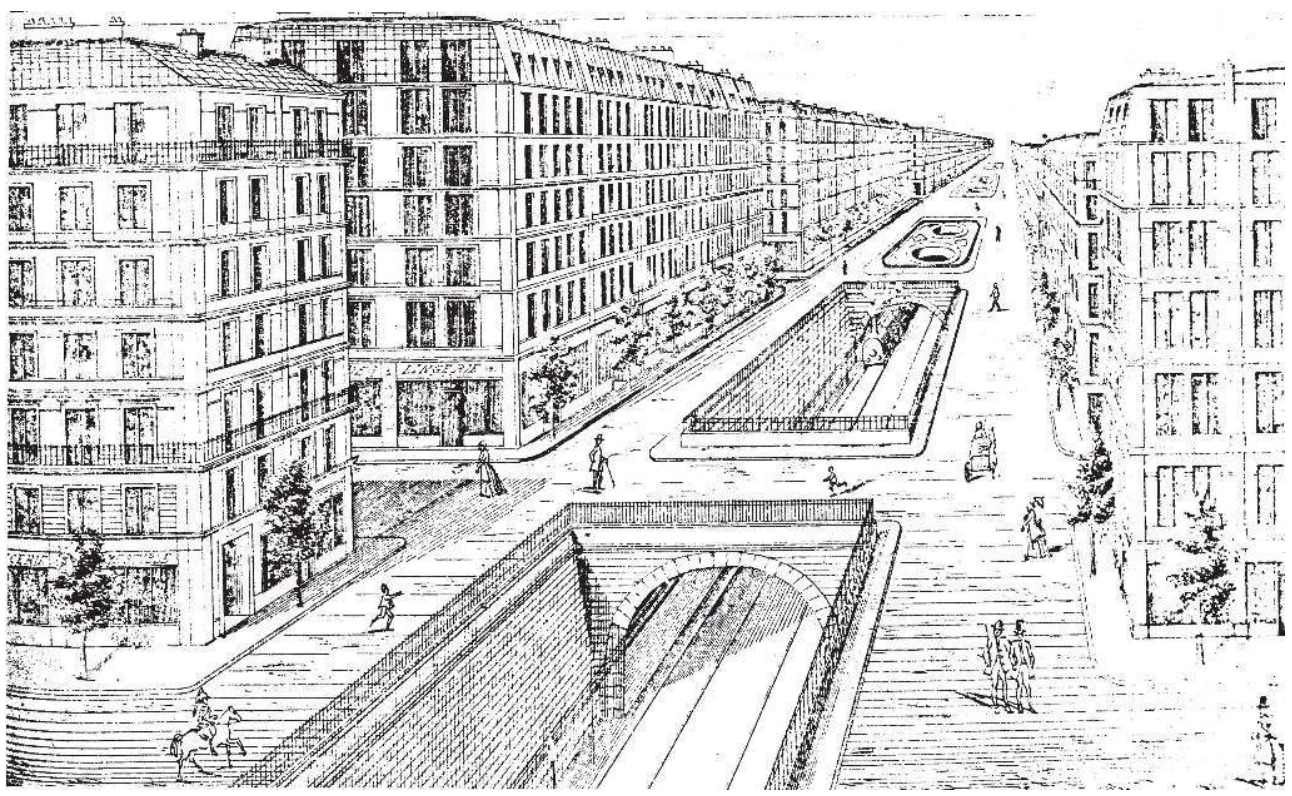

Le projet s'inspire de réalisations londoniennes, et de tranchées semi-couvertes de la ligne de SaintLazare à Auteuil. Le dessin avait été conçu pour un projet antérieur, de 1868, ouvrant une perspective à partir des Champs-Élysées jusqu'à la Défense. II sera proposé pour l'Avenue d'Italie.

18 C'est toutefois dans la banlieue suburbaine que les réponses favorables sont les plus fréquentes. Elles convergent sur une logique économique évidente: la ceinture de banlieue, qui réunit les villages suburbains, parcourt des espaces non encore urbanisés et connece ainsi le plus grand nombre des petites agglomérations avec une grande partie des zones industrielles en tout début de construction. Ce qui donne un coût kilométrique des infrastructures singulièrement bon marché, en contraste avec le Paris intra-muros (moins de 300000 francs du kilomètre, contre trois à cinq millions dans Paris, au minimum, hors expropriations). Cette ceinture joint tous les rayons convergents sur Paris, connectés avec les quatre nouvelles radiales du projet.

Les industriels font leurs calculs en commissions. Dans l'hypothèse d'application des tarifs courants de marchandises par la nouvelle compagnie (tarifs jugés élevés, et très rémunérateurs pour les promoteurs), les baisses de coût du total des transports pour les usagers de marchandises (de la gare à la livraison par équipages de chevaux et chariots) vont de 7 à $15 \%$, par rapport au coût total avec livraison depuis les grandes compagnies ; ce qui signifie aussi une baisse du coût de la vie pour toute la région et un effet multiplicateur des gains de productivité dans les branches exportatrices, assembleuses de productions multiples de la place, à forts coefficients de main d'œuvre. Les baisses de coûts peuvent être beaucoup plus fortes encore, dans les cas de suppression de manutentions intermédiaires, sur la chaîne des livraisons.

Cette amorce de démocratie locale déborde le cercle des notables par un début d'implication de la presse. Le projet Brunfaut reçoit l'appui du plus célèbre journaliste des questions urbaines, Louis Lazare, participant actif aux conseils de quartier, connu pour ses critiques de la première heure contre les projets d'Haussmann. Le chroniqueur municipal pouvait rappeler que dès 1851, pendant qu'on se disputait âprement sur diverses conceptions de la petite ceinture, il avait réclamé une planification urbaine pour coordonner l'ouverture des grandes avenues routières avec les futurs réseaux ferrés 
national et métropolitain. Après avoir développé les critiques de la politique financière et de la corruption au fur et à mesure de l'avancement des percées haussmanniennes, il avait repris ses campagnes sur une thématique significative de l'époque : promoteur d'un syndicalisme de propriétaires, il prenait le contre-pied des promotions haussmanniennes en invoquant un égalitarisme des opportunités de plus-values. Au lieu de réserver le fruit des hausses immobilières aux comptes fantastiques des trésoreries haussmanniennes, aux gros entrepreneurs et aux gros propriétaires, un système d'adjudications loyales devait permettre à tous les propriétaires, gros et petits, de profiter des anticipations de prix dans la transparence. Cette notion d'égalité, dépouillée de sa signification politique, s'appliquait aux affaires à la manière du syndicalisme agricole qui s'amorçait au même moment: s'unir pour des prix profitables et des règles identiques pour chacun, ce qui impliquait un enrichissez-vous pour tous et non plus pour une oligarchie. Le profit était ainsi promu en proportion des ressources individuelles. Cette orientation limitée n'empêche pas Louis Lazare, dans ses brochures puis dans le Courrier municipal, périodique de 1873 à 1879, de fournir au débat public naissant des éléments rationnels et critiques, offrant une expertise soigneusement rassemblée ${ }^{7}$.

21 Auparavant, ce publiciste et historien de Paris s'était trouvé parmi les premiers à critiquer le refoulement des ouvriers vers la périphérie du nouveau Paris intra-muros, ce qui l'amène naturellement soutenir ensuite le projet de ceinture des boulevards extérieurs (intérieurs au nouveau Paris), proposé par le conseiller municipal de la Goutte d'Or, Louis-Léger Vauthier (figure 2). Les deux projets, Brunfaut et Vauthier, qui furent proposés distinctement en raison de sources de financement différentes, étaient en réalité étroitement coordonnés pour former un seul réseau régional, ce que tout le monde, à l'époque, avait compris, pour le combattre ou l'approuver.

\section{Les fondements économiques d'un conflit : exploitation de lignes ou bien exploitation de réseaux}

Louis-Léger Vauthier est un personnage-clé de l'histoire du métro et de l'opposition aux grandes compagnies de chemins de fer en France. Aujourd'hui, en 2004, il est davantage célèbre au Brésil qu'en France. Ingénieur des Ponts et Chaussées, ancien saint-simonien comme tant d'autres, et ancien fouriériste comme quelques-uns, il est appelé par le gouvernement brésilien en 1839 pour encadrer l'équipement du pays. Il dirige les travaux de l'État de Pernambouc, laissant une architecture de style colonial que l'on recommande aux touristes aujourd'hui. Il y mène parallèlement une activité d'intellectuel et de publiciste, réputé savant et philosophe de la science sociale. Revenu en France en raison d'attaques pour ses liens politiques, il est élu député du Cher à la Législative en mai 1849, siège quelques jours à la Montagne, est arrêté en juin avec d'autres montagnard; condamné à la déportation, il en profite pour écrire notamment un ouvrage en faveur de l'impôt progressif. Sur intervention de Proudhon, il est libéré en 1855, à condition de repartir à l'étranger. Ce qui l'amène à diriger des travaux publics en Espagne et en Suisse. Il s'intéresse notamment au tunnel ferroviaire de Saint-Gothard. Il revient en France travailler comme ingénieur civil après l'amnistie. En 1865, en plein triomphe de la politique haussmannienne, il jette un pavé dans la mare en publiant un projet de métro, étudié avec la compétence d'un expert, destiné à atténuer les dégâts de la rénovation : son chemin de fer urbain propose une desserte des quartiers périphériques par une ligne circulaire sur les boulevards extérieurs, complétée par une diamétrale sur les quais de la 
Seine ${ }^{8}$. En mars 1871, capitaine de la Garde nationale, il démissionne pour ne pas servir la Commune. Quatre mois plus tard, il est élu dans le quartier populaire de la Goutte d'Or, où il sera régulièrement réélu jusqu'en 1887 , année où il est battu par un socialiste.

Les projets coordonnés de Vauthier et Brunfaut embarrassent le ministère des Travaux publics et les grandes compagnies plus que tous les autres projets, beaucoup moins étudiés, souvent utopiques et dépourvus des appuis politiques de Vauthier. Ce dernier fait partie en effet de la mouvance des républicains, chez lesquels il exerce une autorité intellectuelle, parmi les modérés comme parmi les gambettistes et l'extrême gauche d'alors. La commission des quatorze ingénieurs, au printemps 1872, avait fait un travail technique considérable sur la faisabilité d'un métro, retenant pour examen approfondi le projet Vauthier avec cinq autres, écartant une quarantaine d'autres propositions sans juger utile de les étudier plus avant.

La plupart des projets écartés sont en effet peu sérieux: de simples idées dessinées sur des brochures et destinées à la presse, parfois même des imaginations farfelues, rêves d'ubiquité greffés sur un sentiment de progrès sans limites, hors des contraintes naturelles. Les systèmes de traction varient du funiculaire à la propulsion mécanique, certains projets n'en ont aucun, estimant que la science proposera des solutions miracles avant quelques années. Rien n'arrête le passage des voies: au-dessus des maisons, à travers les maisons, sur la Seine, sur des piliers, ou établies sur de nouvelles percées spéciales. Entre 1855 et 1895, plus de 240 idées de métro, dites projets, seront ainsi proposées à la presse (voir quelques exemples en fin d'article, figures 17 et 18).

Toutefois le principal aspect de la controverse ne porte pas sur les systèmes techniques : tous les projets crédibles s'accordent pour utiliser la traction à vapeur, seule fiable à l'époque, et emprunter des souterrains sous les rues, afin d'éviter les expropriations, quand les artères ne sont pas assez larges pour laisser passer des voies en tranchée couverte ou sur des arcades, à distance suffisante des maisons. Le conflit durable porte sur la conception des réseaux, l'économie de l'exploitation et la conception du service, au regard de l'urbanisation. À l'occasion de cette première proposition, Vauthier commence à élaborer une théorie économique de la gestion des services publics, remarquable par sa consistance et sa pertinence, aujourd'hui à redécouvrir, comme sans doute d'autres contributions d'ingénieurs des Ponts et Chaussées, dédaignées par les économistes académiques.

La démarche commence par rassembler des critiques de récentes expériences. La plus redoutable concerne la comptabilité des compagnies: Vauthier est un des rares à l'époque à dénoncer le caractère antiéconomique et incontrôlable des fictions administratives qui commandent l'élaboration de leur comptabilité justificative. Dans sa remarquable conférence du Trocadéro, par exemple, il rappelle que les coûts des infrastructures sont décrochés de tout amortissement économique réel, au profit des fixations administratives négociées de remboursement. Afin d'illustrer sa démonstration, il s'appuie sur nombre d'expériences pratiques directes. Il fait ainsi ressortir que les imputations de dépenses, bien triées sur les grilles administratives, sont économiquement opaques, non reliées à leurs fonctions. Ce qui laisse toute la marge nécessaire aux concessionnaires de monopoles pour imposer impunément des coûts très élevés, au nom de l'unité des grands réseaux, du centralisme des fournitures et des prestations internes, sans que jamais puissent être comparées et évaluées des productivités de services en fonction des variations de l'équipement. 
27 C'est ce que Vauthier appelle l'inélasticité de l'outillage ferroviaire dans les conditions d'exploitation des grandes compagnies. Mais, à la différence de théories économiques des réseaux aujourd'hui, l'inélasticité de Vauthier n'est pas une caractéristique inévitable des infrastructures : tout au contraire, elle est un artefact du système de comptabilité, de gestion et d'exploitation qu'il faut corriger par un raisonnement économique appuyé sur une enquête directe, une évaluation des usages pratiques effectifs ou imaginables, sans se laisser piéger par la surabondance inepte des statistiques officielles ${ }^{9}$.

Cette première argumentation, sur l'économie des réseaux versus l'économie des lignes, relève d'une théorie économique générale et s'applique à l'ensemble des réseaux ferrés dans le monde ${ }^{10}$. Une seconde argumentation ne concerne que la France : sous le régime des conventions de 1858-59, les compagnies n'ont pas intérêt à des progrès de productivité pour leurs nouveaux investissements. Le régime, mis en place dans une situation de crise, était destiné à surmonter le manque d'intérêt des compagnies à investir dans des lignes moins fructueuses et non rentables avant plusieurs années. Il avait cloisonné les comptes entre premier et second réseau, accordant une garantie d'intérêt sur les dépenses du nouveau réseau, rassurant ainsi les obligataires et protégeant les revenus des actionnaires des anciens réseaux (tout ceci enrobé avec certaines contreparties sans effets réels). Malgré des mécanismes de report de surplus du premier au second réseau, le cloisonnement des comptes avait renforcé un système de freinage généralisé des investissements, que seules des négociations de subventions supplémentaires aux lignes nouvelles pouvaient surmonter. La renégociation des conventions en 1883, malgré ses modifications, garda le même vice économique fondamental d'une séparation comptable entre premier, second et troisième réseau. Le profit était déconnecté des performances économiques propres à l'agencement global du réseau.

29 Ces dernières critiques étaient bien connues, orchestrées dans des campagnes de presse contre les concessions de monopoles et reliées à la nature des tarifs. La concession ferroviaire s'apparentait, en effet, quels que soient les euphémismes de marché, à des prélèvements contraints, à la manière d'un affermage d'impôt ou d'un péage de pont. Les pamphlets contre les tarifs ou les pénuries n'étaient pas sans une certaine pertinence quand ils assimilaient les hauts tarifs qu'entraînaient les positions de monopole à des rançonnements de voyageurs par les fermiers généraux du rail. Pour comprendre la violence de certaines critiques, il faut se figurer ces trois décennies particulières (1870-1900) où les voies ferrées devenaient le seul moyen économique de transport, écrasant tous les autres, avant que n'arrive l'automobile.

30 A la différence de beaucoup de gambettistes et de radicaux, Vauthier mettait l'accent sur les alternatives économiques, plus que sur la seule étatisation. Au lieu de diviser nationalement le premier réseau et de faire des second et troisième réseaux de simples rabattages sur les premiers, gérés sans souci de productivité, avec des normes d'infrastructure identiques, il fallait établir, en plus du réseau national, de véritables réseaux régionaux, dotés d'une autonomie et d'une souplesse de gestion, capables de réinventer des outils adaptés et proportionnés. Chaque réseau régional, à son échelle, pouvait dessiner des tracés géométriquement optimisés, tandis que les parcours en rabattage sur les grandes compagnies nationales contraignaient à multiplier les détours par les voies principales. Les nœuds hiérarchiques à l'ancienneté empêchaient les connexions de voisinage. Le cas est flagrant avec les deux premiers tracés métropolitains indiqués (figures 1 et 2). Le projet Léon Say, en circuits fermés, obligeait les 
communications d'une diamétrale à l'autre à faire un détour par la petite ceinture (moyennant péages). Le second minimisait les parcours en tout point de l'agglomération en permettant de jouer sur trois cercles et douze rayons. Il convient d'ailleurs de remarquer que la même logique alternative pouvait déjà commencer de jouer dans l'hypothèse où les radiales ne communiquaient qu'avec la seule ligne circulaire des boulevards extérieurs.

\section{Les stratégies en jeu de go, 1872-1875}

31 La théorie de Vauthier reçut une confirmation indirecte dans la conduite des hostilités des grandes compagnies à l'encontre du projet de réseau régional : le point tactique décisif fut la possibilité de développer ou non un réseau cohérent. L'hostilité des compagnies se manifesta par des contre-projets, afin de garder pour elles les trafics les plus prometteurs dans l'immédiat, et de rester maîtresses du jeu dans l'avenir. Avant tout, il fallait éviter que ne se créent de nouvelles têtes de lignes, susceptibles de devenir un jour des points d'appui pour des compagnies nationales concurrentes. De plus, au moment où était envisagée une ligne Calais-Marseille, en concurrence avec les compagnies du Nord, de l'Ouest, de l'Est et du Paris-Lyon-Méditerranée, il fallait absolument éviter de laisser une possibilité de traverser Paris hors des voies construites. En second lieu, pour offrir un minimum de réponse à l'enquête d'utilité publique officieuse de Brunfaut, les grandes compagnies firent plusieurs propositions. Pour le Nord de Paris, la Compagnie du Nord, sollicitée par la préfecture de la Seine, sortit de ses cartons un projet de jonction industrielle. Celle-ci reliait les docks de Saint-Ouen, la vaste plaine de Saint-Denis, (entre les fortifications et l'agglomération de Saint-Denis), un nouveau grand triage destiné à désengorger le triage intra-muros de La Chapelle et un raccordement avec la Compagnie de l'Est (voir figure 4).

La préfecture de la Seine proposa d'intégrer le tronçon à un autre segment de la ligne circulaire de banlieue qu'elle étudiait au même moment, un Chemin de fer de camionnage industriel entre Neuilly et Pantin. Mais le projet de la Compagnie du Nord prévalut. L'exécution de cette ligne détermina, pour une durée d'un siècle, la constitution de la plus vaste zone industrielle dans le voisinage immédiat de Paris : paysage de l'ère du charbon, de la vapeur et des usines à gaz.

33 Fait significatif : dans un premier temps, durant l'été 1872, la Compagnie du Nord envoie son projet Saint-Ouen-Pantin à la préfecture de la Seine, avalisant l'idée que le programme départemental du réseau de banlieue relève du régime des chemins de fer locaux. Mais entre temps, les autres compagnies et les ingénieurs des ponts du ministère s'agitent, face à ce qui leur paraît une menace pour l'équilibre des concessions des grands réseaux. Les deux ministres de l'Intérieur et des Travaux publics écrivent au préfet que les lignes projetées sont d'intérêt général, et non d'intérêt local, ce qui signifie de compétence nationale et non départementale.

Le ministère des Travaux publics, s'étant ainsi saisi du dossier, accélère deux projets. Il pousse l'adoption par les Chambres du projet de Chemin de fer de grande ceinture, dont la réalisation va être effective, pour la plus grande part, entre 1874 et 1882 ; et il fait accorder encore plus rapidement, dans la précipitation, la concession à la Compagnie du Nord. Pour désigner cette dernière opération de la Compagnie du Nord et du dessaisissement inopiné du Conseil général, le préfet déclare sans fard à l'assemblée départementale, d'après le compte-rendu officiel imprimé, que « la Compagnie de chemin 
de fer du Nord demandait au gouvernement la concession d'une ligne allant de SaintOuen à Pantin, s'emparant ainsi d'une partie du tracé circulaire qui avait été l'objet des préférences du Conseil.

Fig. 4 - Contre-propositions des grandes compagnies, en 1873, effectivement mises en œuvre

Grandes lignes proposées en 1873 ,

et effectivement construites

........ Grandes lignes existantes

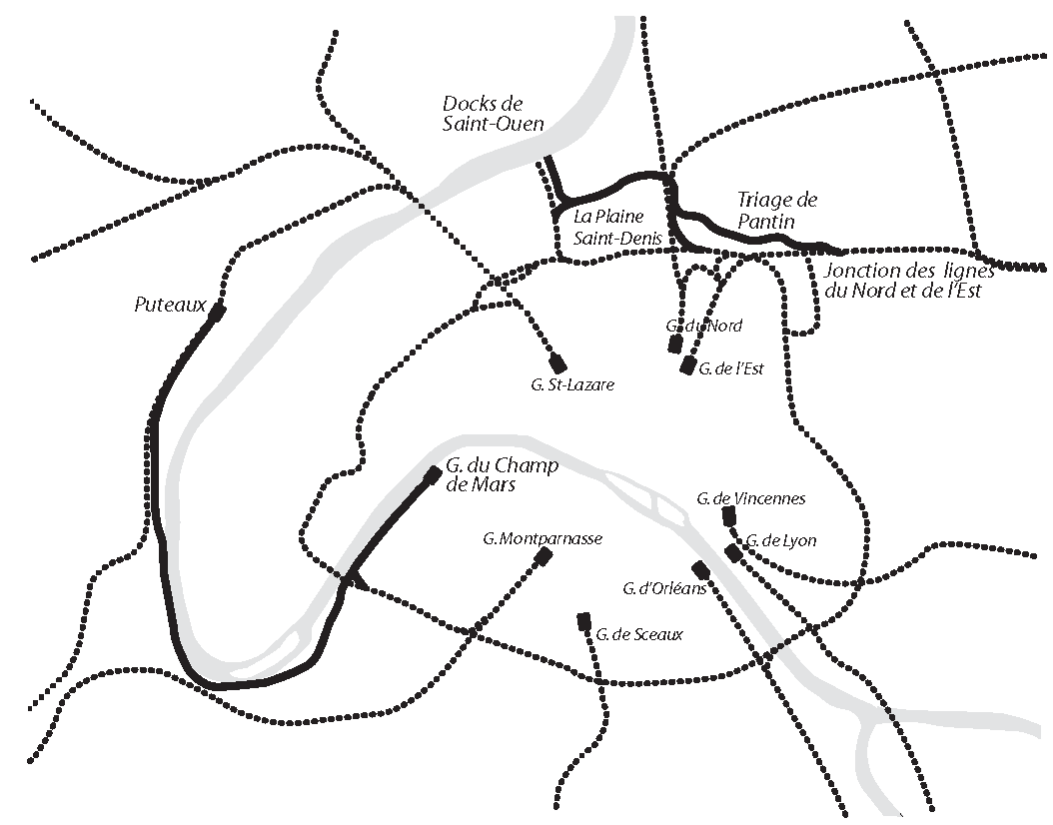

A la suite de l'enquête d'utilité officieuse suscitée par le projet de réseau régional, les grandes compagnies, hostiles à toute concurrence, répliquent par une offre minimale, sur les deux secteurs où les pénuries sont évidentes et les perspectives de recettes les plus prometteuses. Après une suite de péripéties, sont adoptées entre 1873 et 1875 et effectivement réalisées :

- Une ligne au Nord, à la Plaine Saint-Denis. La construction de la ligne va déterminer la plus grande zone industrielle de l'ère du charbon, de la vapeur et des usines à gaz aux portes de Paris.

- Une ligne de Puteaux à la Gare du Champ de Mars. Elle prend une partie du tracé Brunfaut, mais le casse à dessein entre Puteaux et les docks de Saint-Ouen ; elle répond à des besoins industriels pressants (grandes usines sur les quais $\mathrm{du} 15^{\mathrm{e}}$ arrondissement) et verrouille géographiquement une zone où des projets voulaient créer une nouvelle tête de ligne, dans l'axe des Champs-Elysées à la Défense.

L'expression du préfet - «s'emparant ainsi »- est symptomatique d'une manière d'envisager ouvertement, comme allant de soi, les stratégies des compagnies. Il est donc naturel de s'arracher les morceaux de tracé les plus productifs, de dépecer l'architecture d'ensemble $\mathrm{du}$ projet régional pour rentabiliser l'ancien réseau et empêcher la constitution d'une concurrence. Nous sommes là en présence d'une stratégie très caractéristique, à l'œuvre à l'époque dans toutes les régions de France, et que l'on pourrait appeler la stratégie ferroviaire du jeu de go. Le principe du jeu traditionnel chinois, rappelons-le, est que deux joueurs tentent de se constituer des territoires, sur une sorte de damier en croisillons, en plaçant à tour de rôle un caillou sur une croisée, de telle sorte que des cailloux en connexé refermée constituent un territoire, ou prennent un caillou adverse. L'art tactique consiste moins à prendre les cailloux de l'adversaire qu'à l'empêcher de se boucler des territoires. Le gagnant est celui qui s'est constitué davantage de territoires que l'adversaire. Il suffit de remplacer caillou par ligne, et territoire par 
réseau (c'est-à-dire un ensemble de liaisons bouclées, doté d'une continuité topologique) pour rendre compte des batailles stratégiques entre, d'un côté, les six grandes compagnies, et de l'autre côté, les tentatives de nouveaux réseaux. La principale différence est que la partie est inégale dès le départ: les grandes compagnies ont deux mille kilomètres d'avance, avec un arbitre qui leur est acquis, à savoir le ministère des Travaux publics et sa direction des chemins de fer jusqu'à la mort du directeur Franqueville, en septembre 1876.

Une illustration frappante de cette stratégie du jeu de go nous est offerte par le comportement de la Compagnie de l'Ouest à la suite de l'enquête officieuse d'utilité publique suscitée par le projet Brunfaut. Une première initiative est prise par le nouveau service d'étude du métro de la préfecture de la Seine. Elle élabore en avant-projet le quart Ouest du chemin de fer circulaire de banlieue: une ligne Grenelle-les MoulineauxBillancourt-Boulogne-Clichy (le tronçon correspond à la partie Ouest du projet Brunfaut, voir figure 2). C'est la desserte industrielle des bords de Seine, du $15^{\mathrm{e}}$ arrondissement aux usines de Puteaux, en passant par Boulogne et Billancourt.

Cependant, ironise Vauthier dans un rapport au Conseil général :

«[...] le tronçon de Clichy à Grenelle, placé dans le domaine de la Compagnie de l'Ouest, était trop bien à sa portée pour avoir quelque chance de lui échapper. L'administration convint d'ailleurs loyalement que ses vues étaient bien de le confier de préférence à cette grande compagnie. Or, sans avoir contre cette solution une répugnance absolue, le Conseil général a toujours pensé qu'il y a, comme le fait nous le montre, entre les services à long parcours et ceux à courte distance, des différences essentielles, et qu'il ne devait pas, sans mûre réflexion, livrer aux grandes compagnies ses chemins urbains et de banlieue.

Mais le monopole est ombrageux. La Compagnie de l'Ouest ne pouvait, dans sa haute situation, se contenter d'une simple possibilité. Le Conseil général de la Seine regimbait; il fallait le mater. Elle présenta d'un seul coup, pour être soumis aux enquêtes, les avant-projets de cinq tronçons, en relation directe avec Paris ou très voisins de son enceinte $»^{11}$.

Trois des cinq tronçons passent plusieurs étapes de la procédure d'instruction et arrivent au stade de propositions de mise à l'enquête publique :

1. Un segment de l'ancien Grenelle-Courbevoie, réduit du tiers au segment le plus immédiatement productif, un Grenelle-Moulineaux, pouvant être raccordé à la petite ceinture et à la ligne Montparnasse-Versailles.

2. Le tronçon Auteuil-Boulogne, le plus productif de la banlieue en raison de la fréquentation du champ de courses d'Auteuil, un marché que l'Ouest tient captif depuis l'origine par sa ligne Saint-Lazare-Petite Ceinture Ouest, mais qu'il doit sauvegarder contre la menace du projet Brunfaut ou celle d'un nouveau tramway.

3. Un Auteuil-Pont de Sèvres, pour contrer la concurrence d'un projet de tramway. Avec ces trois lignes, trois cailloux en termes de jeu de go, l'Ouest verrouille son territoire contre les projets du Conseil général.

Un nouvel épisode intervient avec l'opposition du service préfectoral du métro : celui-ci critique vivement les contre-projets de l'Ouest, car ils ne desservent ni Puteaux, ni Suresnes, ni Courbevoie.

Cinquième épisode: la Compagnie de l'Ouest, appuyée par le ministère des Travaux publics, se joue de la position préfectorale en reprenant à son compte le meilleur des études du service du métro. Elle présente, en chemin de fer d'intérêt général, un nouveau projet allant des Moulineaux à Courbevoie, suivant à peu près la rive gauche de la Seine 
(voir figure 4). La partie est close avec une victoire de l'Ouest sur toute la ligne, si l'on ose dire: une concession provisoire, et confirmée ensuite, est signée entre l'État et la Compagnie de l'Ouest le 3 août 1875 ; le projet devient la Ligne Puteaux-Moulineaux-Champ de Mars inaugurée pour l'Exposition universelle le premier mai 1889, aux pieds de la nouvelle Tour Eiffel. Il faudra attendre un peu plus d'un siècle pour que cette ligne trouve sa vocation d'origine, intégrée dans un réseau régional, redistribuée en segments du RER $C$ et du réseau ferré d'Ile de France.

41 Seul tout petit succès du Conseil dans la partie : il empêche la Compagnie de l'Ouest de réaliser la ligne concédée Auteuil-Boulogne, en se faisant le défenseur du Bois : il refuse de céder les terrains qu'avait promis pour lui l'administration. Il tentera de reprendre ce segment des Courses de Longchamp dans les projets de métro ultérieurs.

Le cynisme des stratégies en jeu de go n'aboutit pas pour autant à une transparence des intentions, au contraire. Au-delà du cercle des actions et des intérêts tactiques bien compris, s'étend un halo de procès d'intention. Le préfet de la Seine Ferdinand Duval, successeur de Léon Say, nommé le 24 mai 1873, va inaugurer le genre, en ce qui concerne le métro. Au début, il est pris au dépourvu. Il se met au travail sur la base de la réalisation d'un réseau ferré d'intérêt local, et se trouve désarçonné par l'alignement subit du ministère des Travaux publics et de la Direction des chemins de fer sur les stratégies des compagnies, sans distance d'arbitres. Puis il se ravise, retrouve rapidement la subordination de sa fonction et $\mathrm{y}$ ajoute du zèle. Il le fait en jetant le soupçon sur Vauthier, le chef de file des adversaires des compagnies. Il insinue en réponse à un rapport de Vauthier que "si l'on admet que le but qu'il importait d'atteindre était la création d'une compagnie qui serait placée sous la dépendance du département, et qui devrait son existence au Conseil général, les reproches adressés par le rapporteur [Vauthier] à l'administration sont

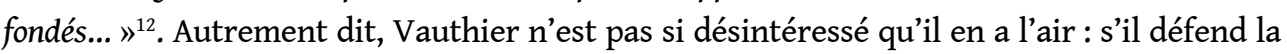
constitution d'un réseau cohérent, c'est qu'il travaille pour le bénéfice d'un futur concessionnaire.

Le mode d'insinuation est classique : a) mettre en rapport une politique et les possibilités que des groupes en profitent économiquement; b) passer de la cohérence logique à l'affirmation d'une intention intéressée par anticipation, sans preuves. Le procédé est très utilisé à la même époque par les grandes compagnies, en province. Elles y généralisent des mésaventures locales avérées, où des votes de concessions de lignes ne sont que prétexte à divers genres de spéculation, sans réelle responsabilité de réalisation.

Ce détail nous offre le premier symptôme d'un problème de débat public qui va passer par plusieurs épisodes: comment les citoyens et les pouvoirs publics peuvent-ils faire la différence entre la critique avérée et le soupçon par simple procès d'intention? Le problème va s'amplifier avec la crise parisienne du boulangisme, le scandale de Panama et l'affaire Dreyfus. Le débat du métro évoluera au rythme de ces conjonctures. La question se pose aussi, après coup, à l'analyste : comment sortir de ces stratégies du soupçon, comment ne pas rejouer le même jeu, avec seulement le privilège rétrospectif en plus? Pour s'en sortir, l'enquête historique peut chercher à prendre la position plus objective du juge d'instruction. Une autre stratégie d'enquête, adoptée par cet article, consiste à expliciter les formes possibles parmi lesquelles évolue effectivement le débat public, afin d'en situer les conditions de fonctionnement. Dans le cas présent, par exemple, il est embarrassant de remarquer que le procédé du préfet et des grandes compagnies, banal, est considéré un peu plus tard, aux époques du boulangisme, du scandale de Panama et de 
l'anti-dreyfusisme, comme une stratégie typique de l'extrême droite. L'analyse devra pousser plus loin les distinctions.

En l'occurrence, le préfet n'accorde aucune place à l'économie politique des réseaux qui préside aux interventions de Vauthier et aux votes de la majorité du Conseil général. Devant cette incompréhension, Vauthier revient à la charge d'une façon plus explicite et pédagogique. Il le fait d'abord en déposant un Vœu au sujet de la constitution des réseaux ferrés régionaux (21 novembre 1876). Un rapport résume l'intervention de notre savant collègue, M. Vauthier :

«Les grandes compagnies construisent et exploitent les lignes secondaires à autant de frais que les lignes principales ; c'est une nécessité de leur organisation, et une conséquence de leur monopole. Une autre conséquence, non moins forcée, c'est que la prospérité due à l'exploitation des grandes lignes se trouve soutirée, pour ainsi dire, par les faibles résultats des lignes secondaires, et que la situation entière des grandes compagnies s'en trouve compromise... $»^{13}$.

La construction des petits segments de ligne de Saint-Ouen et des Moulineaux illustre crûment les conséquences des décisions à la marge des comptes financiers, en toute irresponsabilité pour les usagers: les petits segments de grandes lignes urbaines ne pourront fonctionner, eux aussi, qu'en système de rabattage des marchandises et des voyageurs, terminés en impasses, tout comme les petits trains de campagne, sans interaction avec le développement local, qu'elles doivent suivre au lieu de l'anticiper. Il en résulte un sous-investissement, par sous-estimation du potentiel des usagers et surcharge des coûts alignés sur les gabarits bureaucratiques nationaux. La critique s'applique aussi, sous d'autres angles, à un nouveau projet de métro urbain, étudié par les services de la préfecture.

\section{Nouveaux projets de métro, et nouveaux épisodes du jeu de go (1876-1880)}

En 1876, est mis au point le plus étrange des projets de métro urbain étudiés officiellement. Il est dû à l'ingénieur Alphand, ancien bras droit de Haussmann et toutpuissant directeur des Travaux à la préfecture de la Seine, toujours en liaison avec ses anciens amis ingénieurs ferroviaires de l'Empire. Tandis que l'Empereur s'était vivement opposé à l'entrée des gares dans le centre ville, Alphand décide d'en tenter l'étude, tout en respectant le nouveau caractère urbain parisien. Le respect du monopole des grandes compagnies détermine une troisième contrainte : rabattre autant que possible les apports de trafic sur l'ancien réseau. Le tracé adopté tiendra cette gageure, mais avec un résultat si saugrenu que personne ne le prendra au sérieux. Le projet fait converger l'ensemble des grands réseaux vers le centre de Paris par quatre radiales souterraines et installe leur jonction dans le centre du Paris monumental, sous les jardins du Palais-Royal (voir figure 5 ). 


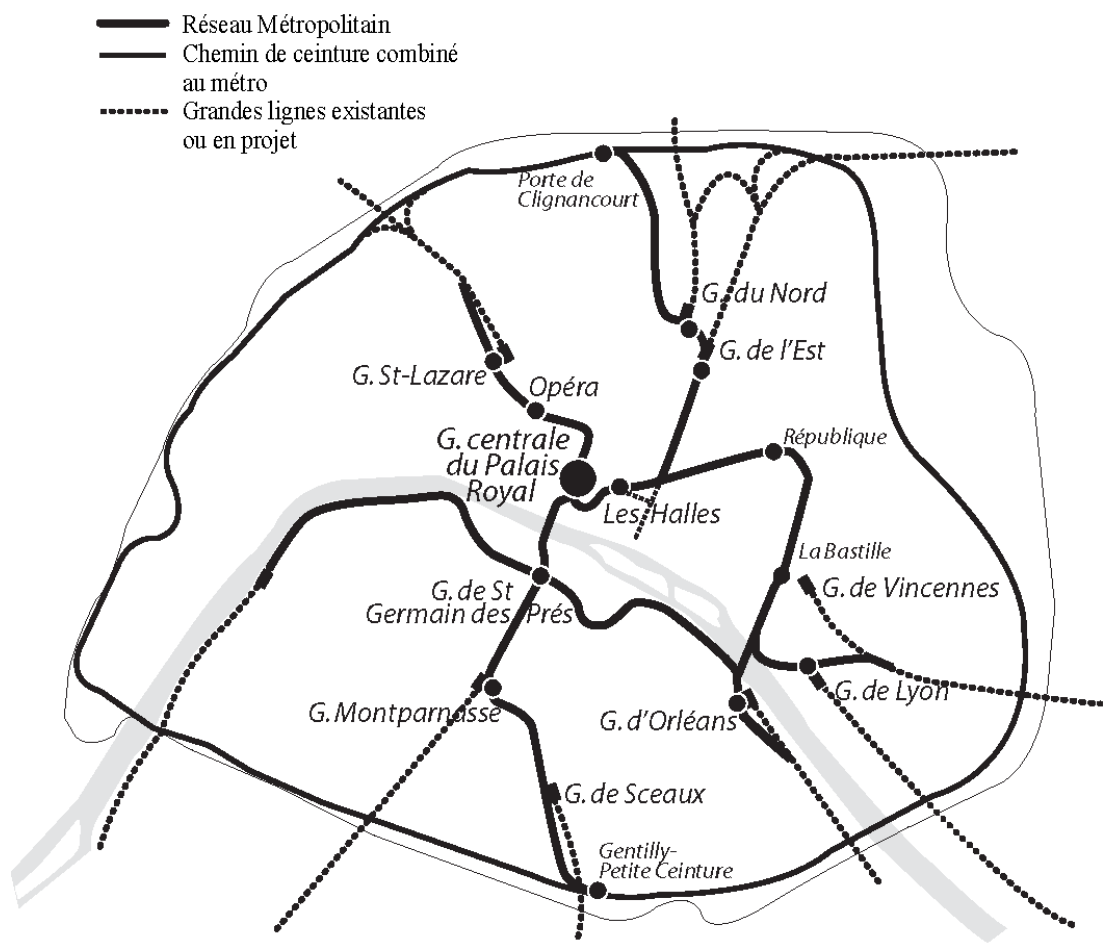

Le projet « Alphand-Huet » est le plus étonnant des métros étudiés officiellement par l'administration. Conçu sous la direction de l'ancien bras droit de Haussmann, Alphand, le dispositif s'est donné pour contrainte de concilier la construction d'un réseau ferré urbain avec la circulation des grands trains des lignes du pays, tout en respectant la philosophie du Paris du Second Empire. La solution adoptée fut une jonction souterraine des grandes lignes au centre de gravité de la capitale monumentale, sous les jardins du Palais-Royal. La Gare centrale de la France, ainsi comprimée à l'intersection de quatre rayons, devait être en même temps le pivot d'un système de circulation parisienne qui intégrerait la Petite Ceinture. Le tout, d'un coût digne des travaux d'Haussmann, serait concédé au syndicat des Grandes Compagnies et construit avec une forte subvention de la ville.

C'est en quelque sorte la conduite jusqu'auboutiste de la géométrie convergente du réseau ferroviaire de la France, rassemblée en un point de concentration où les voyageurs risquaient d'être aussi à l'aise qu'un grand troupeau mené dans un petit corral. À l'intérieur du mur d'enceinte, les quatre radiales se combinaient avec la petite ceinture, comme s'il était plus important de rallonger les parcours par des détours sur la ceinture, moyennant un tarif kilométrique, que de relier commodément les quartiers. Les conseillers n'eurent pas besoin de s'acharner contre le projet : le principal intéressé à qui était offert ce cadeau embarrassant, le Syndicat des ceintures ferroviaires, n'en voulut pas. Plus tard, en 1884, l'ancien préfet Ferdinand Duval, dans une lettre confidentielle à son prédécesseur Léon Say, devenu le numéro deux de la Compagnie du Nord, commentant ce projet d'Alphand, dressé sous sa responsabilité, formulait en clair la première des contraintes imposées au projet, exprimant lui aussi la poursuite du jeu de go contre tout nouveau concessionnaire :

«Mon cher ami, voici les documents que j'ai en ma possession. [...] Le premier projet (dossier rose) a été approuvé par le Conseil général des Ponts et Chaussées et par une décision du ministre des Travaux publics. C'est celui dont j'avais dressé le programme à Alphand, qui l'a fait exécuter par Huet. Il était combiné pour relier ensemble les grandes lignes entrant dans Paris et ne pas pouvoir être tourné contre les 
grandes compagnies. Il devenait ainsi tout à la fois le complément du chemin de

ceinture et la prolongation des lignes de banlieue jusqu'au centre de Paris.... ${ }^{14}$.

rédhibitoire énoncé dans la lettre de Ferdinand Duval: il peut «être tourné contre les grandes compagnies ", dans la mesure où son circuit indépendant de la petite ceinture peut un jour être utilisé comme nouvelle tête de grande ligne dans Paris. Le préfet ne donne aucune suite au vote.

\section{Enjeux d'urbanisation, choix de modes de vie}

\section{Le développement d'un débat public sur les choix d'urbanisation}

51 Au conseil municipal, les discussions sur l'utilité d'un métropolitain s'approfondissent, à l'occasion des rejets de l'emprise des grandes compagnies. D'autres raisons de les repousser sont mises en avant. Peu à peu, le débat municipal va imposer au public d'associer l'avenir de l'urbanisation à la question de l'avenir des transports: quels services seront les plus utiles aux Parisiens? Entre la commodité des uns et des autres, comment choisir? La comparaison avec Londres fournira la trame des controverses. Cette évolution du débat public est amorcée par le Contre-projet de réseau urbain du chemin de fer métropolitain, présenté par l'ingénieur et conseiller municipal Ernest Deligny en 1879.

Collègue et ami de Vauthier au conseil municipal, Ernest Deligny est un autre leader de la politique des services publics. Proposé par Gambetta aux municipales de 1874, il a fait fortune comme ingénieur directeur des mines de Huelva, en Espagne. Très vite, il s'impose parmi les élus pour sa compétence et son esprit indépendant. Il s'opposera jusqu'à sa mort, en 1895, aux pratiques affairistes de ses anciens amis gambettistes, devenus députés et ministres, au point d'être l'un des rares de son clan à qui la presse d'extrême gauche rendra hommage, à sa mort, pour une vie d'intégrité et d'indépendance d'esprit. C'est aussi un signe de bon fonctionnement de la démocratie locale parisienne que de confier le leadership des affaires de travaux publics à ce genre d'homme.

Deligny conteste une idée courante, importée d'Angleterre, sur les besoins futurs de transports suburbains. À Londres, des migrations alternantes domicile-travail commencent à se développer; ces nouvelles migrations deviendraient les principaux besoins de la prochaine génération, à desservir en priorité, si l'on en croit les exposés des motifs de maints projets de métro parisien. Deligny met en cause cette extrapolation et estime que la prochaine génération aura avant tout besoin de facilités de transport pour des activités en cours de travail. Contrairement à ce que proposent les grandes compagnies, l'objectif doit être de faciliter suffisamment ces déplacements d'activité, au service du plus grand nombre, et non pas de pousser à d'hypothétiques migrations alternantes vers la banlieue. Suivant le même esprit, les aménagements doivent se prêter à la connexité des domiciles et des lieux de travail, au lieu de pousser à leur éloignement. Le propos de Deligny est repris, élargi et approfondi en Commission du Conseil. Une synthèse y est opérée avec l'économie politique de Vauthier. Il en ressort un document historique pour la genèse du métro parisien: pour la première fois, sont formulées clairement les bases de la philosophie du métro parisien que nous connaissons ${ }^{15}$.

Revue d'histoire du XIXe siècle, 29 | 2005 
Le texte, signé de deux rapporteurs, l'ingénieur Deligny et l'architecte Cernesson, demande que les prévisions changent de méthode. On était habitué, chez les ingénieurs des chemins de fer, à asseoir les prévisions de trafic sur l'analyse des courants de circulation effectifs et leur extrapolation. Le procédé est enseigné dans les manuels d'ingénieurs des chemins de fer. L'introduction explique qu'on ne peut s'en satisfaire :

«Il semblerait à première vue, que l'importance de la population et sa densité fussent les bases d'appréciation les plus certaines [des moyens de circulation nécessaires]. Il n'en est pas ainsi : la proportion de la population qui se déplace et use, à cet effet, des véhicules mis à sa disposition, peut varier dans une énorme mesure, suivant le prix moyen de l'heure de travail, et le produit de ce prix multiplié par le temps nécessaire pour effectuer le déplacement à pied, comparé au prix de parcours dans le véhicule offert.

Il faut partir du principe que le déplacement par distraction est l'exception, et que, dans au moins neuf cas sur dix, on monte en voiture, en omnibus ou en wagon pour économiser de la fatigue et du temps, c'est-à-dire de l'argent. Pour beaucoup, la fatigue est négligée, quand la course n'est pas longue. Pour tous, le temps importe, aussitôt que le prix du temps dépasse celui du transport. La durée d'un voyage se compose du temps d'attente avant le départ et du temps employé à effectuer le parcours.

Il faut donc, pour conserver au véhicule des avantages économiques, rapprocher les départs, et offrir abondamment les places, de manière à éviter que le temps perdu, dans les salles d'attente et les stationnements, devienne, en moyenne, une partie importante de la durée du déplacement. »

Les ingénieurs étendent ici aux marcheurs à pied urbains et à la gestion de leur temps l'analyse économique de leur prédécesseur Jules Dupuit. Ils ne prétendent pas mesurer directement le temps, contrairement à certains de leurs collègues, mais ils localisent des circonstances qui peuvent révéler le prix que les usagers virtuels attachent à l'économiser. Les premières circonstances sont le choix entre la marche à pied et l'emprunt d'un transport en commun. L'empêchement de faire ce choix peut aussi donner lieu à indication sur les valeurs en usage, lorsque l'obstacle est levé brusquement. Ce qui s'est passé peu auparavant, lors de la mise en service des tramways : le contraste avec l'organisation du service des omnibus a démontré à quel point un système d'offre, loin de révéler une demande, pouvait la comprimer. La levée de la contrainte prend alors valeur d'expérience révélatrice :

«C'est cependant ce qui arrive sur les lignes de circulation très fréquentées, lorsque les départs sont trop éloignés les uns des autres, et lorsque, par surcroît, on est exposé à n'avoir de place qu'à la deuxième, troisième ou quatrième voiture [allusion à la pénurie de voitures de la Compagnie Générale des Omnibus]. Si le temps est beau, si on ne craint pas la fatigue, on laisse la voiture et l'on s'en va à pied. Aussi toute amélioration dans la fréquence des départs, et dans le nombre des places offertes, est-elle suivie d'un accroissement immédiat et considérable du nombre de voyageurs, dépassant souvent toutes les prévisions. »

Conséquence pratique immédiate: il est nécessaire d'inventer un outil ferroviaire différent du dispositif des grandes lignes, voyageurs ou marchandises, pour le plier à des contraintes de services spécifiques :

«Il faut donc rompre cet obstacle au déplacement par un agent de transport puissant, économique, rapide, toujours prêt, quelle que soit la quantité de mouvements demandée et son intermittence. Il faut le chemin de fer, pour rendre abordables tous ces quartiers excentriques de Paris, que les omnibus n'ont pu vivifier; pour rompre ensuite l'obstacle matériel qui nous sépare des champs où l'habitation large et saine pourra se développer... » 
57 Un enjeu de théorie économique d'une portée beaucoup plus générale, laissée ici en arrière plan, développée dans de savantes réunions avec Vauthier, est une réadaptation du modèle économique de Dupuit : il faut raisonner, non sur des courbes continues à la marge, mais sur des expériences naturelles de ruptures (évaluations sur des discontinuités de systèmes). Le mot "rompre » expose pédagogiquement le refus des calculs habituels des polytechniciens ferroviaires en co-variations linéaires continues, afin de mettre en perspective différentes configurations réelles ou simulées du lien transports-urbanisation.

La valeur expérimentale des ruptures de systèmes s'applique en particulier au débat sur le raccordement des lignes de banlieue au métro. Ce sera le point de fixation des controverses entre ingénieurs de la majorité municipale et ingénieurs défenseurs des grandes compagnies, répercuté dans les débats publics.

\section{Le phénomène de Banlieue-sous-Bois}

Le métro de Londres, inauguré en 1863, en expansion continue, consiste en raccordements des grandes gares sur une boucle intérieure. Les trains de banlieue viennent alternativement y tourner en manège pour déposer les voyageurs au plus près de leur destination centrale, au lieu de débarquer tout le monde dans un unique terminus. S'y ajoute le service intérieur de la zone centrale, en concurrence avec des omnibus moins surchargés qu'à Paris, dans une métropole beaucoup moins dense, aux structures foncières plus élastiques du fait d'une prépondérance de grandes propriétés. À Paris, les projets de métro étudiés par l'administration avaient tous inclus le souhait de tels raccordements, sans toujours l'imposer, face aux dépenses considérables qu'impliquait le réaménagement des voies et des bâtiments, dont chacun tentait de renvoyer le paiement au partenaire: subventions étatiques, subventions municipales, compagnies anciennes ou futures.

60 Un modèle d'urbanisation à la façon de la banlieue chic de Londres était dans toutes les têtes, à savoir la réussite de l'opération du Vésinet. En 1867, à la faveur du chemin de fer de Paris à Saint-Germain, la forêt du Vésinet a été divisée en 2000 lots de villégiature. Les promoteurs prévoient des équipements urbains et fixent une protection réglementaire de l'environnement, qui fera l'admiration de générations d'urbanistes. Dans l'immédiat, elle fait aussi l'admiration des spéculateurs fonciers. Pour attirer les premiers acheteurs, les promoteurs offrent des billets gratuits de chemin de fer, comme les grands promoteurs de l'Ouest londonien. Les publicités flattent le voisinage huppé de la villégiature. C'est le début de trois décennies de promotions en banlieue, où l'on construit la ville, non pas à la campagne, mais dans les bois. Une ruée du luxe vers l'Ouest, facilitée par le réseau de banlieue, frappe alors les imaginations. Le chemin de fer permet de porter plus loin ce que la calèche avait permis aux abords du bois de Boulogne. Déjà, sous le Second Empire, entre le village d'Auteuil et le Bois [de Boulogne], la ligne parisienne Saint-Lazare-Auteuil avait précipité une transformation en trois phases, phases qui se reproduisent un peu plus tard autour des autres lignes desservies par la Gare Saint-Lazare.

61 Après la colonisation par les villégiatures, puis la double résidence des familles - les femmes et les enfants à la campagne, l'homme en ville pour les affaires, sans compter les intrigues du soir qui font la joie du théâtre de boulevard -, venait la seconde phase du domicile unique, en zone résidentielle distinguée. Dans une troisième phase s'aggloméraient, en zones moins favorables mais meilleur marché, de nouveaux arrivants 
moins fortunés, mais dont le style de vie conduisait à une coupure entre le domicile et le travail. C'étaient essentiellement des fonctionnaires et des employés du privé. Dans le cas d'Auteuil, puis des autres gares de la proche banlieue (Asnières et Clichy, notamment), commencent à arriver des employés qui travaillent aux abords de la gare Saint-Lazare.

Dans la banlieue Est, un phénomène analogue se développe. Durant les mêmes décennies 1860-1880, s'amplifie ce qu'on pourrait baptiser le phénomène de Banlieue-sous-Bois (suivant les noms de Clichy-sous-Bois, Aulnay-sous-Bois, Rosny-sous-Bois, Pavillons-sousBois, etc.). Là aussi, la dynamique s'amorce avec les lotissements de villégiature et se trouve amplifiée par les services de trains de banlieue, lorsque les lignes n'ont pas de trafic national à desservir. La ligne de Vincennes devient la symétrique de la ligne de Paris à Saint-Germain, ainsi que la petite ligne de la Gare de l'Est qui décroche de la direction de Strasbourg à Bondy pour rejoindre la ligne de Vincennes en passant par Rosny-sous-Bois, Fontenay sous-Bois (figure 6).

Fig. 6 - Le phénomène de Banlieue-sous-bois, entre 1864 et 1883

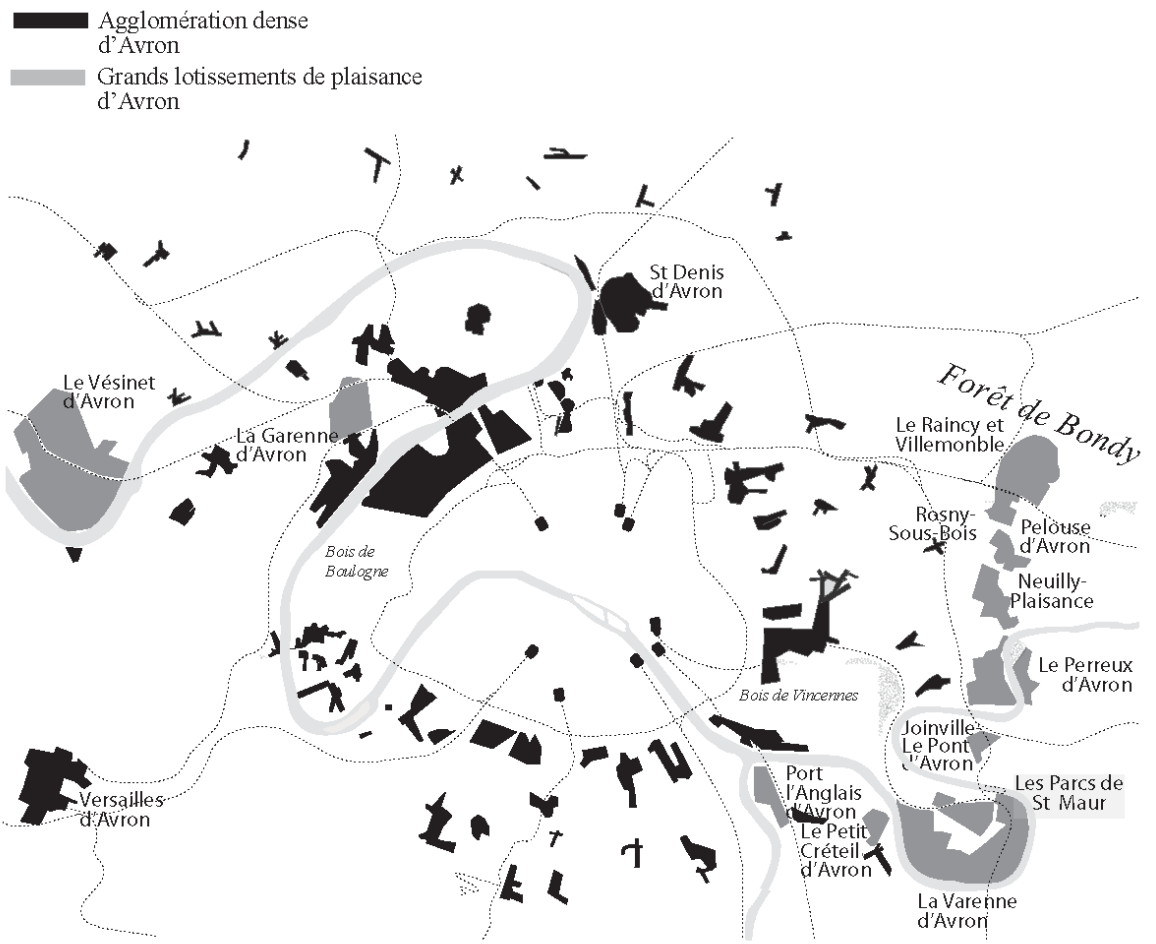

La carte schématise l'urbanisation de la banlieue telle qu'elle se présentait en 1883, d'après la révision des cartes d'état major éditée par le service des armées. J'ai schématisé en noir foncé les zones denses, et en gris, les lotissements les plus importants. Il faut oublier la suite de l'urbanisation pour comprendre la prospective que l'on pouvait faire en 1883 : il semblait alors qu'une demi-douzaine d'opérations visant à imiter celle du Vésinet étaient en passe de réussir, dans la Banlieue Est, à proximité de ses voies ferrées. La forêt de Bondy, en partie investie par les lotissements du Raincy et Villemonble, est encore très vaste. Les lotissements de la boucle de Saint-Maur, sur la ligne de Vincennes, sont un succès. A l'Ouest débute seulement le lotissement de La Garenne, limitrophe d'une urbanisation et d'une industrialisation semi-dense continue.

63 La prédominance de la villégiature, puis du double séjour saisonnier, puis de migrations quotidiennes d'employés, se traduit dans les chiffres des recensements des communes de banlieue. La figure 7 schématise des différences de profils des communes de la Seine, d'après les catégories des recensements propres à la région parisienne, en $1891^{16}$. Il est 
remarquable ici que les profils les plus "bourgeois", marqués par la prépondérance de rentiers, de professions libérales, de patrons et d'employés de commerce, caractérisent sept communes de l'Est, contre quatre de l'Ouest. Les records de ségrégation bourgeoise sont alors tenus par Saint-Mandé et Saint-Maur, devant Neuilly.

Le phénomène, massif à Londres, se retrouve ici à l'échelle de petits échantillons tendanciels. Outre-Manche, la ségrégation sociale est naturelle à l'échelle des voisinages, du fait des aménagements fonciers homogènes par grands lots de grandes propriétés. En banlieue parisienne, le phénomène est rare, il a lieu quand de grands lotissements sont tout neufs, il devient scandaleux si les intéressés s'emploient à le faire durer artificiellement. Un petit incident caractéristique de cet implant de normes londoniennes et de son rejet eut lieu à la Chambre des députés en 1895. Plusieurs députés socialistes mènent alors une attaque en règle contre le Syndicat des Ceintures et la Compagnie de l'Est, au moment où est réitérée une énième demande en concession de métro. L'un d'eux, M. Goussot, dénonce la politique volontaire de ségrégation sociale des hauts cadres de la Compagnie de l'Est, lotis confortablement dans la Forêt de Bondy, au Raincy, à Montfermeil, à Villemonble. Ils bénéficient des réductions de leur compagnie pour des trajets quotidiens où ne se retrouvent que des passagers distingués; les rares ouvriers habitant les villages de la zone réclament des arrêts de trains ouvriers (trains de $3^{\mathrm{e}}$ classe réservés aux ouvriers, suivant les cahiers des charges). La discrimination n'a pas besoin de contrôles aux entrées ou de cartes : il suffit de faire rouler des convois beaucoup plus matinaux que ceux destinés au reste des citoyens. Mais les ingénieurs-résidents répliquent, au titre de leurs fonctions, que ces stations ne sont guère fréquentées que par une clientèle bourgeoise ; et la Chambre de s'esclaffer au bon mot d'un député d'extrême gauche qui conclut que, décidément, la Compagnie de l'Est est une adepte de la lutte des classes ${ }^{17}$. 


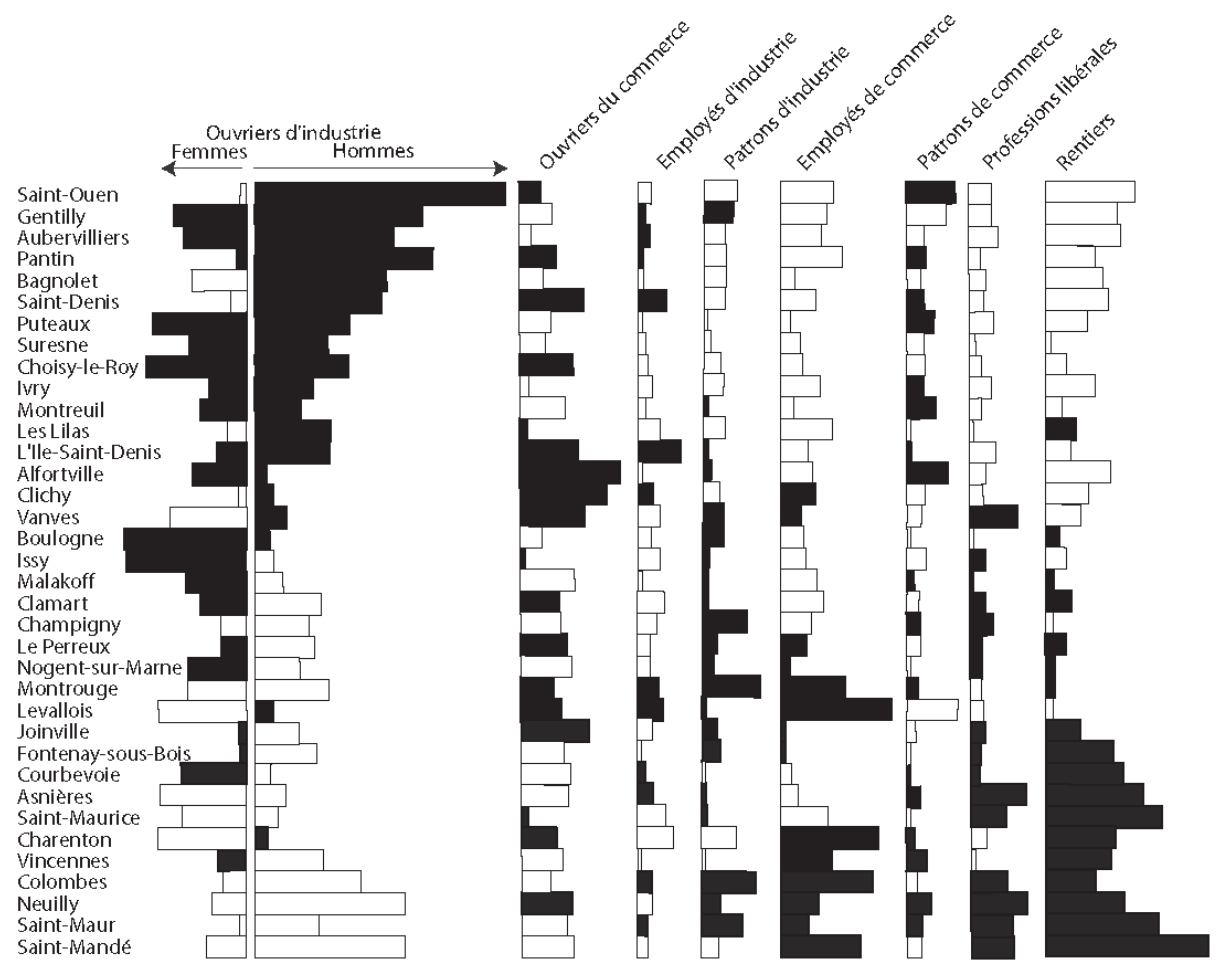

A l'époque des lotissements de plaisance, (1868-1900) la banlieue ne connaissait pas encore la dissymétrie entre l'Est ouvrier et l'Ouest bourgeois du Paris intra-muros. Au contraire se retrouve une certaine symétrie Est-Ouest, Saint-Mandé fait pendant à Neuilly, Saint-Maur à Colombes etc. Le graphique statistique ci-dessus fait ressortir les parentés de profils entre communes, selon les dominantes de classes sociales. En suivant la méthode de J. Bertin (1967, Sémiologie graphique, Paris, La Haye, Mouton), ont été mis en évidence des contrastes statistiques de la répartition sociale des résidents, par communes ; les contrastes ont donné lieu ensuite à rangement vertical des communes selon les ressemblances visuelles, en progressant, de haut en bas, et de gauche à droite, du plus ouvrier au plus bourgeois : les barres noires sont proportionnelles aux écarts positifs à la moyenne. Par exemple, la banlieue compte en moyenne $26 \%$ d'ouvriers d'industrie hommes, Saint-Ouen en compte le maximum, avec $53 \%$, la différence positive de $27 \%$ est symbolisée par une barre proportionnelle noire en haut à gauche du graphique. Neuilly et Saint-Mandé en comptent le moins, $12 \%$ l'écart négatif - $13 \%$ est symbolisé par une barre blanche, de moitié moins longue, en bas à gauche. Boulogne compte le record d'ouvrières d'industrie, (écart + $12 \%$ ).

Les communes ouvrières sont des communes de proximité habitat-emploi (ce qui explique, par exemple, la concentration d'ouvrières blanchisseuses à Boulogne). Les communes les plus bourgeoises deviennent au contraire "résidentielles », elles comportent une combinaison caractéristique de rentiers, professions libérales et employés de commerce. Ces employés de commerce, les moins polyactifs des Parisiens, fournissent le principal contingent du petit flux des migrations alternantes quotidiennes domicile-travail.

\section{Étendre la nébuleuse des fabriques collectives ou organiser l'éloignement domicile-travail ?}

L'intrication entre habitat et transports en commun était devenue évidente. Mais une confusion s'est maintenue sur la politique à suivre. Jusqu'à la fin des batailles du métro, les grandes compagnies conservent officiellement une vocation polyvalente à l'idée d'interconnexion : faire circuler sur les mêmes lignes métropolitaines les grands convois internationaux de voyageurs, les trains nationaux, les trains de banlieue et le service local. Le problème des incompatibilités éclatera durant les épisodes ultérieurs, - nous y 
reviendrons plus loin. Une autre confusion, beaucoup plus difficile à lever, concerne la nature même des voyages métropolitains à faciliter en priorité: l'éloignement du domicile et du travail est-il une fatalité de l'évolution urbaine ? C'est à ce déterminisme évolutionniste que s'attaquent les études prospectives de la majorité municipale. Le rapport Deligny-Cernesson de 1883 martèle le point de départ de la prospective, en début de plusieurs phrases :

«Au contraire de ce qui se passe à Londres, les travailleurs parisiens demeurant très généralement à proximité de leurs bureaux, de leurs magasins, de leurs ateliers, et souvent sous le même toit que le comptoir ou l'établi... »

Les migrations alternantes ne touchent encore qu'une très petite minorité. Ce fait est une évidence pour les élus parisiens, au contact avec leurs électeurs, que ces élus soient de gauche ou de droite, qu'ils soient plus proches des salariés, des commerçants ou des affairistes. Mais ce fait est de moins en moins visible à l'échelle des statistiques officielles, des manières de poser la question des transports et de l'attention du public dans la presse. Là-dessus, se greffe une autre cause de confusion: un certain nombre d'intérêts économiques et fonciers, en plus des exploitations ferroviaires de banlieue, ont tout avantage à avaliser l'idée que les migrations alternantes sont une fatalité de l'avenir, qu'il faut accompagner cette progression de la division spatiale des fonctions, car c'est «le» progrès. Anticipant cette tendance, plusieurs promoteurs de métro se sont livrés euxmêmes à une spéculation foncière en banlieue, rêvant de réitérer le coup du Vésinet. Buisson des Leszes, l'un des plus acharnés, a acheté, avec des entrepreneurs de travaux publics, des terrains aux deux extrémités de la radiale Est-Ouest - région de Puteaux et plateau d'Avron. Ils s'en vantent, car ils doivent donner confiance aux éventuels actionnaires pour rassembler les capitaux en cas de concession ${ }^{18}$.

Le projet alternatif pourrait se résumer ainsi : une décentralisation des attractivités, un maillage favorables aux polarisations nouvelles entre activités complémentaires et arrangements d'habitat, sans contraindre à la séparation des lieux de domicile et de travail. C'est là la perspective qu'avait déjà conçue Vauthier, en 1865, pour réparer les dégâts causés à la vie populaire parisienne par la rénovation urbaine. À l'appui de son nouveau projet de métro, en 1872, l'ancien fouriériste, démocrate de la première heure, avait formulé comment les attractions réciproques pouvaient donner des formes nouvelles, à la condition qu'une politique urbaine et une conception adéquate des transports favorise leurs polarités, au lieu de les chasser pour faire place aux commodités des classes aisées.

«Paris n'est pas une ville mais plusieurs villes groupées dans la même enceinte. Sur divers points se sont créés et développé des centres de vitalité, correspondant à des besoins, à des influences, à des circonstances naturelles ou factices différentes : ici la Seine et sa batellerie; ailleurs les canaux amenant les marchandises du Nord, de l'Est et du Centre; plus récemment enfin, les têtes de ligne des chemins de fer rayonnant dans toutes les directions, apportant les produits de toutes les provenances. C'est ainsi que se sont formés, avec des destinations spéciales et diversifiées, ces populeux et industrieux quartiers que l'on nomme la Villette, Belleville, Bercy, Grenelle. Ces centres secondaires ont besoin d'avoir entre eux les relations les plus actives; ils sont tous à cheval sur la zone des anciens boulevards extérieurs ou y confinent. Leurs rapports s'établissent aujourd'hui par d'autres directions. Que la vapeur annule la distance, et d'immenses courants vont s'établir instantanément de l'un à l'autre.

Pendant vingt ans, [...] l'Empire a travaillé à refouler les familles ouvrières du centre vers la circonférence. L'annexion de la zone suburbaine a été un des moyens de cette action [...] . La voie projetée [de métro sur les boulevards extérieurs], en 
rapprochant en même temps du centre et les uns des autres des quartiers où l'industrie se procure plus facilement l'espace nécessaire à ses installations, où se pressent les ménages d'ouvriers, où les fortunes modestes enfin trouvent à plus bas prix des loyers, va donner à la ville un cachet spécial et une physionomie nouvelle. Ce ne sera plus la population se distribuant sans ordre, et par couches uniformes, sur de vastes espaces, ou se concentrant autour d'un point unique. Sur la ligne des boulevards, - qu'on nous permette, en faveur de sa justesse, cette image un peu hasardée, - comme dans une nébuleuse qui se condense, la puissante attraction de la vapeur va former comme une zone de centres secondaires, vivant d'une vie propre, et groupés autour du foyer principal qui n'en conservera pas moins sa prédominance $^{19}$. »

L'appui à ce processus, manqué en 1872, a effectivement été mis en œuvre par le métro municipal de 1900. Pour comprendre cet autre univers des attractions et des centres secondaires, il ne faut se représenter ni la villégiature du Vésinet, ni les grandes usines à gaz en train de s'étaler à Saint-Denis. Le Paris populaire massif, où s'activent bientôt plus d'un million d'ouvrières et d'ouvriers, est un entrelacs de ce que les enquêtes des Ouvriers des deux Mondes $^{20}$ appelaient des fabriques collectives. Ce sont des réseaux de fabrications, souvent des grandes industries exportatrices, disséminés en un tissu serré de coopération fait d'ateliers et de travaux à domicile, dans les quartiers périphériques parisiens. La meilleure approximation, pour se représenter aujourd'hui ces fabriques urbaines, est d'imaginer la vie du quartier de la confection qui subsistait jusque récemment dans Paris d'aujourd'hui, dit le Sentier, et de la reporter cent ans en arrière. À ceci près que, durant les années 1870 à 1914 , ce n'est pas un seul réseau d'ateliers et de commerces qui est impliqué, c'est au minimum deux centaines de "fabriques collectives» de ce genre, intriquées pour composer elles-mêmes des réseaux à plusieurs échelles, comportant pour les plus petites "fabriques", quelques dizaines d'ateliers, et pour les plus grandes, plusieurs milliers d'ateliers, reliés à des boutiques, des négoces, des grossistes, des halles, et des entrepôts. Par exemple, l'ébénisterie comprend, à la fin du siècle, une vingtaine de milliers d'ouvriers, redistribués en centres secondaires dans l'Est parisien, connectés à des grossistes, à des grands magasins et à des exportateurs pour le monde entier.

Les enquêtes de Pierre Du Maroussem sur l'ébénisterie et l'industrie du jouet ont exploré en détail ces nébuleuses condensées prévues par Vauthier, effectivement étendues et redistribuées durant les années 1880 à 1914. En général, les ateliers et les domiciles de chaque ouvrière, de chaque ouvrier, ou bien coïncident, ou bien se trouvent dans un proche voisinage, même immeuble, même îlot. Le plus grand nombre des trajets domiciletravail, ce sont des changements de pièce dans le même appartement : passage de la pièce à vivre de la famille à la pièce à travailler, pour un ou plusieurs métiers. Le second type de trajet, en procédant par élargissements progressifs, est le déplacement au sein du même immeuble. Dans le $11^{\mathrm{e}}$ arrondissement, beaucoup d'immeubles de rapport ont été conçus architecturalement pour fournir un cadre à ces fabriques. Les rez-de-chaussée optimisent les surfaces pour ateliers travaillant sur les matériaux les plus lourds, disposés en longues courées, parfois même avec distribution d'une force motrice pour dix à vingt unités de travail, reliées par des courroies débrayables un un arbre principal. Sous les toits se trouvent les ateliers qui demandent le plus de lumière : peintures, enluminures, ciselures, incrustations, décorations de toutes sortes. Entre les deux, habitations et ateliers complémentaires se côtoient. Un meuble, raconte Du Maroussem, peut passer par une douzaine de fabrications différentes, en naviguant dans les étages sans changer de maison. Le cercle des déplacements s'élargit avec les liaisons de travail à périodicités moins rapprochées, dans la journée ou dans la semaine : livraisons, approvisionnements, 
et surtout, occasions multiples de marchander, de prospecter, de conclure un paiement, de recomposer un projet, de recombiner une fabrication ${ }^{21}$.

Entre 1872 et 1914, le caractère ouvrier de Paris et de son agglomération s'est accentué : la population recensée " ouvrière " y est majoritaire. De plus, la proportion statistique du « travail à domicile » s'est encore accrue, due notamment à la confection, à l'industrie de la chaussure, aux industries de luxe et autres "articles de Paris ». Le succès du métro à tutoyer ne prend tout son sens que dans ce contexte des fabriques collectives. Paris est en quelque sorte la cour intérieure d'un immense atelier, et le métro urbain aura pour principal usage les déplacements d'activités internes. Ce tutoiement urbain concerne tout autant les ouvrières parisiennes que les ouvriers : leur activité de travail, à domicile ou en atelier, est massive et majoritaire dans la population féminine, y compris aux âges de maternité, à la différence de leurs homologues des autres métropoles européennes.

71 Pour bien se figurer les attractions d'activités auxquelles s'intéressaient Deligny et Vauthier il est aussi nécessaire de prendre en compte une réalité que les recensements se sont mis dans l'impossibilité de saisir directement, et que seules les enquêtes de la SIEPES ont mise en évidence systématiquement : les ouvrières et les ouvriers sont alors pour la plupart des polyvalents, des "polyactifs » aux activités et aux métiers multiples (souvent en partie à leur compte et en partie "à compte d'autrui»). L'assortiment des tâches et leur combinatoire fait jouer des complémentarités d'espace et de temps au fil de la journée, de la semaine, de la saison, des phases de la vie. Cette «polyactivité » est incompatible avec l'éloignement du lieu de travail et du domicile, car son économie repose pour une large part sur la possibilité d'assortir les choses dans un espace familier, entre proches, en famille, entre collègues de métier, en montages de collectifs ad hoc, pour un projet. Ces assortiments sont constamment recomposés. Les recensements sont restés stupidement aveugles sur ces réalités, en ne retenant qu'une seule d'activité par individu. Or, la prise en compte de ces modes de vie change complètement la signification des déplacements et de l'usage des transports en commun. La majorité des déplacements susceptibles d'emprunter un transport, si celui-ci est suffisamment bon marché, concerne la vie intérieure des fabriques collectives: un approvisionnement, une livraison, une transmission de fabrication en cours, une concertation de projet, une réception de produit, une commission, une négociation de commandes, un rassemblement d'inventions, un marché sur échantillons, etc.

Une autre transformation du Paris de l'époque illustre, elle aussi, la condensation de nébuleuses » qu'a évoquée Vauthier. Le projet de métro Brame et Flachat, en 1853, avait prévu la difficulté spatiale qui se poserait aux marchés d'embauche du bâtiment: les rendez-vous de la place de Grève, ${ }^{22}$ chaque matin avant le travail, étaient fréquentés par des ouvriers qui habitaient dans le voisinage immédiat et pouvaient rayonner à pied à partir de ce centre. Brame et Flachat proposent de les loger le long de la future petite ceinture, et de les amener chaque matin aux Halles pour un coût loyer-transports pas plus élevé que leurs loyers du centre. Faute de transports adéquats, la solution qui prévalut, entre 1880 et 1900, fut la création de "grèves» (places d'embauche) satellites, trois, quatre ou cinq par métiers, près des boulevards extérieurs, desservis par la marche à pied ou les tramways ${ }^{23}$.

73 Pour mettre un tracé de métro au service de cette décentralisation des proximités en nébuleuses de fabrique, il importait de rompre avec les tendances à la hiérarchisation foncière du centre à la périphérie. C'était une raison supplémentaire de concevoir, non des lignes, mais un réseau en maillage qui contrarie aussi densément que possible les 
différenciations foncières, pour permettre aux attractions entre fabriques de se recomposer suivant leurs logiques propres, sans que les pouvoirs d'achats ne commandent seul-s les distances. En second lieu, la hiérarchisation des fonctions des lignes métropolitaines rétrogradait l'interconnexion des voies ferrées. Au vu des tendances à l'œuvre, en 1883, il est beaucoup plus important de desservir les arrondissements périphériques que de sauter quatre kilomètres derrière les murs d'enceinte. Les nébuleuses de familles polyactives et polyvalentes se doivent de choisir comme emplacement les enchevêtrements les plus voisins de leurs assortiments de ressources et de spécialités de travail.

Cette philosophie donne lieu à un tracé de réseau de première urgence, voté en séance du 4 juin 1883 (figure 8). Plus tard, le projet sera repris et servira de base à l'étude du tracé définitif dit, lui aussi, de première urgence, voté en 1896 (voir, en comparaison, plus loin, la figure 14). Suivant les principes d'autonomie, il comporte un cercle intérieur, auquel s'ajoutent des radiales, ainsi que des sorties de Paris destinées à desservir plus tard la banlieue. De plus, deux sorties à l'ouest contournent le Bois de Boulogne pour rejoindre la ligne des Moulineaux, concédée aux Chemins de fer de l'Ouest, en cours de construction, ce qui doit permettre de déployer des ateliers et dépôts près de la Seine, sur des terrains encore libres. D'autres radiales pour la desserte de la périphérie et de la banlieue ont été envisagées, mais, par économie, renvoyées à une étape ultérieure.

Fig. 8 - Projet de métropolitain adopté par le Conseil municipal, le 4 juin 1883

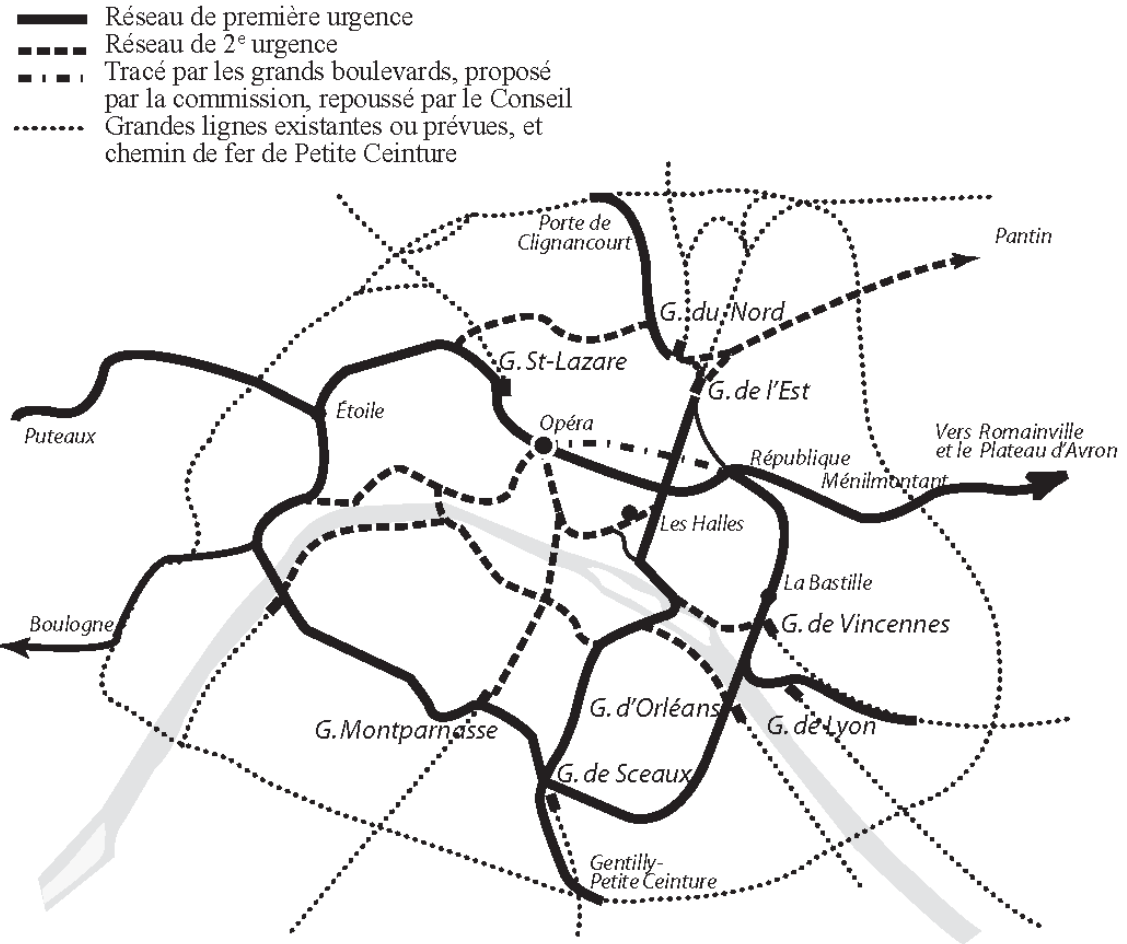

Le tracé voté en 1883 est le premier qui relève d'une nouvelle philosophie municipale, liée à un choix de mode de vie. L'objectif est de favoriser une extension et une décentralisation des proximités domicile-travail, et non de poursuivre l'urbanisation tendancielle de ségrégation sociale et de séparation ou éloignement domicile/travail. Le réseau doit offrir le support d'un maillage de plus en plus fin. Les échappées du parcours en banlieue doivent assurer une indépendance d'exploitation, à l'égard des compagnies, de leurs trains prioritaires et de leur entretien onéreux. Elles pourraient aussi s'articuler au projet Paris Port de mer, sur la presqu'lle de Gennevilliers. 
Le projet de métro subit les contrecoups de la politique ferroviaire nationale. Durant les deux années précédentes, lors du ministère Gambetta, un climat favorable aux entreprises ferroviaires secondaires s'était instauré, pour faire pression sur les grandes compagnies, en menaçant de les racheter ou de leur faire concurrence. Les théories de Vauthier, plus ou moins bien comprises, sont galvaudées à l'échelle nationale et donnent lieu à un projet de loi de rachat pour redistribution en réseaux régionaux. Les mêmes banquiers promoteurs de chemins de fer, Donon et Delahante, encouragés par des gambettistes à relancer un Paris-Marseille, s'intéressent à un réseau régional de métro. Mais, de leur part, le but véritable est vraisemblablement un dessein grandiose analogue à celui que promeut, au même moment, Watkins, le président du Metropolitan Railway: établir une traversée directe de Londres et la relier au futur tunnel sous la Manche, concédé en 1875. Avec l'aide du Calais-Marseille et des deux compagnies de métropolitain, il serait possible de lancer un Édimbourg-Naples, traversant Londres et Paris avec ses propres voies, en attendant l'Orient Express ${ }^{24}$. La Compagnie du Nord, qui suivait de près ces manœuvres et avait sa place dans les tours de table, s'employa à faire échouer ces projets. Le projet de concession du métro fut au nombre des victimes. Comme les précédents projets municipaux, le tracé de 1883 avait le vice rédhibitoire de franchir la petite ceinture et de prendre son indépendance en banlieue ou de s'offrir à d'éventuelles nouvelles grandes compagnies concurrentes. Il pouvait aussi servir de ressource à un autre projet dit Paris Port de mer, projet qui constituait une menace redoutable pour le trafic ferroviaire des marchandises du Nord et de l'Ouest. Une autre cause indirecte de l'échec, concernant plus spécialement ce projet de 1883, fut la signature de nouvelles conventions entre l'État et les grandes compagnies.

\section{Entre les affaires et la démocratie locale : une difficile sortie de crise}

Les années qui suivent connaissent une suite complexe d'épisodes affairistes et de conflits. Pour mettre en perspective leurs modalités et leur évolution, sans détailler le feuilleton entier, le présent article se limitera à retracer quelques moments particulièrement significatifs. Le premier a trait à un échec retentissant d'un projet gouvernemental de métro, en juillet 1887, à l'époque où s'agitaient les promoteurs du canal de Panama. L'examen parallèle des secrets d'affaires privées et de la confusion du débat public permet d'apporter des éclairages, en suivant pas à pas le fonctionnement de l'information des uns et des autres. Les faits de corruption sont bien connus, mais il est instructif d'aller plus loin et de chercher à retrouver quels sont les ressorts de la vie publique locale qui ont permis de ne pas y succomber, malgré tout.

\section{L'élaboration d'un projet en petit comité et la confusion du débat public (1886-1887)}

77 En février 1886, au lendemain de la constitution d'un nouveau cabinet, le ministre des Travaux publics, M. Baïhaut, déclare qu'il met d'urgence à l'étude un projet de métropolitain destiné à desservir la ville de Paris et à raccorder les lignes de chemin de fer existantes. Des négociations confidentielles s'engagent alors, dans l'espoir d'apporter un projet tout prêt et de le faire passer en force : tirant profit de l'urgence, à l'approche 
de l'Exposition universelle de 1889, on éviterait de s'enliser dans les tergiversations du Parlement et du Conseil municipal. Le ministre esquisse d'abord un montage de principe avec Alphonse de Rothschild, président de la Compagnie des Chemins de fer du Nord. Afin d'éviter les échecs de montages précédents (imputés au manque de sérieux et d'honnêteté de coalitions d'entrepreneurs et de financiers de seconde zone), les grandes compagnies apporteraient leur concours technique et financier. Elles construiraient les raccordements de leurs gares au métropolitain, garantiraient un trafic d'apport à la future compagnie, en contrepartie du passage des trains de grandes lignes et de banlieue. Les compagnies procéderaient elles-mêmes aux emprunts, sans passer par un syndicat de banquiers ${ }^{25}$.

Cependant, au bout de quelques jours, le Nord fait marche arrière, par prudence, face aux risques de l'opération. Les ingénieurs du Nord, de concert avec Léon Say, s'emploient à mieux faire valoir les intérêts propres de la Compagnie contre une tendance aux compromis politiques de leur président, Alphonse de Rothschild, qu'ils jugent trop complaisant envers les gouvernements. Ils y parviennent. Le ministre doit alors procéder à un autre montage financier, destiné lui aussi, en principe, à rassurer. La concession serait passée de gré à gré avec le gouverneur du Crédit Foncier, Albert Christophle, à titre personnel, les statuts du Crédit Foncier interdisant d'engager l'institution dans ces opérations. Dans leurs correspondances, les ingénieurs se montrent critiques sur la partie financière de l'opération, pleins de soupçons et de sous-entendus. Mais les négociations sont menées en petits comités de financiers, pour préserver le secret, sans leur avis.

En revanche, une fois arrêtés les montages financiers, la conception technique et les schémas de fonctionnement, dits d'exploitation, dans le langage ferroviaire, est confiée aux ingénieurs Elle est attribuée officiellement aux ingénieurs du Ministère des travaux publics, mais son élaboration entière appartient de fait aux ingénieurs des compagnies, où domine le Nord. En l'occurrence, Alphonse de Rothschild et Léon Say ont obtenu du ministre que les études soient menées, non à la Direction des chemins de fer du ministère, mais dans les bureaux d'étude du service d'exploitation de la Compagnie du Nord, en concertation avec les autres compagnies. Pour assurer le sérieux technique, mais aussi pour maîtriser la frontière stricte entre le secret des études et la propagande publicitaire, mieux valait la discrétion du Nord que la Direction des chemins de fer, trop bien fréquentée par les camarades des Ponts et Chaussées œuvrant pour toutes les parties en présence, partenaires, concurrents et adversaires. L'ingénieur Sartiaux, alors directeur adjoint du Service de l'exploitation, futur numéro un de la gestion de la Compagnie du Nord, mène l'affaire, investi de la confiance d'Alphonse de Rothschild et de Léon Say. Ses abondants courriers conservés jusqu'à aujourd'hui permettent de suivre le travail d'élaboration et de négociation au jour le jour, donnant une vision saisissante du pouvoir de chacun.

En cinq semaines, le projet technique initial est complètement bouleversé. Baïhaut et Christophle s'étaient mis d'accord pour prendre comme base technique le grandiose projet de l'ingénieur des Ponts et Chaussées Paul Haag, en promotion publicitaire depuis 1883. L'ingénieur proposait une liaison directe des grandes gares du nord-ouest de Paris (Saint-Lazare, Nord et Est), aux grandes gares du Sud-Est (Gares de Lyon et d'Austerlitz), par une nouvelle percée diagonale à travers le centre trop encombré. Il combinerait l'ouverture d'une large " percée » de surface, à la manière haussmannienne, et un viaduc ferroviaire, à quatre voies sur l'artère centrale, à deux voies sur les affluents complémentaires. Les brochures de propagande vantaient l'assainissement des quartiers 
insalubres ; elles exaltaient l'œuvre nationale du percement d'un isthme ferroviaire entre le Nord et le Sud de l'Europe, à travers ce qui restait du vieux Paris (voir figure 9 et 10).

Sartiaux et ses homologues des compagnies ne répondirent pas à la séduction que voulait exercer leur camarade Haag, lui aussi ingénieur des Ponts de Chaussées, en leur offrant un boulevard d'interconnexion. Le coût, déjà colossal dans les estimations de Haag, l'était encore davantage avec les calculs de Sartiaux, discrètement élaborés et communiqués en parallèle. Haag comptait sur des reventes de terrain, suivant le procédé haussmannien, et sur des revenus élevés de boutiques louées sous les arcades des viaducs, mais tous ses calculs de recettes sont revus à la baisse par les bureaux d'étude de la Compagnie du Nord.

Fig. 9a - Projet Haag, 1886

Figure $9 a$

Projet Haag, 1886

Le projet Haag fut le plus soutenu et le plus combattu des projets dits " aériens ». Il proposait de défoncer le centre de Paris, raser une partie du Marais pour finir l'œuvre d'assainissement d'Haussmann. Une jonction des gares du Nord-Ouest de Paris (Gares Saint-Lazare, du Nord et de l'Est) avec les gares du Sud-Est (Gares de Lyon et d'Orléans) se ferait par une large percée aérienne à 4 voies, nouvel isthme ferroviaire entre l'Europe du Nord et l'Europe du Sud, analogue à la grande aventure du Canal de Panama.

Ci-contre: le plan de défoncement du Marais en diagonale, des Halles au Quai des Célestins. Au nord, démolition du quartier Montorgueil, avec ouverture d'une gare aérienne dite "Les

Postes" en vis à vis de l'église St-Eustache. Voir dessin figure $9 b$.

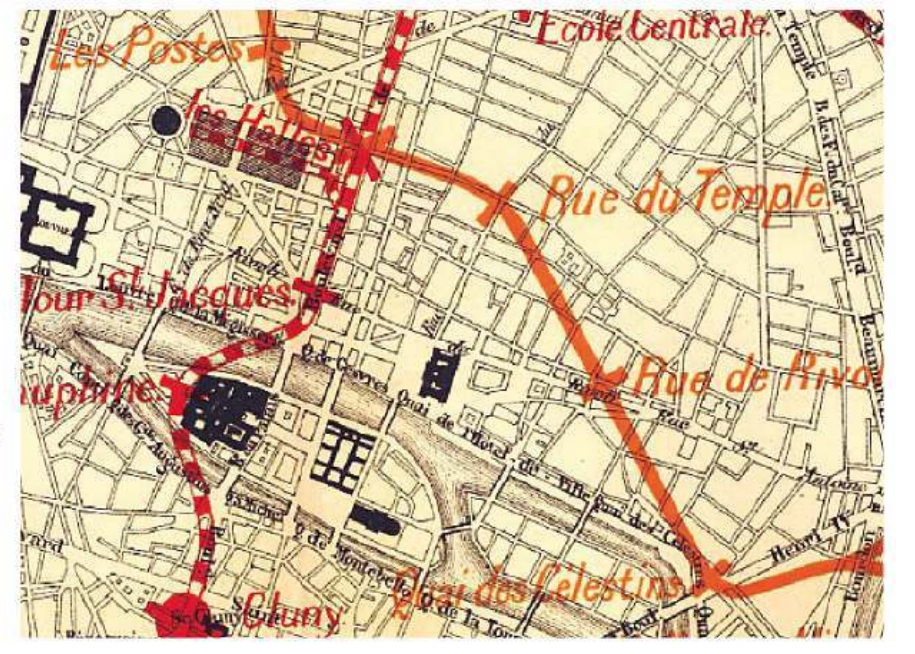

Le projet Haag fut le plus crédible, le plus soutenu et le plus combattu des projets dits " aériens ». II proposait de défoncer le centre de Paris, raser une partie du Marais pour finir l'œuvre

d'assainissement de Haussmann. Une jonction des gares du Nord-Ouest de Paris (Gares Saint-Lazare, du Nord et de l'Est) avec les gares du Sud-Est (Gares de Lyon et d'Orléans) se ferait par une large percée, nouvel isthme ferroviaire entre l'Europe du Nord et l'Europe du Sud, analogue à la grande aventure du Canal de Panama. 
Fig. 9b - Projet Haag, 1886

Figure $9 b$

Gravure distribuée à la presse dessinant la gare surélevée "Les Postes", au chevet de l'Eglise St-Eustache, sur la jonction aérienne Nord-Ouest $\Leftrightarrow \Rightarrow$ Sud-Est.Vue en direction du Sud-Sud-Ouest, Halles en arrière-plan. L'un des bâtiments de la gare est dessiné en réplique à la chapelle de style renaissance qui prolonge l'abside de l'église.

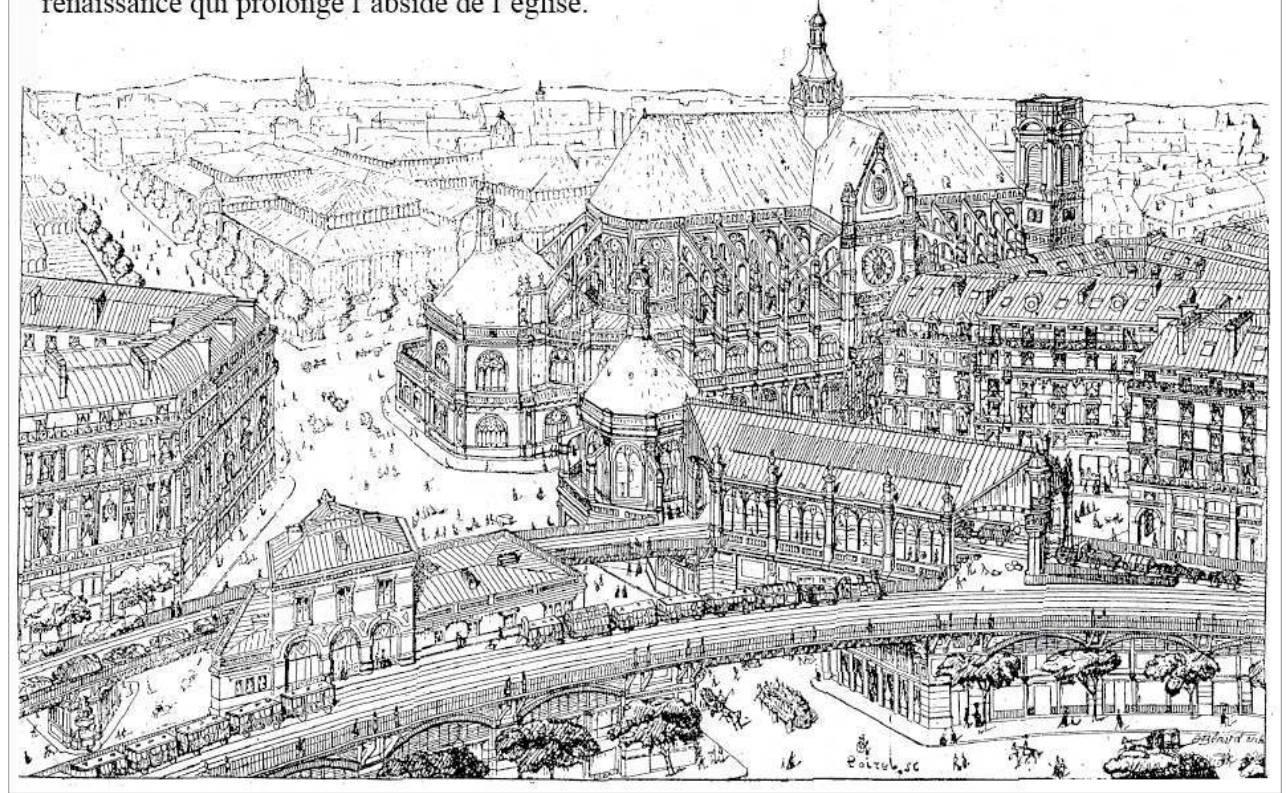

L'ingénieur feint ainsi habilement d'adopter le projet pour mieux l'amender L'ingénieur feint ainsi habilement d'adopter le projet pour mieux l'amender et le vider de son contenu. Il procède d'abord à des calculs détaillés de rentabilité et de coûts, avec des simulations chiffrées de fonctionnement. À titre d'exemple, est reproduite ci-joint une carte coloriée du premier tracé de Haag où Sartiaux a fait ajouter en surcharge verte des surfaces proportionnelles aux recettes brutes de billets escomptés, par simple extrapolation des revenus de lignes d'omnibus et de tramways voisines du trajet (Figure 10 ) . 
Fig. 10 - Plan envoyé au président de la Compagnie du Nord, Alphonse de Rothschild, en 1886

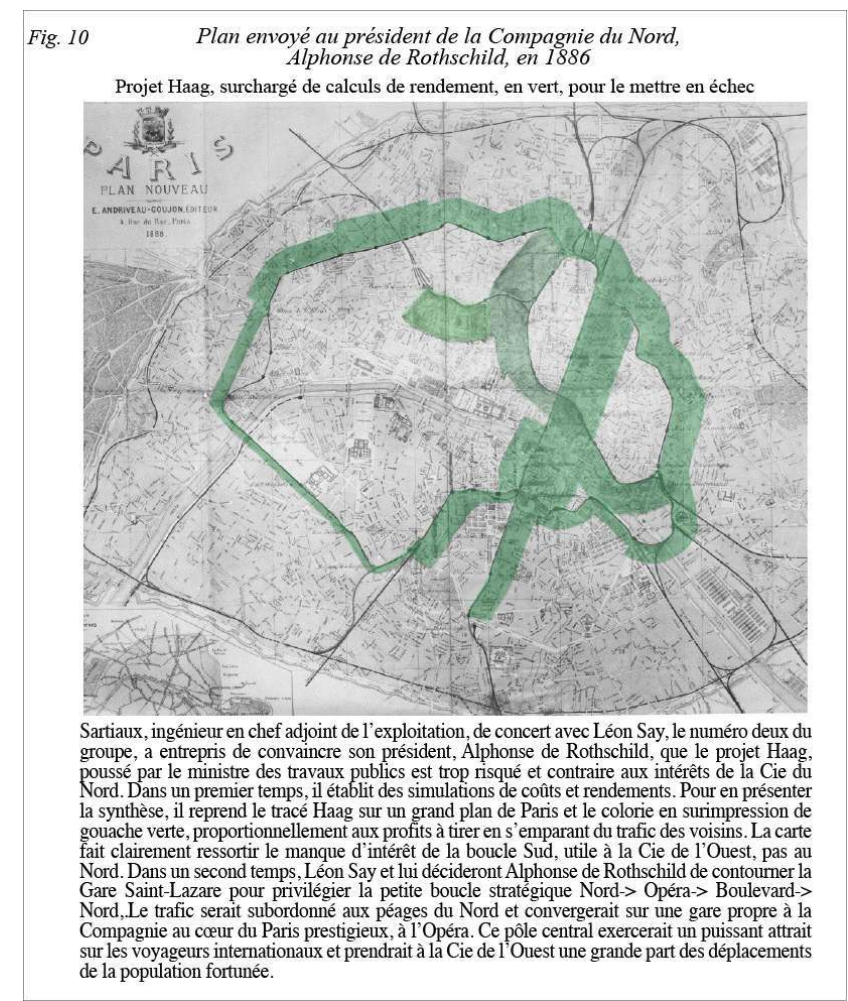

Sartiaux, l'ingénieur en chef adjoint de l'exploitation, de concert avec Léon Say, le numéro deux du groupe, a entrepris de convaincre son président, Alphonse de Rothschild, que les propositions du ministre des travaux publics, pour faire construire le projet de métro Haag, étaient trop risquées et contraires aux impératifs de rentabilité de la Compagnie du Nord. Dans un premier temps, Sartiaux établit une série de calculs de rentabilité et de coûts du projet. Pour commenter le résultat sur un grand plan de Paris, il a colorié en surimpression de gouache verte (ici en gris foncé) les lignes du projet Haag, proportionnellement aux recettes qu'on peut attendre en s'emparant du trafic des lignes proches, exploitées par la Compagnie Générale des Omnibus. La carte fait clairement ressortir le manque d'intérêt de la boucle Sud, qui n'intéresse que les Chemins de fer de l'Ouest. Dans un second temps, Sartiaux et Léon Say convaincront Alphonse de Rothschild de détacher de la Gare Saint-Lazare la petite boucle stratégique du Nord-Ouest pour établir une gare propre de la Compagnie au cœur du Paris prestigieux, à l'Opéra. La boucle serait ainsi moins dépendante de l'Ouest et aiderait à capter davantage de trafics, internationaux (trafic anglais) ou locaux, au profit du seul Nord.

La carte fait ainsi ressortir les trajets les plus rentables financièrement, sur l'axe NordSud, entre Gare du Nord et boulevard Saint-Germain, et sur le petit segment Est-Ouest, entre le Nord et Saint-Lazare. Sartiaux fait porter le document, entre autres, au château de son président, par les bons soins de Léon Say, l'ancien ministre, sénateur et administrateur de la Compagnie du Nord, et à Lax, son camarade directeur des chemins de fer au ministère des Travaux publics. Après avoir démontré et fait admettre, par un volumineux dossier de simulations techniques et financières, que jamais le projet Haag ne permettrait au demandeur en concession Christophle de rentrer dans ses frais, il avance d'autres solutions techniques favorables aux compagnies, et tout spécialement favorables au Nord.

Afin de ne pas heurter de front le ministre, Sartiaux et Lax s'entendent pour ne pas rejeter les percées Haag, mais pour les classer en réseau éventuel, à réaliser après l'Exposition. Sartiaux retient en revanche du projet Haag le principe d'une jonction Gare du Nord-Gare Saint-Lazare, qu'il modifiera encore par la suite en gardant le segment de circuit, mais en contournant la gare Saint-Lazare. Au cours des négociations, il insiste 
pour que soient conservées simultanément, en première urgence, à la fois ce segment, et une autre liaison urbaine plus au Nord, par les boulevards extérieurs. Contre des objections de Lax, il fait valoir que ce ne sont pas seulement des lignes de jonction, faisant double emploi, mais des segments dont la combinaison se prête à des boucles, permettant des combinaisons multiples de trajets. Parmi ces liaisons ressort une boucle centrale, la plus avantageuse dans la future exploitation, alimentée par péages proportionnels aux quantités de passages. Des notes internes sont plus précises : elles démontrent, sur des simulations de circulation, que ces variantes sont décisives pour favoriser les itinéraires du Nord, au détriment des voisins de l'Ouest et de l'Est (figure 11). Une autre carte de rentabilité, dressée à la même époque sur le parcours rectifié conformément aux demandes de Sartiaux, montre que le service urbain le plus productif ne serait plus l'axe Nord-Sud, mais le petit cercle autour du centre des affaires, formé par le parcours Gare du Nord--Gare de l'Opéra, et retour à la Gare du Nord par les boulevards extérieurs.

Flg. 11a - Le travail d'Albert Sartiaux en révision du projet ministériel : «ll faut que la ligne NordOuest soit la pénétration des grands trains à la Gare centrale [de l'Opéra]

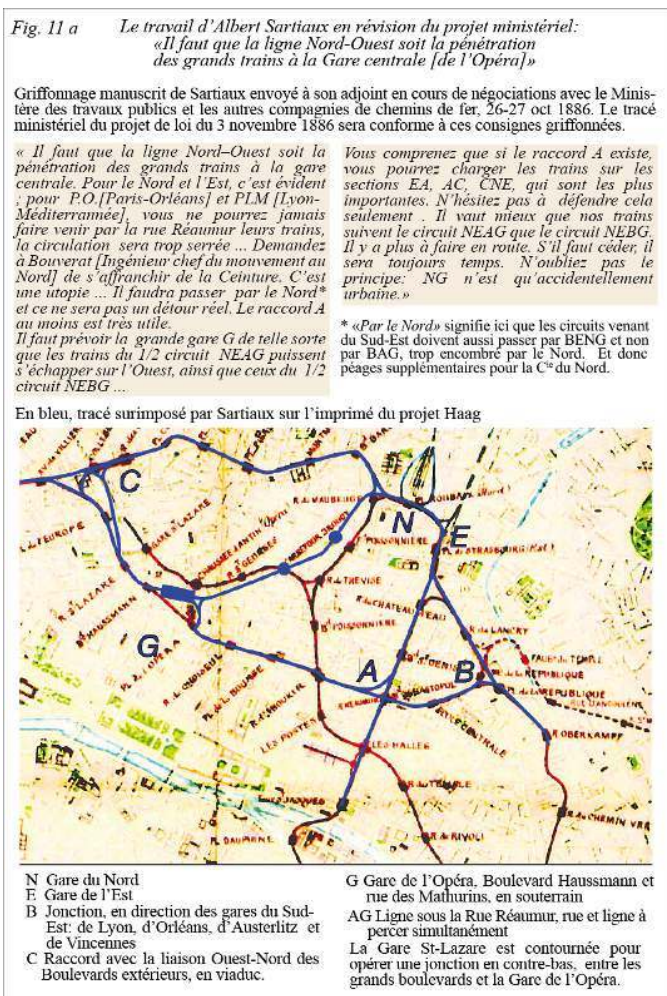


Fig. $11 \mathrm{~b}$ - Projet de la gare centrale de l'Opéra par Sartiaux, octobre 1886 - juillet 1887. Plan, profil et simulation

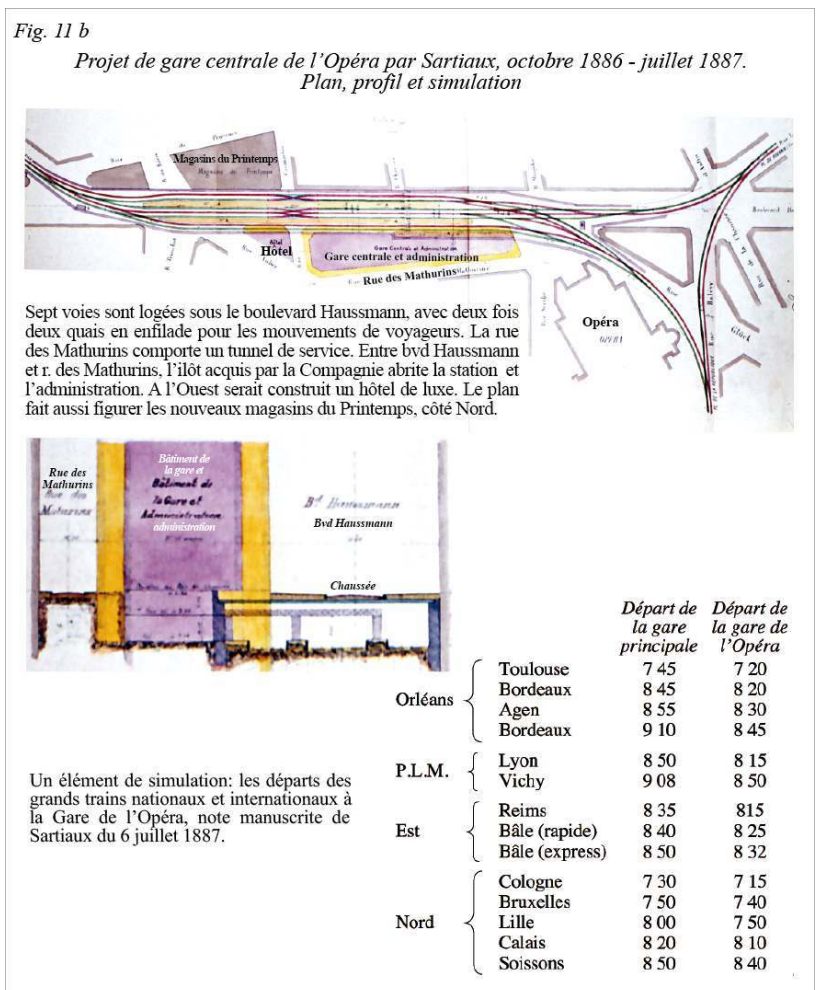

Dans cette logique, le mot rentabilité demeure toutefois étroitement lié aux artifices comptables des conventions de concession aux compagnies. C'est d'un produit comptable net qu'il s'agit, fondé sur le remplissage des seuls convois les plus avantageux, au regard des comptes administratifs. Les simulations de trafic par Sartiaux, soigneusement tenues secrètes, font monter les rendements nets en sacrifiant le service local et le service de banlieue. Ils privilégie l'arrivée des trains prestigieux à l'Opéra. Son optimum demeure une exploitation de pénurie avec capture des passagers les plus fortunés. Ce statu quo comptable est d'ailleurs l'application locale d'un système général mis en place avec les conventions de chemins de fer de 1883. On peut en trouver trace des effets dans les publications officielles du ministère des Travaux publics. Il suffit de rapprocher les diagrammes, dessinés en médaillons, des recettes brutes et des recettes nettes des réseaux de banlieue, figurés par kilomètre, pour visualiser le décrochage entre rentabilité financière et quantité du service rendu (figure 12).

\section{Le secret d'un choix de tracé, bien gardé, jusqu'à ce que...}

Pour le choix du tracé, Sartiaux avance ainsi un intérêt propre à la Compagnie du Nord derrière le souci de la future compagnie du métro. Il veille à en maintenir le secret, mais l'évoque dans ses lettres et télégrammes directs avec les ingénieurs de sa compagnie. Les objectifs sont doubles: donner de l'attrait à ses lignes de banlieue, et assurer les possibilités de pénétration des trains des grandes lignes dans le centre d'affaires, ce qui se traduit par des contraintes coûteuses de gabarit, de profil des courbes et des pentes, et fait préférer le viaduc au souterrain quand ce n'est pas impossible. Aussi se réjouit-il d'obtenir un tracé bien plus favorable au Nord qu'à ses voisins concurrents, l'Ouest et 
l'Est. La gare centrale de l'Opéra donnerait enfin au Nord un terminus dans le centre de Paris, plus prestigieux que la gare Saint-Lazare, la grande concurrente pour le trafic distingué de la banlieue chic et des anglophones, exploitée par l'Ouest. Le projet de gare centrale de l'Opéra comporte un hôtel terminus de grand luxe, à exploiter par la compagnie (figure 11). Deux ans plus tard, l'ingénieur Louis Le Châtelier, nouveau chef d'un service d'étude technique du métropolitain, ironisait sur l'idée du Nord de pouvoir débarquer directement, à l'Opéra, les riches Anglais de leur wagon-lit à leur chambre d'hôtel, sans qu'ils sortent de leurs draps. Quand à l'Est, il se voit contraint de demander au Nord la permission de quelques passages à l'Opéra, moyennant péages.

L'autre aspect de la stratégie du Nord s'inspirait du modèle de la banlieue londonienne, tirant les leçons du succès de la Compagnie de l'Ouest sur les lignes de villégiature : dans les deux cas, la règle d'or était d'avoir un terminus dans le centre des affaires (cas de Saint-Lazare), ou, mieux encore, comme à Londres, d'envoyer les trains de banlieue faire un tour en circuit central, au lieu de s'arrêter une seule fois. Les simulations secrètes de trafic visaient notamment la promotion des lignes d'Enghien-les-bains et de Chantilly, en banlieue chic, rehaussée d'hippodromes. La ligne ne connaissait d'animation semblable à celle d'Auteuil ou de Paris-Saint-Germain que les jours de courses de chevaux, sans atteindre l'affluence de Saint-Lazare lors des courses de Longchamp, dans le Bois de Boulogne. Un tour final de l'Opéra à la Bourse placerait d'un coup les campagnes d'Enghien et de Montmorency dans une position de prestige et d'attrait commercial analogues à celles d'Auteuil et du Vésinet.

Fig.12 - Chemins de fer de Banlieue. Recettes brutes et recettes nettes en 1887

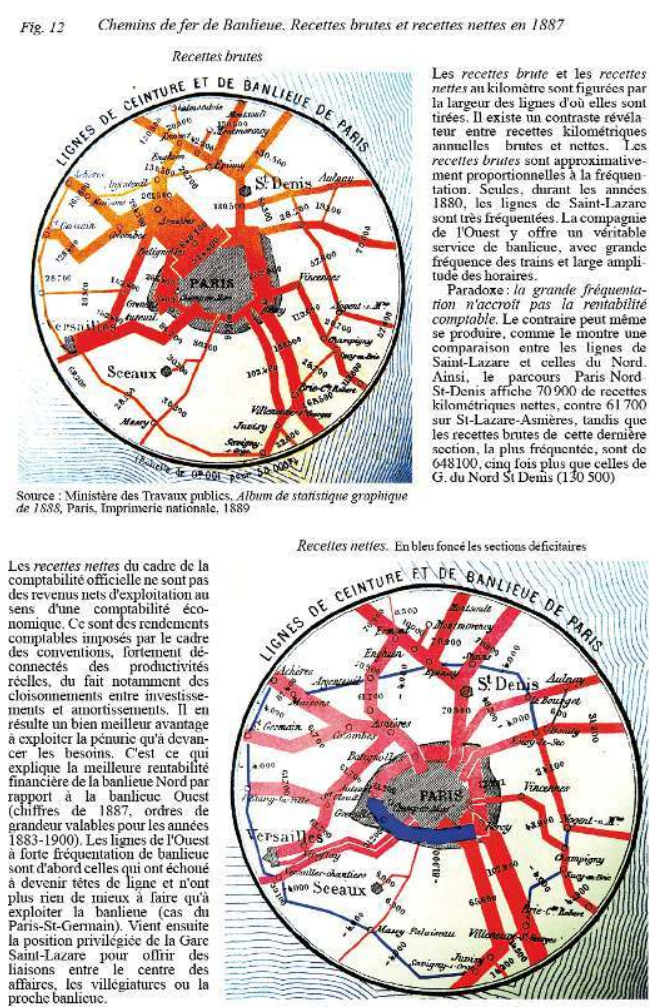

Voici par exemple ce que griffonne Sartiaux, heureux d'avoir obtenu tout ce qu'il voulait pour la Compagnie du Nord, à l'intention de son collègue Cossmann : 
«J'ai dû me gendarmer... avec la partie nord du boulevard extérieur et le Bois de Boulogne que l'Ouest préférait se réserver, et je le comprends ! [...] On ne se doutera pas, si l'affaire aboutit, et on ne doit pas s'en douter, combien le petit bureau technique aura pioché et combien nous aurons bouleversé l'idée première qui était nuisible pour le Nord et pour l'avenir du métro lui-même ». Il tenait aussi au caractère partiellement inavouable des buts de l'opération. Les «cinq monopoles » des chemins de fer avaient toujours mauvaise presse, même si un budget de publicité arrosait copieusement les journalistes. Dès lors, contre les plaintes du mépris pour les besoins locaux, la desserte locale de Paris devait apparaitre comme prioritaire, en distorsion avec le projet réel. De plus, la Compagnie du Nord avait une raison particulière d'être prudente : l'antisémitisme montant, et les tendances paranoïdes de la presse populiste, risquaient de faire d'Alphonse de Rothschild un bouc émissaire de choix. La prudence générale de la maison des Rothschild a vraisemblablement aidé à éviter l'extension de l'amalgame. On voit d'ailleurs dans les télégrammes où Léon Say informait Sartiaux sur les négociations financières, tenues séparément à plus grande distance de la Compagnie du Nord, que celle-ci maintenait un prudent retrait, face aux pratiques affairistes de ministres, élus, journalistes et maisons de banques moins bien assises.

Autour du métro ne vont cesser de s'agiter des montages financiers avec des marges énormes d'intermédiaires, à différents titres : publicité, frais de syndicats d'émission, commissions de banque en général. C'est l'une de ces marges exorbitantes que commente Léon Say dans le télégramme suivant adressé à Sartiaux, au moment de négociations sur les tracés du réseau. A la suite d'une discussion qu'il a eue avec le directeur du Journal des Débat, Charles Patinot, Léon Say explique l'origine d'une campagne de dénonciation, campagne qu'il ne désapprouve pas. Un autre journal, L'Etoile, baptise Métrotripotageolitain. le montage du Ministre Baïhaut avec Wilson (deux personnages condamnés plus tard dans des scandales de corruption) et avec Christofle, concessionnaire pressenti. Le télégramme de Léon Say laisse voir que, sans être d'accord avec Patinot lui-même, tout en étant familier avec le directeur des Débats, il reste officiellement attaché avec sa Compagnie du Nord à la réalisation du métro; il lâche néanmoins des arguments contre la corruption autour du gouvernement, trouve effectivement scandaleuse une commission de syndicat d'émission à $12 \%$, et se tient en retrait prudent et sceptique sur l'ensemble de ce montage financier.

«Mon cher Sartiaux

C'est Patinot qui a voulu partir en guerre contre Christophle et Wilson. Je crois que la $C^{\text {on }}$ [combinaison] va partager entre des amis les $12 \%$ réservés et que les tripotages n'auront pas de limites.

Quant au tracé et à la convention sur le trafic d'apport, il prétend qu'il ne s'est pas trompé ; c'est une appréciation personnelle fort légèrement conçue; j’aimerais avoir une petite note sur les erreurs de cet article. Je lui ai dit que la garantie d'intérêts ne balancerait pas le compte du trafic d'apport, mais la capitalisation de la perte n'empêche pas, selon lui, le compte des revenus d'être surchargé ; cela retarde les comptes au moyen d'une accumulation, mais le compte accumulé est porté plus tard. ». Tout à vous. Léon Say ${ }^{26}$

Indépendamment de l'aspect financier, la stratégie du secret, pour élaborer l'aspect technique, efficace dans la négociation entre techniciens et fonctionnaires, échoua complètement en débat public. Le projet de loi déposé le 3 avril 1886, conforme aux plans arrêtés entre ingénieurs des compagnies, bien accueilli dans un premier temps, fut 
progressivement dévoilé dans sa vraie nature urbanistique, sous le feu de la critique municipale et des campagnes de presse.

Les controverses publiques se multiplient, mais sans qu'on puisse encore parler de débat, encore moins de délibérations. Tous les faiseurs de projets prennent le public à témoin, et l'inondent de brochures, organisent des conférences, s'immiscent dans celles des autres, parfois même, créent des périodiques pour la circonstance. Les meetings se multiplient. Face à la propagande des promoteurs du projet Haag, puis du projet Baïhaut-Christophle, la majorité du Conseil parvient à lancer une importante contre-offensive, à faire entendre son désaccord, mais sans qu'aucun des camps ne prenne le dessus ni ne débatte réellement avec ses adversaires. Des dizaines de réunions de quartier sur les problèmes urbains ou sur la seule question du métro se succèdent, mettant à disposition des Parisiens des projets, des plans, des gravures séduisantes, des dénonciations croisées entre projets concurrents.

\section{Comment, sur fond de cacophonie, émerge un clivage entre métro d'intérêt local et métro des grandes compagnies}

92 Au milieu de cette cacophonie sans vrai débat, seuls, durant cette phase, l'assemblée nationale, le conseil municipal et quelques sociétés savantes font figure d'appuis à une discussion rationnelle, malgré tout, accessibles à tout le public par voie de presse, offrant parmi les articles, de temps en temps, des informations vérifiées ou vérifiables, discernables par vision critique et recoupements. Les lobbys et, à l'assemblée nationale, l'affairisme et la corruption ne constituent pas un obstacle insurmontable à la compréhension des projets. Les discours rémunérés aux assemblées se doivent d'être d'une qualité non moins élaborée que les autres, d'établir leur crédibilité sur des critères d'appréciation partageables, sans quoi, tout comme pour le marché publicitaire aujourd'hui, il ne servirait à rien de se payer leurs services.

En d'autres termes, pour pouvoir aborder l'histoire de l'affairisme avec un certain recul, sans rejouer la posture des juges d'instruction, il importe de bien distinguer les raisons de se manifester en public - intéressées ou désintéressées -, et les critères d'excellence auxquels doivent se plier les interventions publiques, quelles que soient les conditions qui les ont propulsées. Ainsi, les appréciations de ce que doit être un bon métro évoluent et se reconfigurent selon les milieux dans lesquels elles se font entendre. Un clivage caractéristique se dessine, durant le premier semestre 1887, entre les intervenants à l'assemblée nationale et les intervenants au conseil municipal. À l'assemblée nationale, les députés ont été sensibles à la partie convergente des arguments du promoteur Haag, $\mathrm{du}$ ministre des Travaux publics Baïhaut, et du concessionnaire virtuel avancé, Christophle. Un bon métro doit être si possible aérien, et ne peut devenir rentable sans l'apport des trains des grandes compagnies (grandes lignes et banlieue). Au conseil municipal, la majorité radicale et radicale-socialiste ( autonomiste) partage avec une petite partie des opportunistes la philosophie de Vauthier-Deligny: il faut un métro local au service de l'urbanisation et des styles d'activité propres aux Parisiens ; le réseau doit être autonome, organisé en circuits spécialisés qui n'oublient pas la périphérie. Les parties les plus rentables doivent financer les parties les moins rentables grâce à l'unité de gestion d'un réseau global, subdivisé au besoin en un calendrier de première, seconde et énième urgence. 
94 Le clivage traverse les réseaux d'influence politique, opportunistes, radicaux et socialistes, selon qu'ils sont liés au conseil municipal de Paris ou directement rattachés à l'assemblée nationale. Par exemple, entre radicaux, la divergence se manifeste à l'occasion d'un vote municipal particulièrement retors à l'encontre de la Compagnie du Nord. Le tracé proposé en viaduc, entre Saint-Lazare et Gare du Nord, est vivement attaqué par les habitants du quartier. Leur conseiller municipal, Léon Donnat, un républicain conservateur réputé gouvernemental, fait adopter, avec plusieurs collègues, un amendement qui conditionne l'accord et les subventions de la Ville de Paris à la mise en souterrain du tronçon. Cela est parfaitement compatible avec une circulation locale, mais ne l'est pas avec le circuit des grands trains internationaux prestigieux que le Nord entend utiliser pour gagner la gare de l'opéra. Les députés radicaux de la majorité gouvernementale y voient une manœuvre qu'ils appellent, évidemment, l' " enterrement » du métro, et leur organe Le Radical des 28 et 29 juin s'emporte: "Les élus de Paris ont préféré sacrifier les intérêts généraux, plutôt que de rien abandonner de leurs intérêts particuliers ... ${ }^{27}$. Durant ces controverses, les comptes rendus imprimés des débats des assemblées municipale et nationale constituent la référence la plus communément utilisée pour discuter ensuite entre concitoyens. Les procès-verbaux officiels de la municipalité imitent au plus près ceux de l'assemblée nationale, avec impression de débats, résolutions, rapports et documents. Ils ont rejoint les publications de l'assemblée nationale comme repères les plus usuels pour la presse, les réunions publiques, et, à travers ces deux derniers circuits, les discussions de comptoir.

L'histoire du dévoilement des secrets de la Compagnie du Nord est particulièrement révélatrice de la conjoncture de ces controverses, du mode de leur diffusion et de leur effet sur les convictions des citoyens. Entre février 1886 et juillet 1887, les services de Sartiaux ont récupéré huit brochures de Vauthier et Deligny, diffusées au public, répondant point par point chaque mois aux libelles et rumeurs successifs lancés par les publicités en faveur du projet Haag; dans ce dernier camp se retrouvent des agents directement salariés par la société de Haag, les influences du ministre des Travaux publics, Baïhaut, les compagnies de chemins de fer dotées d'un énorme budget de publicité mis en place pour la signature des conventions de 1883 , le réseau d'influence de Christophle, doté lui aussi d'un budget publicitaire considérable, mis en place pour combattre le boulangisme, parallèlement au large canal des fonds de Panama. Ils sont parfois rejoints, sans pactiser, par le puissant réseau des Pereire, opérant pour le compte de la Compagnie des Omnibus et d'investisseurs en immobilier et équipements urbains : la Compagnie est réputée pour les généreux arrosages de ses campagnes menées pour défendre son monopole des transports dans Paris. Cette dernière manifestait une grande inquiétude à l'égard des projets municipaux, beaucoup plus menaçants pour elle que les projets de Haag, quant aux risques de concurrence.

En contre-offensive de ces lobbies, une brochure de Vauthier et Deligny, datée du 10 janvier 1887, révèle au public les conditions dans lesquelles a travaillé l'équipe de Sartiaux pour élaborer les projets gouvernementaux. Elle imprime notamment :

«Le personnel de cette compagnie [du Nord] a conçu les dispositions du projet; a fait dessiner, imprimer, distribuer les plans; cela n'est plus un mystère pour personne; les plans eux-mêmes le disent hautement. Ce personnel a rédigé les conventions; le Ministre les a reçues toutes faites des mains de son directeur, qui les tenait lui-même de la haute volonté qui commande rue de Dunkerque [siège du Nord] $\ldots »^{28}$. 
D'après les archives de Sartiaux consultables aujourd'hui, ces révélations sont minutieusement exactes, dans chaque détail. Sartiaux est furieux en constatant la fuite, d'autant plus que ce mode de travail hors ministère avait été concerté avec le ministre pour garantir la confidentialité. Sur le coup, l'anecdote n'est qu'un petit élément parmi d'autres, dans un contexte d'affaires incomparablement plus grosses. Mais, signe d'un cheminement cumulatif des informations les mieux avérées, le rapport parlementaire Pradon, celui qui allait faire échouer le projet gouvernemental, cite à son tour l'assertion de Deligny-Vauthier, avec plusieurs autres de leurs considérations qui, mises bout à bout, démontent l'ensemble de la stratégie de la Compagnie du Nord dans la métropole, et sapent la crédibilité du projet. Il est aussi remarquable que Vauthier et Deligny ne prononcent pas le nom d'Alphonse de Rothschild: dans le contexte, la brochure se place sur un terrain purement rationnel d'appel aux citoyens, et évite précautionneusement de donner prise au discours antisémite que développent les campagnes boulangistes au même moment : c'est donc la rue de Dunkerque (Compagnie du Nord) qui est visée, là où Sartiaux a effectivement fait tirer les plans pour le ministre, et non "la finance internationale juive » embusquée au Château de Ferrières, bien que le château fût le lieu d'arbitrage ultime et décisif du Nord, entre Alphonse de Rothschild, Léon Say et Sartiaux.

Ce fonctionnement du débat en prise réciproque n'opère que dans le cercle restreint de ces assemblées et de leurs comptes rendus. Dans cette conjoncture, l'espace de discussion de l'assemblée nationale et du conseil municipal, imprimé in extenso pour le public, fait contraste avec la confusion de la presse et du grand public. Parmi les journaux, des dizaines de titres sont manifestement payés par les grandes compagnies et les promoteurs du projet, - nous sommes à l'époque des plus gros budgets de "publicité» d'affaires, une époque qui ne distingue pas les articles d'information et les articles sur commande rémunérée $e^{29}$. La conjoncture est aussi marquée, à Paris, par la crise du chômage, par une forte agitation socialiste et boulangiste, ainsi que par les débuts d'une surenchère anarchiste.

Pendant tout ce temps, une contre-offensive municipale, sans grand lobby affairiste à son service $^{30}$, mobilise néanmoins $d u$ monde, sur des bases d'information directe entre concitoyens. Des comptes rendus manuscrits des meetings, conservés à la préfecture de Police, font état de "réunions publiques » sur la question du métro, depuis cette époque et jusqu'au vote définitif en 1898. Durant les offensives et contre-offensives de 1887, les positions sont indécises, flottantes, entre les initiatives municipales et les campagnes inspirées de promoteurs de projets. Un faux problème récurrent revient constamment au premier plan : le métro doit-il être aérien ou souterrain? C'est un indice de l'entretien publicitaire de la confusion, car dès que l'on prend connaissance des débats techniques, il est clair que le dilemme n'a pas de sens, et qu'il faut déterminer d'abord les fonctions, en relation avec les possibilités techniques et leurs coûts. Seul le lobby du projet Haag relance constamment cette manière de poser le problème, différencié sur ce point de ses alliés. Il est rejoint par des groupes d'entrepreneurs parisiens de travaux publics, lançant une campagne sur le thème de la lutte contre le chômage par les grands travaux. Une bande d'anarchistes est payée par l'équipe du projet Haag, bien connue et ménagée par la préfecture de Police, heureuse de localiser et tenir en réserve des provocateurs faciles à manipuler. La "bande de [Léon] Roux" va de réunion en réunion pour exiger un métro aérien - c'est la solution du chômage, explique leur message salarié -, et conspuer les positions municipales à l'aide d'insultes et d'accusations vagues de corruption. 
100 Entre temps, l'instruction du projet ministériel s'est poursuivie. Une négociation a eu lieu avec le conseil municipal. Le ministre Baïhaut, par souci d'efficacité, s'engage dans des compromis sur le réseau, accepte le rétablissement d'un tracé plus autonome, permettant des circuits par les boulevards extérieurs, desservant les faubourgs, au lieu d'aller faire des kilomètres sur la petite ceinture, nuisibles pour le service parisien, utiles seulement pour les péages et la rémunération du Syndicat de Ceinture réunissant les grandes compagnies. Mais, fait significatif, si les ingénieurs des compagnies acceptent d'intégrer des modifications de tracé sur ordre du ministre, ils refusent absolument d'admettre une extension du métro en banlieue, indépendante de leurs réseaux: les conseillers redemandaient une sortie par l'Ouest, vers Puteaux, comme en 1879, acceptée par Baïhaut. Mais Sartiaux fait donner Léon Say et Alphonse de Rothschild contre le ministre, avec succès, ce qui montre à quel point la menace est grave à ses yeux, plus que tout le reste. Sans doute est-ce la crainte d'un réseau concurrent, puisque Delahante, promoteur d'une relance du Calais-Marseille, a fait demander par son cousin la concession du projet Vauthier-Deligny. Sartiaux finit par obtenir qu'au lieu d'une sortie indépendante hors de l'enceinte fortifiée de Paris, ne figure dans le projet qu'une ligne Étoile-Porte Maillot, étant entendu que la ligne pourrait être prolongée par une concession aux Chemins de fer de l'Ouest. Vauthier relève la manœuvre, et explique à la Chambre que c'est là un exemple de ce qu'on a coutume d'appeler, au conseil municipal, Le blocus de Paris par les grandes compagnies $^{31}$. 
Fig. 13 - Compromis ministériel du 10 décembre 1886, rejeté par les députés le 21 juillet 1887

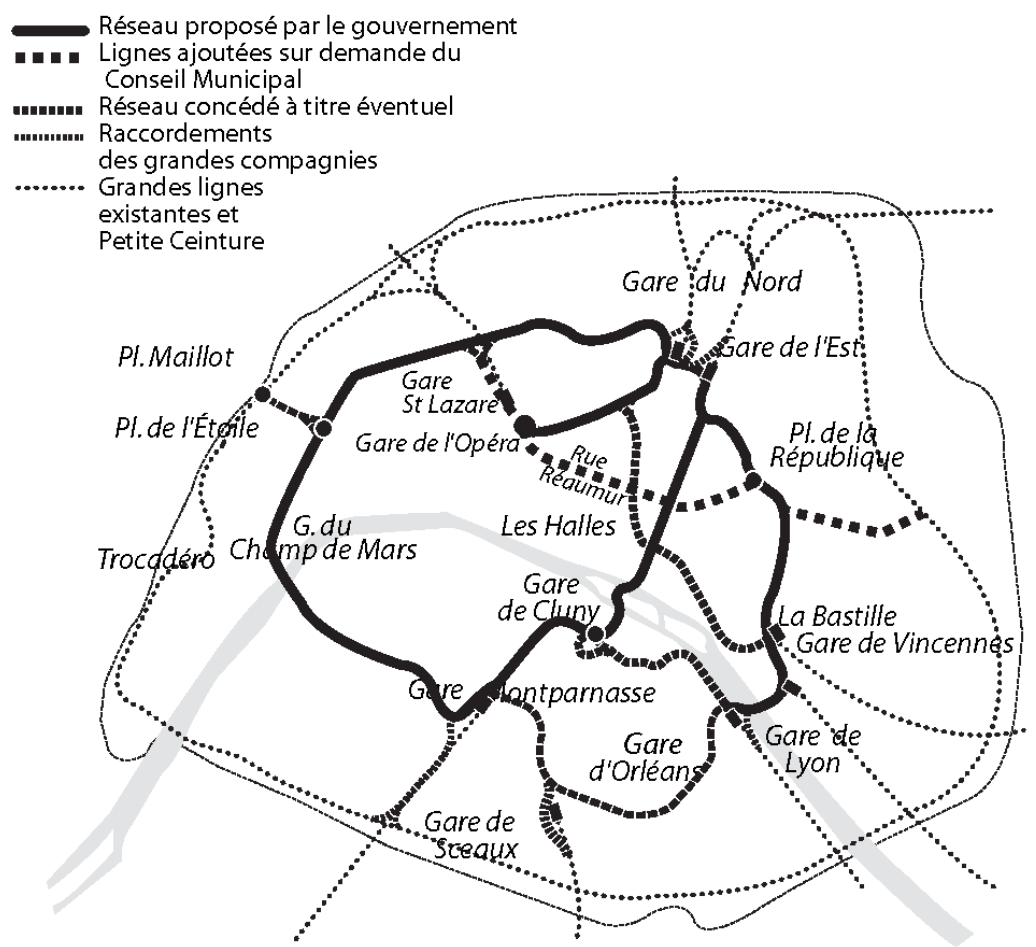

Le rejet retentissant de ce projet par la chambre des députés, le 21 juillet 1887, a marqué l'histoire de la capitale. Monté par le ministre des travaux publics Baïhaut, il est issu d'une suite de compromis qui l'ont laissé sans cohérence. En pointillé (réseau éventuel) figure l'ancien projet Haag, à construire en seconde urgence, mais que seuls, parmi la coalition, ses promoteurs imaginent devoir être réalisé. Les grandes compagnies y ont substitué un projet plus réaliste de raccordement des gares et de rapprochement des terminus dans le centre de Paris, à l'approche de l'Exposition. Le Conseil municipal de Paris a imposé de la ligne circulaire, pour lui donner une réelle fonction de desserte locale, au détriment des contraintes de grand gabarit. Le rassemblement sur le papier des deux philosophies laisse sceptiques tous ceux qui connaissent un peu la question : les exigences de fonctionnement des grandes lignes de voyageurs et de la desserte locale, dans les mêmes tunnels semblent incompatibles.

Lorsque le projet ainsi remanié arrive en discussion devant les députés, fait de morceaux mal recollés (figure 13), l'argumentation du conseil municipal a produit suffisamment d'effet pour semer le doute, à défaut de rallier les députés.

Le rapport, très bien documenté, se dit officiellement favorable au projet, mais, de bout en bout, il en fait ressortir les insuffisances, distille les arguments critiques des élus de Paris et déplore le refus des grandes compagnies de lui répondre lorsque qu'il leur fait demander par écrit, à plusieurs reprises, comment elles parviendraient à concilier le service des grandes lignes, le service de banlieue et le service des parisiens. Dès lors, il ne cache pas que les procès d'intention des adversaires ne manquent pas de bases et n'ont reçu aucun démenti sérieux. Les discussions en séance amplifient la critique. Les conditions financières prévues au projet, de gré à gré avec Christophle, sans adjudication, dans un climat de dénonciation de l'affairisme, font le reste : le projet est refusé en bloc le 21 juillet 1887. L'Exposition de 1889 n'aura pas son métro ${ }^{32}$. 


\section{Le grand meeting du métropolitain}

103 A Paris, l'agitation explose. Une série de «meetings» de protestation a lieu, qui doit culminer par un Grand meeting du métropolitain dans la salle du Cirque d'Hiver, le 30 juillet, annoncé par le journal La France. Ce quotidien affairiste, soutien zélé du projet Baïhaut, lance un appel à protestation de masse sans retenue : «Parlons, écrivons, réclamons crions... Pour que l'opinion force la main aux pouvoirs publics, il faut qu'elle ne se lasse pas de manifester; il faut une agitation qui ne prête à aucune équivoque... ». Les anarchistes n'en croient pas leurs yeux, et se promettent de ne pas rater pareille convocation bourgeoise, qui emprunte leur langage pour appeler à une "agitation» débridée. C'est un samedi soir, jour de paye, le public ouvrier est nombreux. Organisé par le député Lockroy, radical partisan du projet, le grand meeting est boudé par ses « amis » radicaux de la municipalité. Lockroy prend la parole, mais il est interrompu à chaque phrase. Le rassemblement tourne au style GrandGuignol des réunions publiques de la fin du Second Empire : comme au début de la pièce de Cyrano, le public joue la véritable représentation, c'est à qui improvisera les interruptions les plus comiques, au détriment des orateurs. Lockroy abandonne la partie, il est supplanté par les socialistes. Vaillant, conseiller municipal socialiste, tente de capter l'indignation de la foule: "Le vote de l'assemblée nationale est une insulte aux Parisiens", lance-t-il.

Camélinat, député ouvrier, ovationné, surenchérit. Mais des anarchistes, propagandistes salariés du métro aérien, montent à l'assaut de la tribune. Une bagarre commence avec un ouvrier éméché. Le meeting se termine en pugilat. Selon les versions des journaux, le meeting avait rassemblé entre un et vingt milliers de personnes. Après le « coup de tampon ", des groupes se dispersèrent en chantant C'est Boulanger qu'il nous faut! Vu rétrospectivement, ce Grand meeting du métropolitain représente le point de décomposition le plus extrême dans l'histoire du débat public parisien autour du métro, entre 1872 et 1900, celui où la délibération entre citoyens devient impossible ${ }^{33}$.

\section{L'enquête d'utilité publique de 1891, et le retour des citoyens dans la délibération}

Après l'échec au parlement du projet Baïhaut-Christophle-Grandes compagnies, de nouvelles tentatives de concession sont lancées. La Compagnie du Nord reçoit plusieurs demandes d'entrer dans diverses combinaisons. Elle se voit proposer d'entrer seule en connexion avec un métro en anneau central, ce qui limiterait l'investissement aux parcours potentiels les plus rentables. Dans cette perspective sont étudiés successivement, entre autres, un nouveau projet De Hérédia (du nom du ministre des Travaux publics), un projet Donon, l'infatigable financier lanceur et re-lanceur du métro depuis 1872, ainsi que celui d'un nouveau venu, Léon Donnat, ingénieur fraîchement élu conseiller municipal de la Muette, dans le $16^{\mathrm{e}}$ arrondissement, et que le ministre des travaux publics tente d'imposer à la Compagnie du Nord. Durant l'année 1888 est esquissée la combinaison qui va être proposée par les gouvernements successifs pendant quatre années, jusqu'à ce que le scandale de Panama ne fasse retirer de la piste tous ses promoteurs $^{34}$. Ce qui est appelé parfois le "projet Yves Guyot », du nom du ministre des Travaux publics, et davantage connu sous le nom de "projet Eiffel », rassemble en effet les grands noms de la promotion du canal de Panama. Auréolé du succès de la tour, 
l'ingénieur Eiffel a obtenu l'appui des entrepreneurs du canal, de la maison Bunau-Varilla, pour demander la concession, tout en conservant l'appui de Donon. Le projet officiel, daté du 11 avril 1890, prévoit la constitution d'une société au capital de 25 millions. Il consiste en un « anneau central ", se combine avec un second projet, celui de la prolongation des lignes de la Compagnie du Nord dans Paris, l'une à l'Opéra, l'autre aux Halles. Par convention, il est prévu que le Nord fournisse à la nouvelle compagnie du métropolitain le matériel roulant et la main d'œuvre, en location (figure 14).

Le projet donne lieu à une enquête d'utilité publique en juillet et août 1890. Les dépositions inscrites dans les cahiers mis à disposition par les mairies des 20 arrondissements permettent de mesurer jusqu'à quel point un débat public s'est reconstitué, depuis la confusion de 1887. Les promoteurs de Panama ont déployé à prix d'argent un effort de recueil de signatures en faveur de leur métropolitain. Ils présentent, à la fin de l'enquête d'utilité publique, 139735 signatures en faveur du projet Eiffel. Mais leurs procédés se retournent contre eux. Une enquête municipale sur les conditions de leur racolage prend des allures de petit scandale. Les signatures

«ont été extorquées par le ministère d'agents d'affaires véreux ... Chacune d'elles a été payées 3 centime. Ces pétitions ont été pour la plupart déposées chez les marchands de vin, où des racoleurs étaient chargés d'obtenir des signatures argent comptant. $\|^{35}$

107 A l'inverse, les cahiers d'enquête rassemblent les résultats de débats étroitement articulés entre les conseillers municipaux et la vie des quartiers. Le climat passionnel et irrationnel s'est estompé. La majorité des dépositions, hormis les pétitions achetées par le groupe Eiffel et Bunau-Varilla, est défavorable au projet, pour redemander un réseau local autonome desservant l'ensemble des arrondissements. Des réunions de quartier ont eu lieu, qui ont créé des comités ad hoc pour l'adoption d'un métro municipal, organisé de nouvelles réunions, rédigé des pétitions soigneusement élaborées d'un point de vue d'aménagement urbain, où figurent notamment des cartes comparatives entre projet Eiffel et projets municipaux. Des habitants de toutes conditions, souvent avec des styles personnels d'expression, trace d'une élaboration localement enracinée, parviennent à intégrer un intérêt particulier de voisinage, ou bien de profession, avec la perspective d'ensemble de la vie urbaine. Tel comité de quartier ne se limite pas à demander un tracé qui le desserve mieux, il mobilise les compétences des résidents (ingénieurs, architectes, comptables, etc.) pour élaborer des contre-propositions qui ne dépassent pas les coûts publiés. Des sections locales de partis et de syndicats ouvriers expliquent en détail comment seul le projet municipal serait utile aux activités de leurs adhérents. Des commerçants du centre argumentent qu'ils n'ont pas envie de voir leur quartier se transformer le soir en sinistre zone désertée, comme cela vient de se produire pour la City de Londres, ce à quoi aboutirait, à terme, la stratégie de la Compagnie du Nord avec ses trains de banlieue à l'Opéra, destinés à aspirer chaque soir les employés aisés pour les répandre dans la coquette vallée de Montmorency. 
Fig. 14 - Projet de la Compagnie Eiffel, combiné avec le projet de la Compagnie du Nord, 12 avril 1890

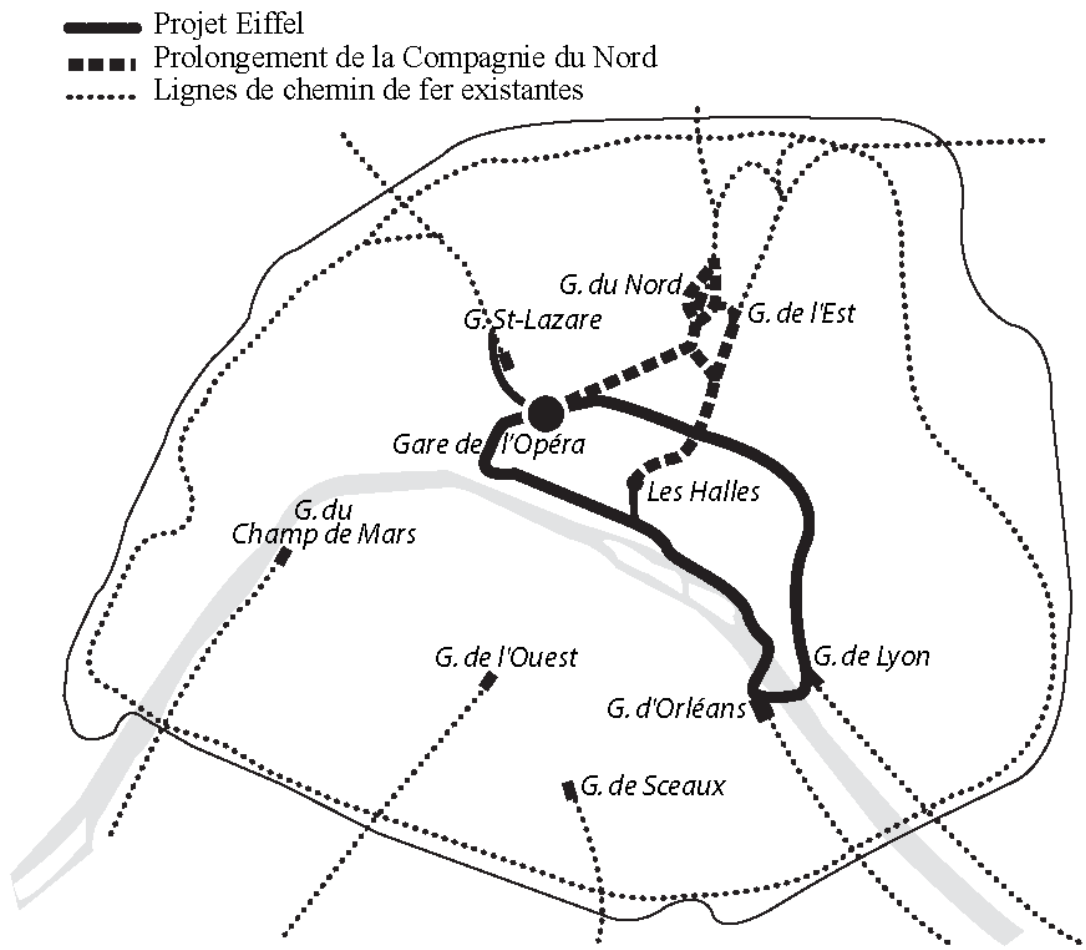

Le « projet Eiffel » ou « Projet Yves Guyot » mobilise les mêmes personnages que les promoteurs du Canal de Panama, pour proposer une affaire calculée au plus rentable : un trajet court

d'interconnexion partielle des gares, laissant de côté les gares les moins intéressantes de Sceaux et de l'Ouest, plus éloignées et à moindre trafic. Le projet est combiné avec la Compagnie du Nord pour lui permettre de construire enfin sa gare de l'Opéra, à laquelle elle tient plus que tout, en un point stratégique de raccordement.Le scandale de Panama empêcha vraisemblablement qu'il y ait un scandale du métro : un syndicat d'émission travailla aux mêmes conditions que les syndicats de Panama, si l'on en croit la presse et les archives de police. L'éclatement du scandale, en automne 1892, dispersa les promoteurs. La Compagnie du Nord, prudente, veilla à ce que les projets, élaborés sous son expertise demeurent financièrement séparés, ce qui lui permit de ne pas être compromise.

Les quartiers périphériques, où les élus socialistes tendent à remplacer les élus radicauxsocialistes, développent des arguments semblables, avec une tonalité davantage ouvriériste. Cependant, les justifications demeurent de style radical-socialiste, et, à regarder les contenus plutôt que les étiquettes, il s'avère que les positions sont très voisines de celles des élus radicaux de 1872 ou des communards amnistiés, élus en 1884 et 1887. Les demandes de service public et d'aménagement pour le peuple parisien expriment avant tout un désir de lutte contre les inégalités, au nom de principes universels et d'une vie démocratique. Les biens collectifs urbains, transports et autres équipements, doivent répondre à des critères de justice universelle. À l'encontre d'un métro pour les grands et pour le prestige des affaires, ils invoquent, non pas un métro pour les petits ou pour la classe ouvrière, mais un métro pour tout le monde, qui n'oublie pas les ouvriers.

L'éclatement du scandale de Panama, en septembre 1892, met hors jeu les promoteurs du projet Eiffel et évite vraisemblablement que n'éclate un scandale du métro analogue à celui de Panama. Car, s'il faut en croire les archives de la préfecture de Police et les insinuations de la presse, un syndicat d'émission pour constituer la Société demandeuse 
de la concession a utilisé les procédés déjà éprouvés des compères pour la société du canal de Panama, à savoir commissions exorbitantes et « frais de publicité » pour obtenir bonne presse et souscriptions avantageuses.

110 Il est remarquable aussi que, dans cette situation de critique virulente contre la Compagnie du Nord, bien peu reprennent les discours antisémites des boulangistes contre le président Alphonse de Rothschild. La propagande antisémite demeure outrancière, mais son emprise a manifestement diminué. Une condition de bon fonctionnement d'un espace public est ici remplie de façon remarquable; elle illustre la démarcation entre une critique rationnelle et la "maladie du soupçon ». Ce deuxième type de réaction à la domination financière et aux scandales -développant une vision complotiste- , est un des éléments capables de détruire un espace public et une démocratie, comme vient de le démontrer la menace boulangiste. La critique rationnelle se présente, dans cette conjoncture historique, comme le premier terme de l'alternative, fondée en l'occurrence sur une intense vie démocratique locale, capable de distinguer le soupçon illimité et la critique arbitrée par l'enquête citoyenne et la preuve bien fondée.

\section{La dernière manche : le vote et la construction d'un métro pour les Parisiens}

111 C'est au cours d'un nouveau bras de fer avec les grandes compagnies ferroviaires, à l'approche de l'Exposition universelle de 1900, qu'une énième décision de créer le métro parisien sera prise et s'avérera être la bonne. Après l'épisode des projets Eiffel et de la Compagnie du Nord, les autres compagnies ferroviaires mettent en avant à leur tour leurs projets de prolongation, à l'imitation de la Compagnie du Nord, et gardent l'espoir de procéder à une interconnexion semblable à celle de Londres. La Compagnie d'Orléans avait avancé un projet plus modeste pour la ligne de Sceaux : une simple prolongation de son terminus jusqu'au carrefour du Luxembourg. La modestie du projet lui avait permis de surmonter le veto parisien, dans la mesure où l'opération ne compromettait pas les chances d'un réseau local. À l'approche de l'Exposition de 1900, les tergiversations se retrouvent placées sous la pression de l'urgence. Les grandes compagnies relancent de nouveau leurs différents projets de rapprochement de leurs gares vers le centre. En octobre 1894, le ministre Barthou propose un nouveau métro d'interconnexion, avec une première urgence pour desservir l'Exposition. Les différentes commissions de coordination (localisation de l'Exposition, coordination des transports) travaillent dans la fièvre. Mais le projet préparé par le ministre Barthou et le commissaire général de l'exposition, Picard, se révèle décidément n'être qu'une combinaison de rapprochements des gares des compagnies, sans service sérieux des transports locaux (voir figure 15).

Les euphémismes ne sont d'ailleurs plus de mise, et chacun parle ouvertement de projets de «lignes de pénétration dans Paris». Malgré la pression ministérielle et celle des compagnies, l'opposition municipale est vive, et trouve un écho résolu dans la population parisienne. Les attaques de plus en plus virulentes de la presse du centre ou de droite, comme Le Temps et Le Journal des Débats, n'ébranlent pas les refus de la municipalité. L'État et l'Exposition ne pouvant se passer des subventions municipales, projets et contreprojets se succèdent encore durant plusieurs mois sans pouvoir aboutir.

113 Les élus de Paris procèdent alors à un chantage efficace, au moment où les gouvernements leur sont de plus en plus favorables : ils subordonnent la subvention de la Ville de Paris à la concession par la municipalité d'un métro autonome. De plus, pour 
couper court aux tentatives de subordonner un réseau à l'exploitation des grandes lignes, la subvention ne sera donnée qu' « à la condition qu'aucune concession de chemins de fer destinés à l'Exposition ne sera accordée à l'intérieur de Paris sans l'assentiment du Conseil municipal » (délibération du 13 juillet 1895). Après un bras de fer de quatre mois, le ministre des Travaux publics finit par céder sur le principe, par lettre du 22 novembre 1895.

Fig. 15 - Projet du gouvernement, octobre 1894

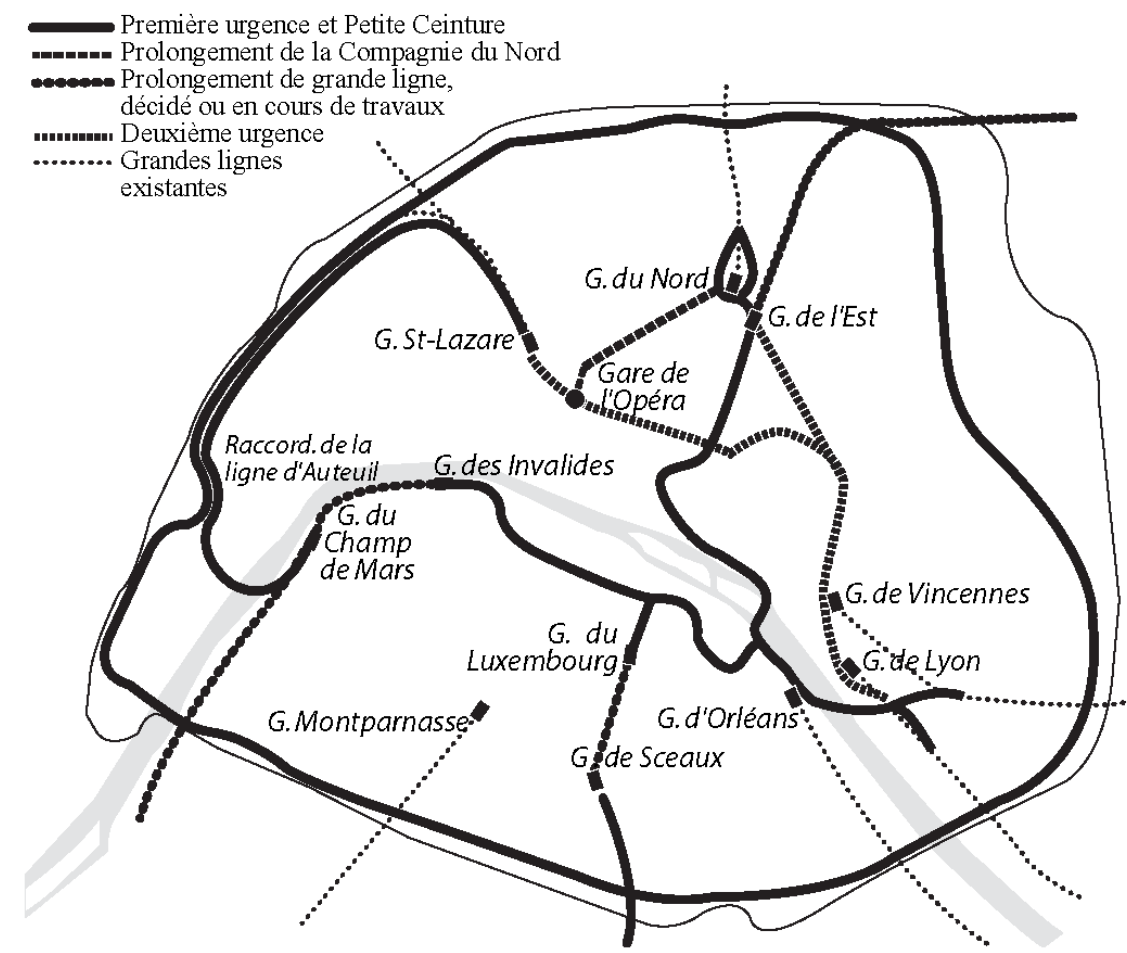

Le tracé du projet ministériel, pour l'échéance de l'Exposition universelle de 1900, est ouvertement un projet de pénétration des grandes compagnies au centre de Paris. Avant l'Exosition, la Compagnie du Nord doit prolonger ses voies jusqu'à une nouvelle gare de l'Opéra, tandis que les lignes de SaintLazare et la Compagnie du PLM rejoignent les réseaux de la rive gauche (l'Orléans, la ligne de Sceaux le Versailles Rive Gauche) sur le site de l'Exposition, à la nouvelle gare des Invalides. Dans un second temps, après l'Exposition, les réseaux de l'Est, de Lyon, les lignes de la gare Saint-Lazare, la ligne de Vincennes seraient interconnectés aux deux sous-ensembles, par une seconde percée transversale, rive droite, et par la Petite Ceinture.

La vie démocratique parisienne est alors à son apogée, et a certainement pesé dans le revirement gouvernemental. Aux élections municipales de 1893, la plupart les programmes consultables aujourd'hui comportaient des engagements sur un métro local autonome, pris dans des réunions d'investiture et des meetings de quartier. La presse locale a acquis une place de référent d'autant plus consulté qu'une partie des grands journaux a été déconsidérée par les scandales, et que la majorité des journalistes ont dû réfréner les abus les plus criants de plumes rémunérées. En même temps, le tissu des rassemblements en co-présence (débats, conférences, comités, associations, syndicats, partis, mutualités, groupes d'aide sociale, groupes de loisirs) fonctionne comme un contrôle local critique des journaux, tout autant que des rumeurs. Chaque élu parisien est devenu une institution au carrefour de nombreuses associations volontaires, d'institutions d'aide sociale et de surveillance d'équipements collectifs. Un défilé 
d'habitants se presse chez eux plusieurs fois par semaine, pour demander non pas des services clientélistes, mais des déblocages d'une administration alourdie, de plus en plus réglée contre l'arbitraire par des procédures strictes. La majorité élue compte davantage de conseillers ayant ajouté le mot socialiste à leurs différentes étiquettes. Toutefois, ceux d'entre eux qui ont le plus d'influence et de durée, quelle que soit l'étiquetage électoral - plus ou moins révolutionnaire-, doivent respecter des règles du jeu qui demeurent « radicales-socialistes » au sens littéral, c'est à dire de démocratie radicale et réformatrice, plutôt que classiste. Parallèlement, beaucoup de ceux qui portent encore des étiquettes à composante radicale en affadissent ce côté radical et se retrouvent battus aux élections, au profit des composantes socialiste.

Le revirement ministériel in extremis, quatre ans avant l'Exposition universelle, met la majorité municipale au pied du mur. Le conseil explore l'hypothèse d'un réseau électrique à petit gabarit, qui permettrait un maillage beaucoup plus serré, un coût kilométrique réduit de près de moitié, débarrassé des questions de vapeur de locomotives. Depuis la mort d'Alphand, en 1891, les élus se sont émancipés de l'emprise technique de l'État, en se dotant d'un corps particulier d'ingénieurs de la Ville de Paris. La première œuvre de prestige de ce nouveau corps sera précisément l'étude technique du métro demandée par les conseillers. L'ingénieur Bienvenüe démontre la faisabilité du réseau projeté. Le 20 avril, le conseil municipal de Paris adopte le principe d'un réseau autonome électrique, sur rapport du conseiller André Berthelot. Ici prend place un remarquable exploit technologique, souvent souligné : la conception d'ensemble est un saut dans l'inconnu, elle s'est séparée des modèles éprouvés de technologie ferroviaire et de conduite des passagers. Après des études plus détaillées de tracé et de fonctionnement, un réseau de première urgence est adopté par la municipalité, long de 65 kilomètres (voir figure 16) De nombreuses étapes de préparation et de négociations nécessitent encore une nouvelle année, le gouvernement freinant un « socialisme municipal » parisien de plus en plus conquérant. Néanmoins, dans la précipitation, une décision historique est prise : le gouvernement accepte la construction directe de l'infrastructure par la Ville, ce qui marque une étape nouvelle dans le socialisme municipal. Le principe sacro-saint de l'exploitation privée des travaux et réseaux collectifs (travaux publics, transports, gaz, électricité) est battu en brèche par la mise en œuvre d'un service public contrôlé par une instance démocratique. Le gouvernement ne va toutefois pas jusqu'à autoriser la « régie directe ", il s'en tient à la formule de concession en régie et sur adjudication. 

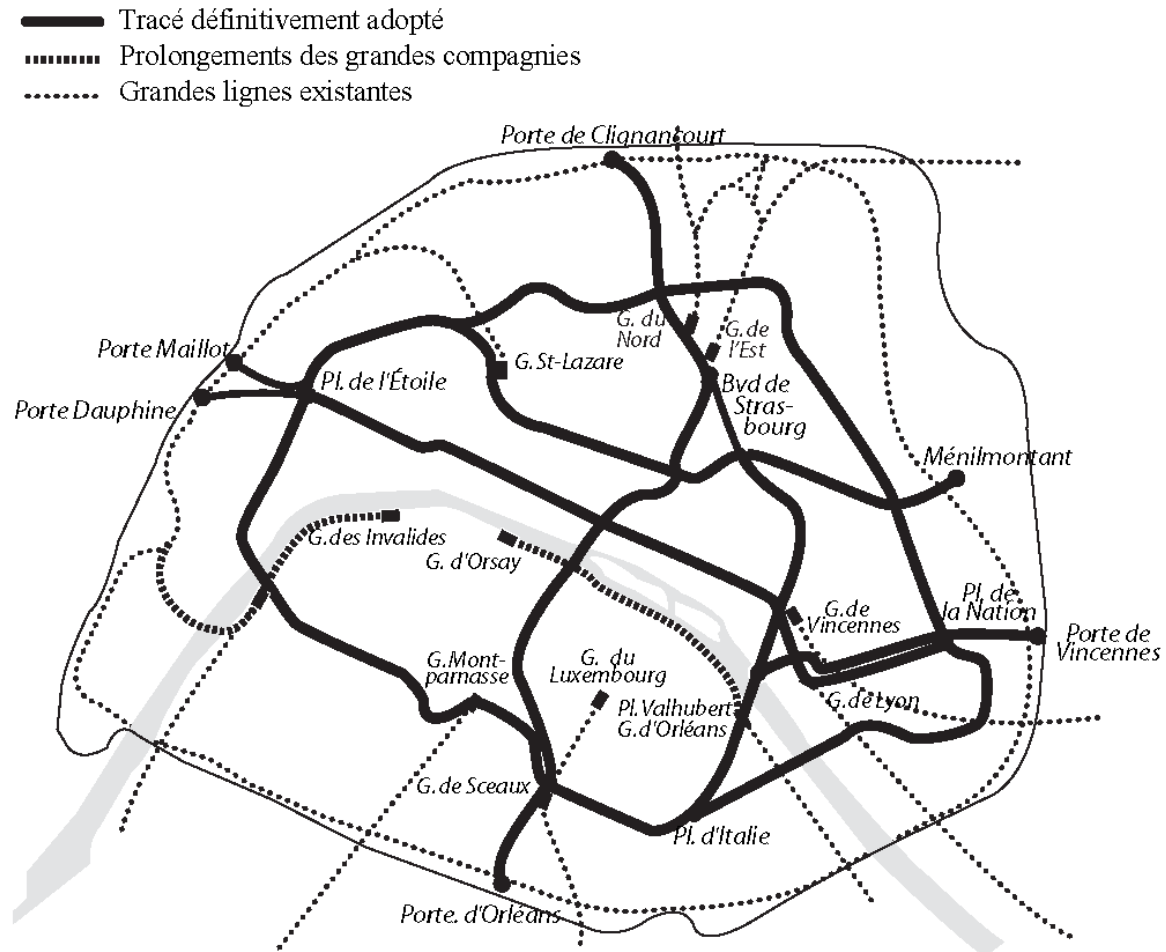

Le tracé voté met en œuvre le principe d'un réseau autonome et spécialisé dans le trafic urbain. Depuis l'époque des premiers projets, la périphérie de Paris s'est remplie, mais le principal objectif du service demeure : desservir les activités de tous les habitants, par un maillage de connexions aussi équivalentes que possible, ce qui doit offrir un maximum de chances de maintenir les proximités habitat-emploi par une décentralisation favorable à la recomposition des attractions. L'entrelacs des fabriques collectives doit pouvoir se réorganiser en nébuleuses, et l'espace parisien, demeurer, à plus grande échelle, une sorte de cour intérieure d'un immense atelier.

Suit alors un autre exploit : la vitesse record des travaux, sous la conduite des ingénieurs municipaux, sans dépassement de devis. Les premiers coups de pioche, en quatre endroits différents, sont donnés le 19 septembre 1898, malgré une grève de terrassiers en cours. Treize mois plus tard, le 19 octobre 1899, est inauguré le premier tronçon de tunnel. Et le nouvel équipement électrique roulant, testé, sécurisé, est mis en service le 19 juillet 1900. Il n'aura fallu que 22 mois pour mettre en place à la fois l'infrastructure et la superstructure, un matériel entièrement nouveau, destiné à prendre en charge un public en masse, sous des tunnels électriques, suivant un mode de fonctionnement inédit. Certes, l'échéance de l'ouverture de l'Exposition n'a pas été tenue, l'inauguration a eu lieu trois mois auparavant, et la presse a l'occasion de compter les arrivées de nombre d'équipements retardataires durant les trois premiers mois de l'Expo. La pénétration des voies de Paris-Austerlitz dans le centre, jusqu'au Quai d'Orsay, est inaugurée le 28 mai 1900 , avec un mois et demi de retard, après 28 mois de travaux. La prolongation du Champ-de-Mars à la Gare des Invalides et la liaison Saint-Lazare-Invalides par Auteuil sont mises en service juste à temps, mais au prix d'un fonctionnement provisoire, sur un chantier inachevé. Le Nord a ainsi gagné toutes les batailles depuis 1872 sauf une, la dernière. Il doit se limiter à rénover sa gare terminus sur place, comme l'Est, loin du site de l'Exposition universelle. Les immeubles achetés autour de l'Opéra, en vue de la gare et de l'hôtel terminus, sont rétrogradés à de simples enrichissement de son domaine privé. 
Après l'exposition, la compagnie se remet à dessiner des plans d'interconnexion, qui ne sortiront plus des cartons. Entre temps, les usines à gaz de la Plaine-Saint-Denis ont commencé à noircir la réputation des campagnes entre la Gare du Nord et Enghien-lesBains.

\section{Épilogue : le succès du métro, et la contre-expérience du Nord-Sud nationaliste}

117 La confrontation du bilan, entre 1900 et 1914, avec les projets, fait ressortir un succès qui dépassa les espérances. Le rapporteur Berthelot, contestant, comme Vauthier, la méthode de projection des ingénieurs des Ponts et Chaussées, prenant en considération les évaluations des parisiens et les ruptures de systèmes, avait estimé que pour le premier réseau, de 41,5 kilomètres, le nombre de voyageurs serait, avec la projection très basse des ingénieurs, au grand minimum de 73 millions de voyageurs transportés dans l'année. Une hypothèse moyenne, la plus vraisemblable suivant le rapporteur, calculée par extrapolation des ruptures d'offre et des nouvelles places offertes, portait la prévision à 100 millions de voyageurs. Une fourchette maximale, correspondant à l'occupation des deux tiers des places offertes, portait l'effectif à 146 millions $^{36}$. Au moment des projections, la presse des milieux d'affaires jugeait l'hypothèse de 73 millions, au contraire, déjà excessive et illusoire. Les leaders de l'opposition au projet, au sein du conseil municipal, proches de ces milieux d'affaires, les conseillers Rousselle et Sauton, dénonçaient une mégalomanie irresponsable. Rousselle s'écria : «Les chiffres qu'on fait miroiter devant nos yeux sont fictifs; l'époque à laquelle on atteindra le trafic de 140 millions de voyageurs est si lointaine, si nébuleuse, que ni nos ingénieurs, ni M. le Préfet de la Seine n'osent espérer vivre assez longtemps pour la voir jamais... Je décline, je le répète, toute responsabilité dans une telle aventure... Je me refuse à faire un tel saut dans l'inconnu $\|^{37}$.

118 Or, les résultats effectifs dépassèrent légèrement l'hypothèse la plus optimiste de Berthelot, atteignant le double de la projection des ingénieurs: en 1905, avec 35 kilomètres en service, l'effectif transporté atteignit précisément ce chiffre de 140 millions que Rousselle estimait inaccessible du vivant de sa génération. En 1906, où sont en service 44 kilomètres, l'effectif est de 179 millions. En 1913, sur un réseau déjà étendu à des lignes complémentaires, sont en service 88 kilomètres en moyenne (92 à la fin de l'année), où sont transportés 467 millions de voyageurs. Du côté des coûts, les bonnes surprises furent aussi considérables. En 1897, le coût de l'infrastructure, pour le même réseau, était estimé à 3,5 millions de francs du kilomètre par le service municipal. Les premiers quatorze kilomètres ne coûtèrent que 2616000 francs chacun, en moyenne. À la performance municipale de la réalisation directe s'était ajoutée la performance d'un emprunt de la Ville à $3,25 \%$, quand le privé aurait emprunté à $5 \%$. Les autres méthodes de calcul, incluant différents éléments de la superstructure et des coûts indirects, aboutissent à des écarts analogues. Dès l'année 1901, le haut débit du métro en fait le plus intensif du monde, devant ceux de New York et Londres ${ }^{38}$. Les articles du Temps et du Journal des débats, sur le joujou parisien, et sur cette chauve-souris des voies ferrées, publiés cinq ans auparavant, se trouvent ridiculisés par les résultats ${ }^{39}$.

119 Ce succès éclatant du métro, appuyé sur la participation démocratique et la supériorité d'une gestion de service public, fut l'objet d'une attaque de grande ampleur, qui tourna au 
fiasco. Dans la foulée de l'affaire Dreyfus, les élections municipales des 7 et 21 mai 1900 avaient donné lieu au triomphe des nationalistes, l'emportant de 47 sièges sur 80 , plaçant pour la première fois une majorité de droite et d'extrême droite à la tête de la municipalité parisienne. La droite «patriote » et le centre droit affairiste s'entendirent pour combattre le mauvais exemple de socialisme municipal que donnait le métro, et sanctionner sa supposée complaisance pour la finance étrangère (la compagnie du métro étant sous leadership du baron belge Édouard Empain), en lui opposant une expérience d'initiative privée bien française. Dès l'annonce des résultats des élections, les perdants de l'adjudication de 1898 prennent des dispositions convergentes avec la nouvelle majorité. Un leader au Conseil, Sauton, malgré des accusations graves et précises de corruption dans la presse, fait obtenir la concession d'une ligne à sa protégée, l'entreprise Berlier et Janicot, le 23 décembre 1901. Berlier pourra revendre plus tard sa concession à des promoteurs de plus grande envergure.

La presse financière, dès janvier 1900, annonce la constitution de la Société du Chemin de fer Nord-Sud Parisien. Cette société relance de nouveau le projet malheureux de prolongement de la Compagnie du Nord à l'Opéra, et la complète par une interconnexion des banlieues Nord et Sud, avec au passage une spéculation sur l'achèvement du boulevard Raspail, sur le parcours duquel la société achète des immeubles en espérant une concession avec des conditions d'expropriation analogues à celles des beaux jours d'Haussmann. Les grands perdants à l'adjudication de 1898, trahis par une entreprise qui a accepté de jouer le jeu municipal, menée par le baron Empain, s'y retrouvent au moment de la phase de lancement ${ }^{40}$. Puis, après une révision à la baisse des projets initiaux et un certain nombre de défections, demeure la mise en œuvre laborieuse de la concession au Nord-Sud (actuelles ligne 12 et partie de la 13). L'affaire devait être la démonstration expérimentale d'un moindre coût et d'une meilleure gestion de l'initiative privée.

121 Ce fut l'inverse qui se produisit: erreurs techniques, lenteurs, coûts plus élevés de 30 à $50 \%$, commodités moindres. La démonstration des vertus de l'initiative privée tourna au fiasco et à la preuve inverse, celle d'une supériorité de service public : supériorité pour la distribution équitable d'un bien collectif, et supériorité pour l'efficacité de la gestion d'un réseau ${ }^{41}$.

\section{Au final : un changement majeur d'évolution urbaine, par voie démocratique.}

L'irruption nationaliste comme la crise boulangiste ont mis à rude épreuve la démocratie locale, mais celle-ci s'en est sorti dans les deux cas. Les élections municipales de 1904 et 1908 ont dissous la coalition, en battant les uns et en contraignant les autres à s'aligner sur le «socialisme municipal » s'ils voulaient renouveler leur mandat. Néanmoins, une dynamique s'est cassée, et, vue rétrospectivement, la participation citoyenne des Parisiens a connu en 1891-1896 un apogée qu'elle ne retrouvera pas de sitôt. Son fonctionnement a été d'une grande complexité, dont on ne se doute plus guère aujourd'hui. Mais son principe s'est appuyé sur quelques règles simples d'articulation. Deux plans d'expérience et de réflexion ont été couplés et mis en prise :

a. l'imagination du monde de l'action politique, c'est-à-dire comment se figurer le pouvoir et le grand public des concitoyens, communauté fictive dont chacun est un membre réel ; et 
b. les rencontres en interaction effective, notamment dans les assemblées, constituant un public tangible.

123 Un test de réussite de ce couplage a été l'issue des crises de la "maladie du soupçon». Ce terme, transposé du langage clinique sous la Révolution pour décrire la dérive terroriste des sans-culottes, est aussi adéquat pour décrire les crises boulangiste et antidreyfusarde: le cercle vicieux du soupçon sans fin est un danger constitutif de la démocratie, car il tient sa source dans le fait même d'être exposé au pouvoir des concitoyens, sans garant d'autorité protectrice intangible. Il se développe quand le fonctionnement critique et l'imagination du public s'emballent en se déconnectant des modalités démocratiques d'enquête et de mise à l'épreuve: plus rien n'arrête les généralisations en vertu desquelles les hommes politiques mentent, la presse ment, le désintéressement est toujours intéressé, une pensée cache toujours une arrière-pensée, le visible bienveillant cache toujours l'invisible malveillant.

À l'inverse, l'expérience des sorties de crise met en évidence la constitution de ces possibilités d'enquête et de mise à l'épreuve. Le déroulement de l'enquête d'utilité publique de 1891, puis les campagnes électorales municipales de 1893 et 1896, en sont des exemples remarquables. Au lieu de laisser circuler dans la confusion les thèses de chacun des promoteurs de métro, a pris forme un débat en prise réelle sur les enquêtes citoyennes des uns et des autres, entre concitoyens assemblés et grand public imaginé ; selon cette dynamique, sous son aspect de «cercle vertueux », l'élaboration des idées, leur déstabilisation et leurs transformations, reposent sur des possibilités d'obtenir des réponses à des questions sur l'avenir de la capitale, sur la consistance comparée des projets, sur la véracité des journaux, sur le bien-fondé des propagandes. Les réunions de quartier sur les questions municipales constituent des publics qui confrontent les articles de presse entre eux ainsi qu'avec les témoignages convoqués ou rapportés, et avec les discours des élus. La dynamique de l'enquête fait tomber le pouvoir propre des experts en les contraignant à faire comprendre aux électeurs leurs arguments supposés techniques, s'ils veulent être entendus. La supériorité de l'expertise se prouve par l'argumentation convaincante, et non par l'argument d'autorité. Il n'est plus possible de dire n'importe quoi sans conséquences : rationalité et force de conviction pèsent plus lourd au fil des controverses. Cette dynamique est certes une idéalisation, au sens où elle souligne les aspects positifs sans mettre en avant les ratés, mais il est essentiel de discerner ce qui fait réussir un débat, sans s'arrêter aux seuls ratés, plus spectaculaires.

En termes plus généraux, la sortie de crise du débat public et la reconnexion de mises à l'épreuve démocratique se sont appuyées sur une logique de ce qu'on peut appeler des « publics intermédiaires ", c'est-à-dire des lieux où l'imagination du pouvoir et des concitoyens lointains peut être confrontée, dans des conditions d'interaction en prise sur les enjeux, avec des concitoyens proches; des lieux où les schématisations générales de l'action politique et de ses acteurs puissent ainsi être mises à l'épreuve à l'aide d'un collectif en co-présence, de ses possibilités propres d'initiative, d'enquête, de vérification, d'interpellation des différents représentants : élus, porteurs de projets, fonctionnaires, experts, témoins.

126 Le style Grand-Guignol qui a présidé au métingue du métropolitain nous fournit l'opposé caricatural extrême de cette possibilité d'interaction. Il théâtralise à sa manière la maladie $\mathrm{du}$ soupçon. L'interruption systématique des «représentants» par des plaisanteries à leur détriment, importée de la contestation politique de l'Empire, produit d'autres effets quand elle sabote la délibération entre concitoyens. Face à un pouvoir 
autoritaire, la dérision était une arme efficace de délégitimation, mais face à un pouvoir démocratique contesté, elle peut prendre une portée nihiliste destructrice de l'initiative concertée.

Les projets du métro et les débats sur les futurs modes de vie urbains ont fonctionné au rythme de ces conjonctures de l'imagination citoyenne, plus ou moins en prise avec la réalité sociale. Les images de métro aérien (figures 17 à 20) nous font sourire, car elles donnent l'impression de délires inoffensifs. Cependant, leur désengagement des contingences politiques ne leur enlève pas ce caractère quelque peu délirant, porté par une fiction de toute-puissance, au-dessus ou à travers les embarras de Paris. De façon apparentée, le soupçon politique particulier aux crises boulangiste puis anti-dreyfusarde, a comporté une identification à la puissance souveraine poussée jusqu'au déni des limites que pouvait apporter la volonté d'autrui. La progression des débats sur le métro et le partage d'une responsabilité pour l'avenir de la ville ont fait passer du rêve aérien à une concertation qui, bon gré mal gré, a fini par avoir prise sur la réalité collective commune. Jamais on n'avait vu ainsi les citoyens d'une métropole enquêter à ce point sur les plans qui se tramaient, en débattre de façon rationnelle, clarifier les enjeux et s'emparer des arguments techniques, au point de provoquer un infléchissement historique majeur au développement de leur cité.

Fig.17a - Des métros aériens. Images de promotion pour faire rêver au-dessus des embarras de Paris. Projet Arsème Olivier

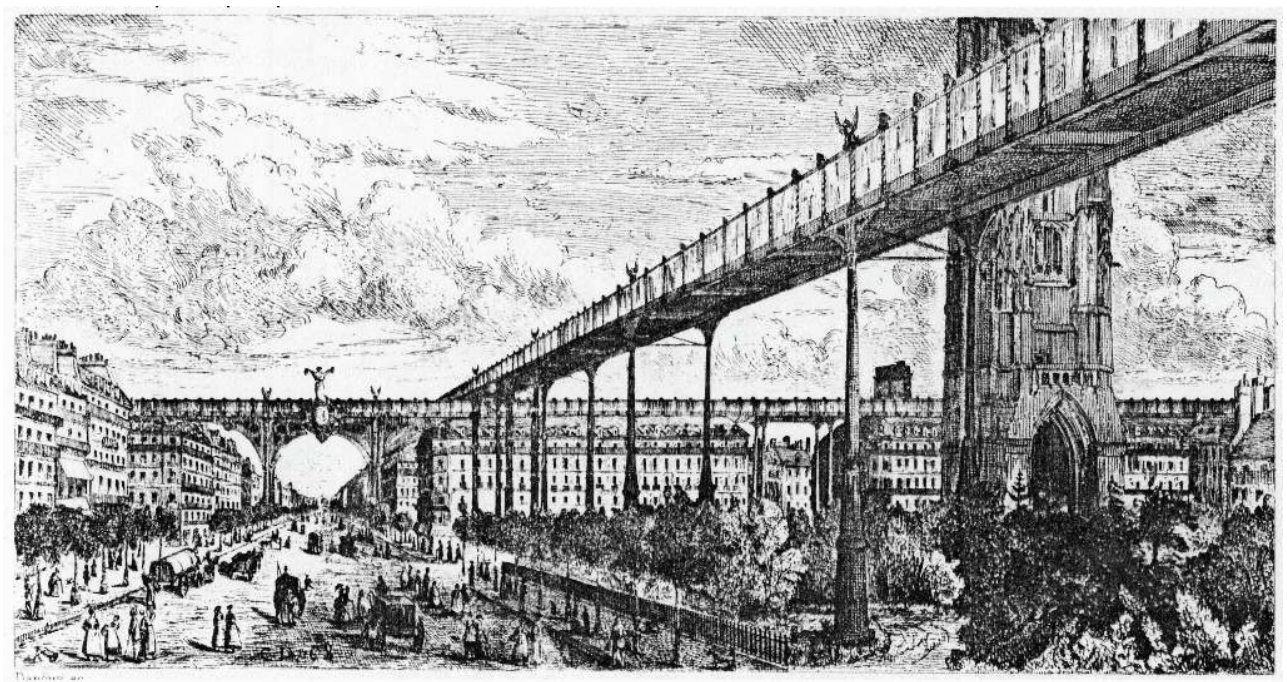

Un réseau au-dessus des toits, traction funiculaire, une paire d'ascenseurs par station. Gravure de 1872 : passage près de la Tour Saint Jacques, vue sur la grande croisée Est-Ouest et Nord-Sud, avec perspective sur la nouvelle Rue de Rivoli. 
Fig.17b - Des métros aériens. Images de promotion pour faire rêver au-dessus des embarras de Paris. Projet Mazet

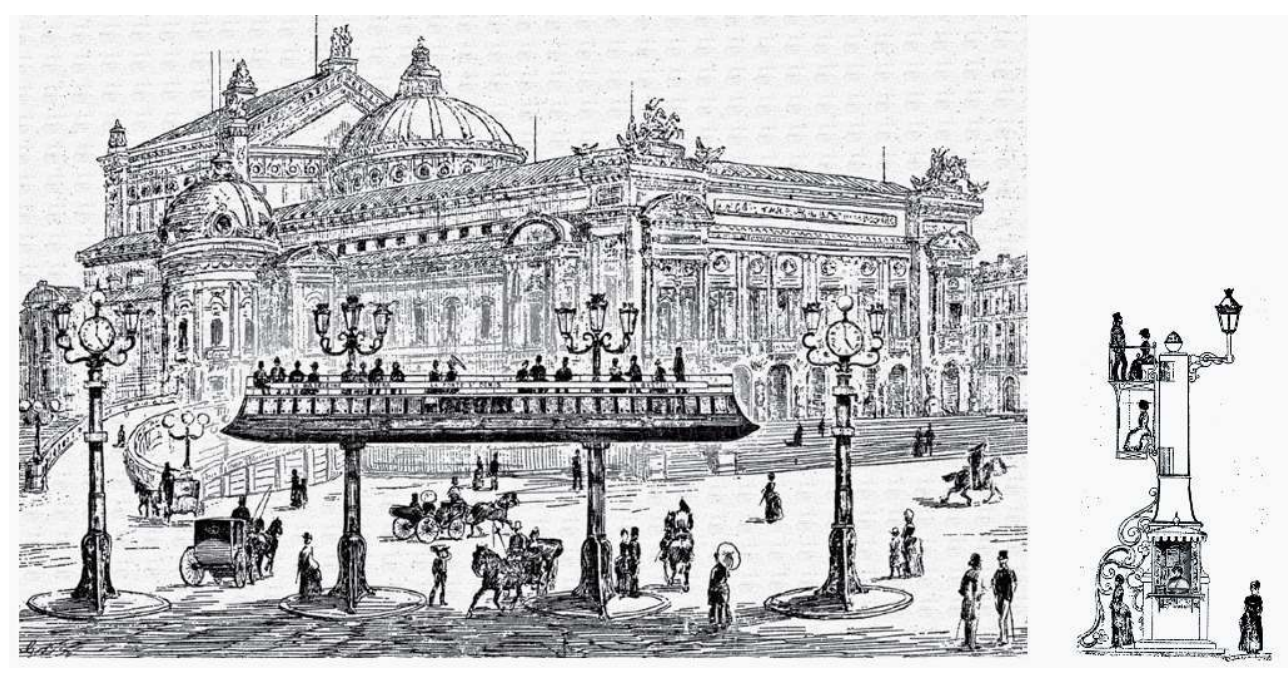

Mazet, capitaine au long cours, propose des bâteaux suspendus sur « rails » (crochets), fixés verticalement par paires sur des piliers. Les bâteaux automoteurs avancent, de eux à trois piliers, deux-trois-deux-trois... Ici, gravure de 1884, « passage du bâteau devant l'Opéra ». Cabine fermée et, au-dessus, « pont » ou « impériale ». Le projet frise le canular ; il est cependant enregistré sérieusement à la Préfecture de Police.

Fig.18-20 - Projets Tellier, 1886 - Projet Dupuis, Nibart et Varrailhon, 1886 - Projet Heuzé, 1878

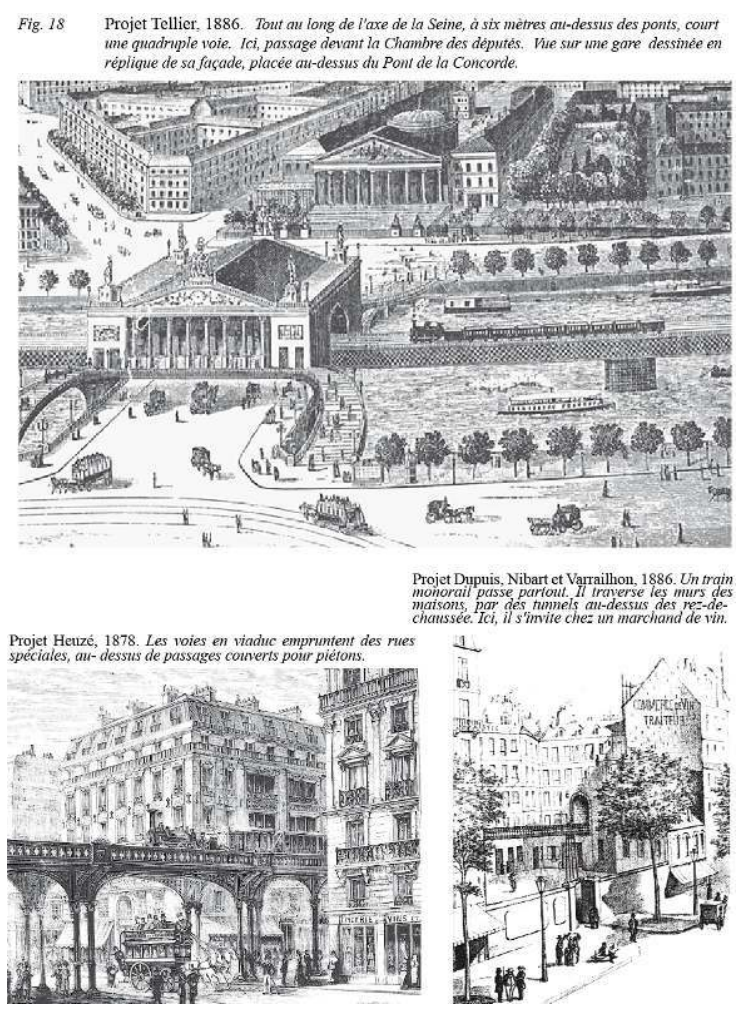




\section{NOTES}

1. Cet article utilise une ancienne recherche menée entre 1967 et 1975 sur les origines du métro. À l'époque j'avais entamé une prospection d'archives et pris contact, entre autres, avec le Service technique du métropolitain, constitué à la préfecture de la Seine en 1898 et encore en activité en 1974. Ce dernier possédait de riches archives vivantes, bien conservées depuis l'origine. Or, une aubaine s'était présentée : lors d'un déménagement de combles, en 1974, le service récupéra des archives depuis longtemps reléguées, remontant à 1874, héritées des services d'études spéciales créés depuis cette époque. Parmi elles, de nombreux manuscrits, courriers, notes de négociations, études critiques de projets et contre-projets, échanges de notes non officielles entre camarades ingénieurs représentant des intérêts adverses, publics et privés. Des griffonnages de l'ingénieur Bienvenue au jour le jour permettaient de voir émerger la forme métro que nous connaissons. L'ensemble se prêtait à des recoupements avec des archives privées de promoteurs de projets des grandes compagnies, en cours de versement à la même époque aux Archives nationales.

Or, brusquement, en quelques semaines, la plupart de ces archives furent pilonnées sans crier gare (juin 1975). Le pilonnage fut effectué au nom de la modernisation de l'administration parisienne. La réforme territoriale, le redécoupage de la préfecture de la Seine entre nouveaux départements, donnèrent lieu à des méthodes expéditives de réorganisation, traduites en consignes de déblaiement d'archives de tant de mètres cubes par jour, aux bons soins d'ingénieurs des travaux publics. En principe, un service de la RATP, à la Direction des Travaux neufs, bénéficiait d'un reversement, et se chargeait de trier les archives utiles. Il conserva surtout celles qui décrivaient la consistance des tunnels, ainsi que deux à trois dizaines de milliers de photographies de travaux. Mais tout le reste, dossiers de travail des ingénieurs, dossiers des anciens projets de métro, imprimés, presse, tracts de propagande, correspondance des administrations et des élus, fut détruit. Pour ma part, j'abandonnai le chantier, dont je reprends aujourd'hui (janvier 2005) quelques éléments, à l'invitation de la Revue d'histoire du XIXe siècle.

2. Conseil général de la Seine, Procès-verbaux, 1871, Rapport Léveillée et délibération, 10 novembre, p. 636. La délibération porte sur un mémoire du préfet Léon Say du 8 novembre 1871, dont elle critique la conception et change le programme.

3. Sur les chemins de fer, les classiques de référence, utilisés ici, demeurent François Caron, Histoire de l'exploitation d'un grand réseau : la Compagnie du chemin de fer du Nord, 1842-1937, Paris, Librairie Mouton, 1973, et Louis Girard, La politique des travaux publics sous le Second Empire, Paris, Éditions Armand Colin, 1952. Sur le contexte politique et l'offensive des radicaux, des éclairages nouveaux ont été apportés par la thèse de Marie-Noëlle THIBAULT, La question du rachat des chemins de fer dans l'idéologie républicaine au XIXe siècle (1852-1883), thèse de l'Université de Dijon, 1975. Sur le contexte républicain et radical, parmi une littérature beaucoup plus abondante, s'impose toujours un ancien classique, Pierre Sorlin, Waldeck-Rousseau, Paris, Éditions Armand Colin, 1966.

4. Le rapport de la commission a été édité : Rapport de la commission spéciale sur l'étude des chemins de fer et tramways d'intérêt local à établir dans le département de la Seine, Paris, Imprimerie de C. de Mourgues frères, 1872. Parmi les quatorze ingénieurs figuraient un représentant de chaque grande compagnie, le directeur de la Petite Ceinture, nommé rapporteur (M. Mantion), des ingénieurs des Ponts et Chaussées, du ministère des Travaux publics et de la préfecture de la Seine, et un seul ingénieur civil. 
5. Conseil général de la Seine, Rapport ...sur l'établissement de chemins de fer d'intérêt local dans Paris, session extraordinaire d'avril-mai 1872, ouv. cité, pp. 16-17.

6. Le projet Brunfaut, accompagné des rapports et comptes rendus des commissions locales, et autres annexes, a été publié dans un gros volume : Jules Brunfaut, Chemin de fer métropolitain et de la banlieue de Paris. $2^{e}$ partie, Paris, Société du Chemin de fer métropolitain, 1873, 355 p. Autres brochures, du même auteur et du même éditeur : Chemin de fer circulaire de la Banlieue de Paris, son coût, son revenu, 1872, et Chemin de fer métropolitain[...]. Mémoire à Messieurs les députés, 1873.

7. Le Courrier municipal. Journal administratif et historique, 1873-1879, prend le relais de brochures épisodiques, dont une série fut publiée sous le titre Bibliothèque municipale pour les années 1862-1868. La chronique critique rend compte de multiples aspects de la vie quotidienne; elle s'en prend notamment à toutes les compagnies de transports, dont les administrations accusent les coups : les archives intérieures de ces dernières, compagnies ferroviaires, omnibus, tramways, constituent des dossiers autour de chaque critique et étudient des remèdes si elles les trouvent fondées. La politique du syndicat des ceintures est vilipendée, tant pour ses façons de subordonner les livraisons de marchandises locales au passage du transit, que pour sa mauvaise volonté manifeste dans son offre de services aux voyageurs, freinant les demandes déjà peu exigeantes du ministère des Travaux publics. Les diatribes de Louis Lazare contre la nouvelle ségrégation sociale parisienne qu'il voyait progressivement se former sont devenues célèbres.

8. Louis-Léger Vauthier, Chemin de fer circulaire intérieur sur la ligne des anciens boulevards extérieurs et le quai rive droite de la Seine. Avant-projet, 1865 (daté du 31 mars). Projet étudié en bonne et due forme, déposé à la préfecture de la Seine, c'est le premier du genre à s'inscrire dans la procédure des nouvelles lois sur les chemins de fer locaux. Un projet modifié est étudié pour répondre aux délibérations du Conseil général, en 1872 : Chemin de fer circulaire intérieur sur la ligne des anciens boulevards extérieurs et le quai rive droite de la Seine. Mémoire à l'appui du projet, Paris, Imprimerie Édouard Blot, 1872.

9. Louis-Léger Vauthier, Conférence sur les conditions techniques et économiques d'une organisation rationnelle des chemins de fer, 13 juillet 1878, Ministère de l'Agriculture et du Commerce, Exposition universelle internationale de 1879 à Paris. Congrès et conférences du Palais du Trocadéro [...], Première série. Industrie, Chemins de fer [...], Paris, Imprimerie nationale, 1879. Du même : Projet de réorganisation des chemins de fer français, réseau national et réseaux régionaux, Paris, A. Chaix, 1878 ; Réseau secondaire et d'intérêt commun des cinq départements de la région Nord: Aisne, Oise, Somme, Nord et Pas-de-Calais, mémoire à l'appui de l'avant-projet, Paris, A. Chaix, 1868.

10. La théorie économique des réseaux de Vauthier reste à redécouvrir aujourd'hui, semble-t-il, et serait à comparer à la théorie de son collègue des Ponts et Chaussées Jules Dupuit, qu'il connaît bien et qu'il complète sans la contredire, lorsque par ailleurs, avec Deligny, il élabore une réflexion sur les ruptures de systèmes d'équipement et l'intègre à une économie de l'urbanisation. Pour une critique de la comptabilité des compagnies de chemins de fer, françaises et anglo-saxonnes, voir l'ouvrage fondamental de Yannick Lemarchand, Du dépérissement à l'amortissement. Enquête sur l'histoire d'un concept et de sa traduction comptable, Nantes, Ouest Éditions, 1993. Il relève les erreurs d'un ouvrage à succès traduit en français d'Alfred D. Chandler, The Visible Hand. The Managerial Revolution in American Business, Cambridge (Mass.), Harvard University Press, 1977, traduction française, La main visible des managers: une analyse historique, Paris, Éditions Economica, 1988 (pp. 348-349). L'ouvrage, très enseigné dans les écoles de commerce, participe de l'auto-célébration managériale. Malheureusement, sa thèse est fondée sur un contresens systématique : l'ouvrage imagine que les comptabilités bureaucratiques des compagnies sont des comptabilités économiques, sans rien voir des fictions comptables décrochées d'une signification d'efficacité industrielle. Il parvient ainsi à prendre les comptes rendus de gestion pour des modèles de l'arrivée de l'ère des managers, incarnations de la rationalité économique montante. 
11. Rapport présenté par $M$. Vauthier au nom de la $2^{e}$ commission..., Conseil général de la Seine, Rapport et documents, 12 novembre 1875, p. 6.

12. Conseil général de la Seine, Procès-verbaux, 18 novembre 1875, p. 421.

13. Conseil général de la Seine, Procès-verbaux, 21 novembre 1876, p. 693.

14. Lettre du 10 mai 1884 de Ferdinand Duval à Léon Say, papiers Sartiaux concernant les projets de métro parisien (Souligné par nous). Ces papiers correspondent à 25 grosses liasses de 25 à 30 centimètres d'épaisseur chacune, contenant des papiers opérationnels confidentiels, correspondances, brouillons de projets, notes de réunions, ayant appartenu au Directeur adjoint de l'exploitation de la Compagnie du Nord. Les manuscrits et imprimés portent principalement sur les années 1883-1901. Les papiers étaient anciennement classés en fonction des projets, ils touchaient tout autant les projets combattus par la Compagnie (Sartiaux étant le chef stratégique des offensives) que ceux promus par elle, ouvertement ou en catimini. Sartiaux, comme l'explique François Caron, fut un grand ingénieur, le véritable chef opérationnel de la politique de la Compagnie durant ces années-là, ayant accès direct auprès de son président, Alphonse de Rothschild, et travaillant en liaison étroite avec Léon Say, devenu le numéro deux de la Compagnie, l'homme de toutes les concertations avec ses collègues ou anciens collèges ministres. J'ai consulté ces papiers en 1974-1975, alors qu'ils venaient d'être versés, et avant qu'ils ne soient re-classés, destinés à la série $48 \mathrm{AQ}$ des archives nationales. Il ne semble pas que François Caron ait eu la chance de consulter ces liasses; mais je n'ai rien relevé qui aurait pu contredire son ouvrage. Bien des éléments, par contre, viennent éclairer en complément les aspects spécifiquement parisiens de la politique de la firme; ils prêtent à confirmation des aspects critiques que François Caron a exposés sur la gestion de la Compagnie, notamment le malthusianisme de ses investissements, ainsi que le caractère fictif et anti-économique de la comptabilité officielle imposée aux compagnies. Par la suite, ces liasses seront désignés ici par la simple mention Papiers Sartiaux.

15. Contre-projet de réseau urbain du chemin de fer métropolitain, présenté par M. E. Deligny, ... comme amendement au projet de l'administration, Paris, Imprimerie de C. de Mourgues frères, 1879. Ernest Deligny, Louis Cernesson, Rapport au nom de la commission spéciale du métropolitain, Conseil municipal de Paris, Procès-verbaux, séance du 30 avril 1883. Ernest Deligny, Le Chemin de fer métropolitain de Paris, Paris, Imprimerie de Chaix, 1884.

16. Graphique d'après les données de la préfecture de la Seine, Service de la statistique municipale, prises dans l'Annuaire statistique de la Ville de Paris, Résultats statistiques du dénombrement de 1891, Paris, Masson, 1894, pp. 793-811. Suivant la méthode de Jacques Bertin sont tracés les écarts aux moyennes, visualisés les contrastes caractéristiques et regroupés les profils qui présentent intuitivement des airs de famille (Jacques Bertin, Sémiologie graphique, Paris, La Haye, Mouton \& Gauthier-Villars, 1967).

17. Journal officiel, Chambre des députés, séance du 11 janvier 1895, interpellation Chauvin, pp. 19-28. De volumineux dossiers de chaque compagnie sur leur exploitation de banlieue, leur contestation par des ligues d'usagers, de résidents, se trouvent archivées en série F 14, sous la rubrique tarifs voyageurs. Voir, entre autres, F 14 11267, 11368 11281, 11283, 11303, 11204.

18. Avec ses brochures de projets, Buisson des Leszes ne cesse de harceler les pouvoirs publics, depuis une première demande en 1870 , jusqu'en 1894. Les dossiers d'instruction soulignent un manque de sérieux du projet d'étude et le côté hautement spéculatif des demandes. Les journalistes eux-mêmes n'y croient guère, sauf lorsque le personnage s'associe à des promoteurs de plus grande envergure, notamment l'entrepreneur de chemins de fer et banquier Donon. Sources: les dossiers d'instruction dans les Archives Nationales, F 149166 , dix brochures imprimées, (1870-1894); des notes de renseignements et commentaires extrêmement critiques dans les papiers Sartiaux; d'autres documents manuscrits se trouvaient également à l'ancien Service du contrôle du métro, les uns dénonçant l'inconsistance technique, les autres dénonçant un but de "lavage de capitaux", c'est à dire un objectif de profits sur les lancements de 
souscriptions d'actions et de reventes foncières sans dispositions véritables de pour réaliser le projet lui-même.

19. Louis-Léger Vauthier, Chemin de fer circulaire intérieur sur la ligne des anciens boulevards extérieurs et le quai rive droite de la Seine, mémoire à l'appui du projet., Paris, imp. Édouard Blot 1872, pp. 39-40.

20. Enquêtes collectives coordonnées par Frédéric Le Play (ed.), Les Ouvriers européens, études sur les travaux, la vie domestique et la condition moral des populations ouvrières de l'Europe, Paris, Imprimerie impériale, 1855, puis Société internationale d'études pratiques d'économie sociale (SIEPES), Les Ouvriers des deux mondes : études sur les travaux, la vie domestique et la condition morale des populations ouvrières des diverses contrées et sur les rapports qui les unissent aux autres classes, Paris, Société internationale d'études pratiques d'économie sociale et Librairie de Firmin-Didot, Première série, 5 volumes, 1857-1885.

21. Pierre Du Maroussem, La question ouvrière, Paris, A. Rousseau, 1891-1896, 4 tomes : tome 1, Charpentiers. Compagnons et indépendants; tome 2 :, Ebénistes, grands magasins; tome $3:$ Le jouet parisien. Grands magasins, "sweating system"; tome 4: Halles centrales de Paris et commerce de l'alimentation. Ces enquêtes font partie des investigations de la SIEPES ou les prolongent. Les recherches de cette société savante forment peut-être la plus grande enquête anthropologique comparative intégrée jamais menée à bien dans l'histoire des sciences sociales, à redécouvrir aujourd'hui. Concernant les fabriques collectives (concept élaboré par la SIEPES) les enquêtes comportent 33 monographies parisiennes et des dizaines d'articles sur ces fabriques, comparées entre métropoles urbaines, en espaces ruraux ou mixtes et examinées pour leur productivité au regard de formes de production plus classiques. Les enquêtes comparatives entre Paris et Londres confirment un aspect de la prospective de Deligny et Vauthier, reprise à leur suite par Louis Le Chatelier ( $L a$ Question du métropolitain, Paris, Baudry, 1888). La différence des déplacements à Paris et à Londres, à cette époque, tient à l'ensemble des styles de vie familiaux et à la configuration des activités. En particulier, à Paris, les compagnes adultes d'ouvriers ont une très forte polyactivité, à leur compte ou (et) «à compte d'autrui », alors qu'à Londres les épouses d'ouvriers sont le plus souvent «femmes au foyer " dès que le revenu du ménage le permet. À Paris, la polyactivité de chaque membre des foyers, intégrée au sein de fabriques collectives, est connectée à des complexes de production polycentriques disposés en voisinages, par l'effet simultané des affinités d'activités entre spécialités de travail et affinités des partenariats de ménages, ce qui se traduit par des attractions opposées aux séparations ou aux éloignements du domicile et du travail. En revanche, à Londres, la tendance à la monoactivité des foyers ouvriers se prête à l'acquisition d'une maison à bon marché en banlieue, éloignée du lieu de travail unique : seul le mari et, éventuellement, des fils, effectuent des aller et retour quotidiens à horaires fixes entre lieux séparés de travail et de domicile, ce qui présente les avantages de l'habitation à bon marché sans les inconvénients de lieux d'activités multiples à fréquenter dans la journée.

22. Sur le fonctionnement de «la grève » comme place d'embauche à Paris, liée au marchandage public, voir mon article « Droit et bon droit. Un droit des ouvriers instauré puis évincé par le droit du travail (France, XIXe siècle)», Annales, nov.-déc. 2002, n 6, pp. 1521-1557, avec une illustration commentée de «La foire aux maçons », de Jules Pelcoq, p. 1529.

23. Édouard Brame et Eugène Flachat, Chemin de fer de jonction des halles centrales avec le chemin de ceinture, Paris, Boulevard du Temple, 1854, pp. 24-25 ; Office Du Travail, Le placement des employés, ouvriers et domestiques en France. Son histoire, son état actuel, avec appendice relatif aux pays étrangers, Paris, Berger-Levrault, 1893.

24. Theo C. Barker, Michael Robbins, A History of London Transport, London, George Allen \& Unwin, 1963, p. 211 ; François Caron, ouv. cité, pp. 263-367 ; papiers Sartiaux.

25. La principale source de ce récit se trouve dans les papiers Sartiaux, à la fois notes manuscrites personnelles au jour le jour des négociations, correspondances avec des proches et des moins 
proches, et dossiers de documentation sur tous les protagonistes, manuscrits ou imprimés, concernant les financeurs, les entreprises, les élus nationaux et locaux, les journalistes, les techniciens et autres concepteurs des projets.

26. 8 décembre 1886. Papiers Sartiaux, non classés lors de la consultation. Sur les diverses pratiques d'abus bancaires, beaucoup moins étudiées que les aspects politiques des scandales, voir Jean Bouvier, Les deux scandales de Panama, Paris, Juillard (collection Archives) 1964. Un dossier d'archives des négociation du montage financier entre Christophle et le Ministère se trouve aux Archives nationales, F14-9170.

27. Préfecture de la Seine, conseil municipal, Procès-verbaux, Rapport Lefebvre-Roncier (annexes, imprimé $n^{\circ} 69$ ) débats et vote, 21 au 24 juin, puis 2 et 3 juillet. L'amendement Donnat, qui enterre le tronçon Saint-Lazare-Gare du Nord, est discuté les 22 et 23 juin. La division entre radicaux de l'assemblée nationale et radicaux du conseil municipal, à propos du métro, est analysée dans Jacques Néré, La crise industrielle de 1882 et le mouvement boulangiste, Paris, Faculté des lettres de l'Université de Paris, thèse dactylographiée, 1958. -La thèse demeure une référence importante que j'ai utilisée pour analyser le radicalisme parisien. Sur le métro et les radicaux, voir pp. 102-105.

28. Ernest Deligny et Louis-Léger Vauthier, A Monsieur le président de la Commission des Chemins de fer [de la Chambre des députés], Paris, Imprimerie des Arts et Manufactures, 10 janvier 1887, p. 25.

29. Une commission d'enquête parlementaire rend public le budget des compagnies à cette époque, Jean Darlan, Rapport général par M. Jean Darlan,... (28 mai 1895), Paris, Motteroz, 1895.

30. Seule une maison importante, celle des Delahante, par l'organe d'un cousin de Gustave Delahante, s'est portée publiquement demandeur en concession du programme municipal, puis du projet Vauthier-Deligny.

31. Chambre des députés, $4^{\mathrm{e}}$ législature, session $1887, \mathrm{n}^{\circ} 1661$, Rapport fait, au nom de la commission chargée d'examiner le projet de loi ayant pour objet l'établissement du réseau métropolitain de Paris par M. Pradon, annexe, compte-rendu d'une audition de Vauthier, p. 502.

32. Chambre des députés, Rapport Pradon, puis débat et vote du 21 juillet. Baïhaut sera l'un des deux seuls députés envoyés en prison parmi la centaine de "chéquards » dénoncés par le scandale de Panama, pour des faits contemporains à l'élaboration du projet de métro. Au conseil municipal de Paris, la corruption à cette époque est beaucoup plus rare : on en a une preuve a contrario très convaincante dans la faiblesse des dossiers à charge rassemblés par la préfecture de Police, malgré un acharnement à collectionner les ragots contre les élus autonomistes, adversaires du principe même de l'institution de la préfecture de Police. Néanmoins l'un des rares corrompus avérés de l'époque, Lefebvre-Roncier, est précisément le rapporteur du projet des compagnies le plus favorable à un compromis, en correspondance privée directe avec Sartiaux.

33. Les lecteurs qui connaissent la chanson Le grand métingue du métropolitain de Mac-Nab reconnaitront dans l'épisode bien des traits qui ont inspiré ses couplets. Les grèves de Vierzon, évoquées dans la chanson, défrayent la chronique parisienne un peu plus tôt, en octobre 1886 . Mac-Nab, inspiré principalement par le meeting du Cirque d'Hiver du 30 juillet 1887, y a superposé aussi la trace d'événements un peu antérieurs. Le mot "meeting » est alors à la mode. Sur les meetings du métropolitain, voir Archives de la préfecture de Police, BA 1568, récits d'indicateurs et récits de presse. Le compte-rendu le plus circonstancié se trouve dans le Journal des débats du 31 juillet. Plusieurs des 16 rapports d'indicateurs de police racontent en détail le déclenchement de la bagarre par des ouvriers éméchés, notamment le maçon Quinque qui a pu servir de modèle au héros caricatural de la chanson. Toutefois le manichéisme lyrique prêté à Quinque, vraisemblable, est inscrit parmi des visions plus complexes, où personne ne semble dupe : accusations de provocations, bagarres entre services d'ordre et exfiltration de l'ouvrier Quinque par des mouchards, afin d'empêcher les blanquistes de le lyncher. L'issue fut moins drôle, embrouillée et désespérante pour les citoyens qui voulaient s'informer en débattant. 
34. Seul parmi cette vague de promoteurs du métro, de la mouvance des anciens gambettistes dite "opportunistes ", Léon Donnat n'est pas un corrompu avéré, il semble compromis pour avoir seulement eu de mauvaises fréquentations.

35. Préfecture de la Seine, Conseil municipal, Procès-verbaux, débats du 29 octobre, pp. 452-453. Les cahiers de l'enquête d'utilité publique se trouvent aux Archives Nationales, F 149157.

36. Préfecture de la Seine, Procès-verbaux, annexes, Rapport, présenté par Mr André Berthelot, ... sur la mise à l'enquête du projet de chemin de fer métropolitain urbain, à voie étroite, à traction électrique, étudié par la direction des Travaux du 30 mars 1896.

37. Préfecture de la Seine, Procès-verbaux, 30 mars 1898, pp.353-354. Au moment de l'adjudication, la Société générale de traction remit une note de prévision qui s'en tenait aux calculs des ingénieurs, avec une légère augmentation, soit 80 millions de voyageurs pour la même longueur des 41,5 premiers kilomètres (note officieuse remise par la compagnie le 5 février 1898, Archives Départementales de Paris, V1, 0 8, 7).

38. Les calculs comparatifs de débit s'exprimaient en trafic kilométrique annuel. En 1901, il est à Paris de 4,8 millions de voyageurs, à Londres de près de 3 millions, sur le Manhattan Railway de New York, de 3,15 millions, d'après A. Dumas, Le chemin de fer métropolitain de Paris, Paris, Le Génie Civil, Béranger, 1901. Parmi les autres ouvrages ayant établi des bilans, voir notamment Louis Biette, Les chemins de fer urbains parisiens, Paris, Éditions Baillière, 1928. Pour une vue synthétique, située par rapport à l'ensemble des moyens de transports en France, voir, C. Colson, « Revue des questions de transports ", Revue politique et parlementaire, $n^{\circ} 233,10$ novembre 1913, pp. 317-338

39. Le 16 avril 1896, à propos du projet municipal, Le Temps réitérait péremptoirement la confusion courante entre gabarit et débit :

«Le métropolitain [...] ne se raccorde à rien. Il a d'ailleurs, ou aurait de bonnes raisons pour cela. On prévoit, en effet, pour cette chauve-souris des voies ferrées, oiseau ou souris, suivant les cas, une voie réduite d'un mètre, c'est-à-dire de petits wagons dans lesquels le public s'entasserait et dans lequel il serait ballotté et bousculé. On demandait un chemin de fer métropolitain; c'est un tramway que l'on nous offre. Et quel tramway! Souterrain, lugubre, confiné, lent, sortant de terre en des points inaccessibles. 32 trains à l'heure, dit le projet! Alors que sur l'Elevated Railway, sur le célèbre métropolitain de New York, qui est le type du genre, avec les grandes voitures à voie large, et sur viaducs, on ne dépasse pas 30 trains à l'heure. [...] Les petits manèges tournants de la Foire au pain d'épice renseigneront parfaitement nos édiles sur le fonctionnement du métropolitain dont ils se sont fait soumettre le projet. »

40. L'adjudication du métro avait amené à concourir tous les grands investisseurs de l'électricité, des tramways et du matériel ferroviaire. La Compagnie général de traction l'avait emporté, avec le baron Empain, appuyé par Schneider et un groupe de banquiers. Lui seul avait accepté toutes les exigences municipales, ce qui fut ressenti comme une trahison par les autres grandes sociétés de tramways et d'électricité. Face à lui, le principal concurrent avait été une coalition étrange, formée de Thompson-Houston et des adversaires les plus acharnés du métro qu'avaient été la Compagnie des Omnibus et la Compagnie générale des Tramways. La coalition ThompsonHouston-Pereire propose une vaste opération immobilière sur les terrains des fortifications, couplée avec métro et tramways. Au début de 1900, pour prendre leur revanche, plusieurs sociétés reprennent les projets de prolongation et d'interconnexion de la Compagnie du Nord, dont la loi de concession du métro avait réservé la possibilité. Pour constituer la Société du NordSud Parisien se retrouvent, dans une première phase, la Compagnie française des Procédés Thomson-Houston, le Comptoir d'Escompte et la Société française de Constructions Mécaniques. Mais après la phase d'étude, les actions se placent mal. La société n'arrive pas à obtenir de concession avant que la majorité municipale de 1900, favorable au Nord-Sud, ne soit disloquée par les élections de 1904. L'opération du boulevard Raspail, menée par la Ville, échappe à la compagnie, et la revente des terrains achetés (évalués à 2,1 millions) ne se fait pas dans de bonnes conditions. Le Nord en vient à refuser de s'engager dans l'affaire, l'interconnexion des 
gares s'avère hors de portée. Les études techniques réévaluent l'estimation des coûts à sept millions du kilomètre, deux fois et demie le coût du premier réseau municipal. La société du Nord-Sud doit réduire ses ambitions au rachat de la concession faite à Berlier et Janicot pour constituer la première ligne du Nord-Sud. Par la suite sera ajoutée une seconde ligne des beaux quartiers, Saint-Cloud-Trocadéro, et deux petits compléments. La société s'aperçoit que les procédés tant vantés par Berlier ne sont pas adaptés au métropolitain, ce qu'avait déjà établi la commission d'adjudication de 1898, et doit se soumettre aux projets techniques des services de la municipalité. Une suspicion de corruption entoure toute cette affaire du Nord-Sud, que laissent entendre les commentaires d'ingénieurs, la presse, les rapports de police, et même les archives de l'adjudication, sur un mode allusif -notamment, aux Archives de Paris, sur l'adjudication, V1089 ainsi que les imprimés détaillés de la Commission municipale du métro; sur les compagnies de tramways, leur gestion et leur " publicité», Arch. Nat, F 14-15031 et 15025 ; et sur le Nord Sud, Arch. Nat., 65 AG E 552. Sur les principaux groupes de tramways et d'électricité, voir le survol de John P. McKay, Tramways and Trolleys: the Rise of Urban Mass Transport in Europe, Princeton, Princeton University Press, 1976 et l'étude de Armand Mossé, Du régime des transports en commun à Paris, Paris, Librairie Chevalier et Rivière, 1906.

41. Un bilan particulièrement sévère est établi par Louis Biette, inspecteur départemental des travaux de Paris, Les chemins de fer urbains parisiens, ouv. cité; C. Colson, dans son article cité, estime les coûts du Nord-Sud supérieurs de $40 \%$ à ceux du métro construit par la municipalité et concédé à la Compagnie du métro - calculés tout compris, infrastructure, superstructure et frais financiers.

\section{RÉSUMÉS}

Comment a-t-on décidé de construire le métro parisien? L'enquête sur les trois décennies de débats (1870-1900), d'après archives inédites, privées et publiques, porte sur deux dimensions oubliées: le développement d'une intense vie démocratique locale, et un véritable choix d'urbanisation, l'un ayant ouvert la voie à l'autre. Paris connaissait une urbanisation tendancielle de type londonien, que voulaient consacrer les grandes compagnies de chemins de fer et les milieux affairistes. La sphère publique locale, malgré des crises (boulangisme, scandale de Panama), a fini par imposer un débat public rationnel et a obtenu un métro adapté au style de vie particulier de la capitale d'avant 1914.

How was the construction of the Parisian underground railway decided? The enquiry bears upon three decades of debates (1870-1900), and is based on private and unpublished official archives to recapture two forgotten dimensions, namely, an intense local democratic life, and a true choice of urbanisation. The first paved the way for the second. In the Parisian suburbs a lesser propensity to expand in a London fashion had taken place. The big railway companies and high business quarters wanted to strengthen that propensity. The local public sphere got over several crisis (the populist crisis of boulangisme and the scandal of Panama) and succeeded in imposing a rational debate which led to the invention of a type of underground railway suited to the particular Parisian pre-war working-class way of life. 